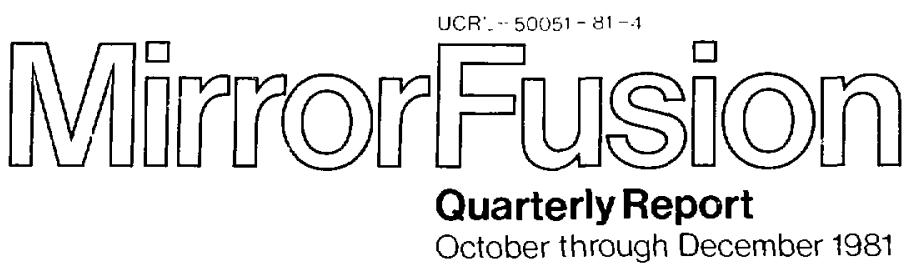

\section{The Cover}

Work continues in the mammoth vacuum vessel of the Mirror Fusion Test Facility (MFTF) while Mike Ross (at right) of the Laboratory's Public Affairs Office conducts a press conference preceding the formal dedication ceremonies for the facility. Answering questions of Bay Area news reporters are (from left) Alvin Trivelpiece, Director of the Otfice of Energy Research, Department of Energy (DOE); T. Kenneth Fowler, Associate Director for Magnetic Fusion Energy (MFE) at Lawrence Livermore National Laboratory (LLNL); Roger Batzel, Director of LLNL, and W. Kenneth Davis, DOE Deputy Secretary. For the dedication on October 23, Davis presented the keynote address. Afterwards, tours of MFTF were conducted by project scientists and engineers. Highlighting the tour was this interior view of the 11 -m-diam MFTF vacuum vessel, which reveals the recently installed $750,000-1 b$ yin-yang magnets encased in their stainlesssteel jackets.

\section{Scientific Editor}

M. A. Harrison

General Editor

C. Gerich

Manuscript date

March 31, 1982

Distribution Category IIC-20, 20a through $20 \mathrm{~g}$

Work performed under the :-Ispices of the L.S. Department of Energy by the IICLLNL under contract number W- $7405-E N G-48$.

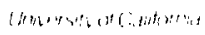 \\ 는 Lawrence Livermore}

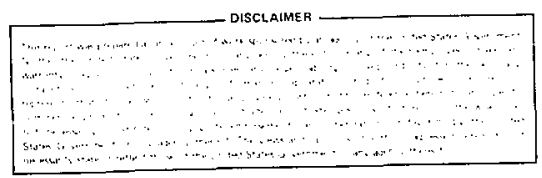




\section{Preface}

Our intent in the Mirror Fusion Quarterly Report is to provide a timely summary of activities within the Magnetic Fusion Energy (MFE) program at Lawrence Livermore Natior il Laboratory (LLNL). In a given Quarterly, not all MFE projects are necessarily represented. Throughout, details are kept to a minimum; readers desiring additional information are encouraged io read referenced documents or to contact the individuals engaged in the projects.

The information in each Quarterly is presented in the same sequence as in the Field Work Package Proposal and Authorization System (WPAS) submissions prepared for the U.S. Department of Energy; the main sections are

- Applied Plasma Physics,

- Confinement Systems,

- Development and Technology.

- Mirror Fusion Test Facility.

On occasion, we shall include information pertaining to the LLNL role as Lead Laboratory for the Open-Systems Mirror Fusion Progam. Each of these sections is introduced by an overall statement of the goals and purposes of the contributors. As appropriate within each section, statements of the goals of individual programs and projects are followed by articles containing summaries of significant recent activity. 


\section{Contents}

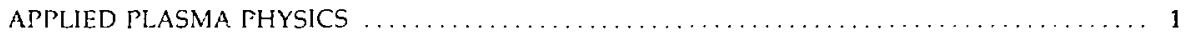

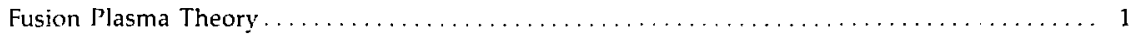

Simulation of Long-Timescale Plasma Phenomena

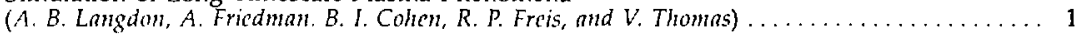

Analytic Model of the Radiation-Dominated Decay of a Compact Toroid

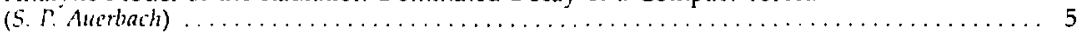

High-Frequency Microinstabilities in Hot-Electron Piasmas

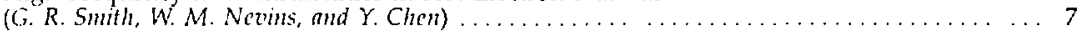

Improved Heating with Two-Frequency ECRH

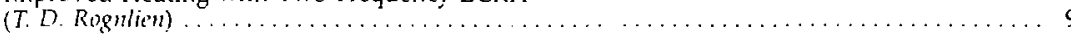

Exact and Approximate Configurational Invariants

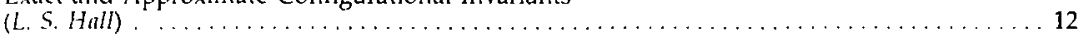

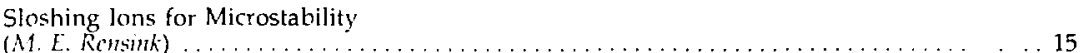

Negative lon Formation in Hydrogen Discharges and Vibrational Population

Distribution for Hydrogen Molecules in a Hydrogen Discharge

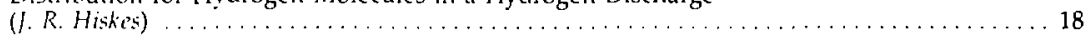

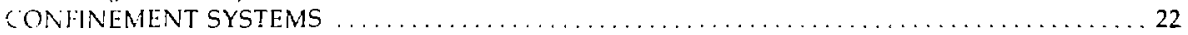

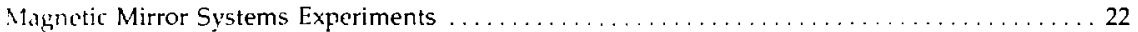

Tandeni Mirror Experiment Upgrade (TMX Upgrade) $\ldots \ldots \ldots \ldots \ldots \ldots \ldots \ldots \ldots \ldots \ldots$

Introduction

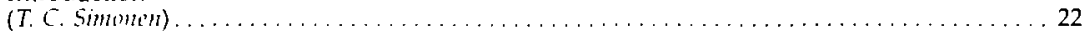

Final Assembly of TMX Upgrade

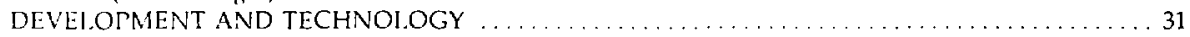

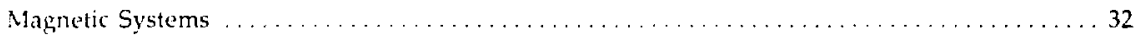

Superconducting Magnet Development

(D. N. Comish, R. W. Hoart, R.M Scanlm, and I. P. Zhasnik) ................ 32

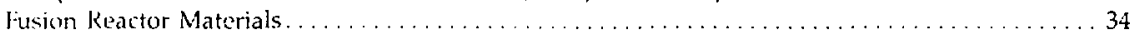

Summary of RTNS-II Operation: 1981

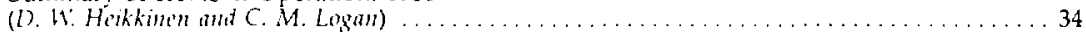

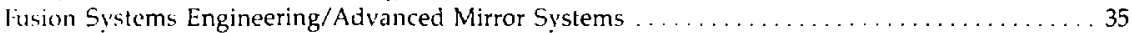

Comparative Study of End Plugs for Tandem Mirror Reactors

(C. A. Corlson, W. L. Burr, B. M. Boghusian, R. S. Devolo,

1. N. Moggett, G. H. Hamilion, B. M. Johnstom, W. N. Kumai,

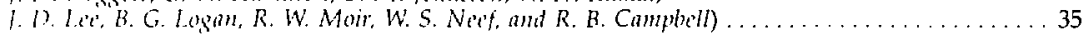

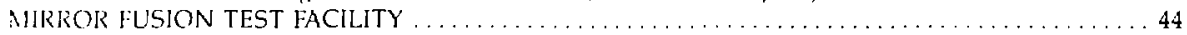

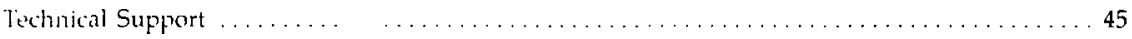

introduction

$\begin{array}{ll}\text { (6.) l). P'orter) } & 45\end{array}$

The Redesigned Axisymmetric-Barrier Upgrade of MFTF-B

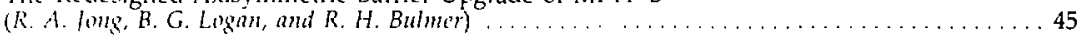

Perturbation of Solenoid Magnetic Field by Steel Support Beams

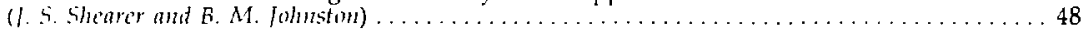

Calculation of Net Trapping and Pumping Rates in the A-Cell Thermal Barrier

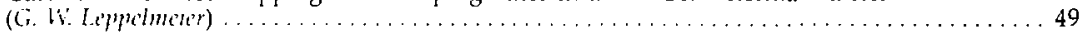

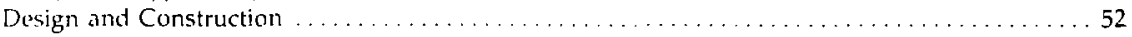

General Progress

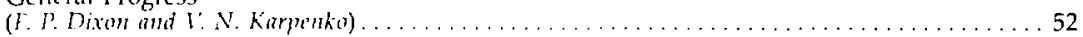

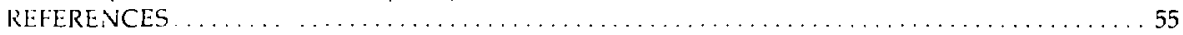

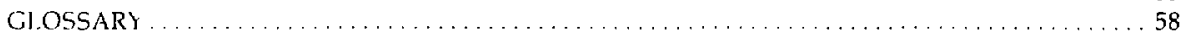

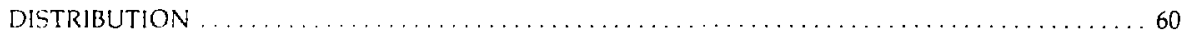




\section{Applied Plasman Physics}

Applied Plasma Physics is a major suborganizational unit of the Magnetic Fusion Energy (MFE) Program. Within this unit are Fusion Plasma Theory, Experimental Plasma Research, and the National MFE Computer Network.

Fusion Plasma Theory encompasses the work of two groups - the Fusion Plasma Theory and Com putations Group and the Computational Chysics Group of the National MFE Computer Center (NMFECC). The first unit has the responsibility for developing theoretical-computational models in the general areas of plasma properties, but specifically for the LI.NI. mirror experimental progran. Exporimental data are interpreted and theories are developed in reginies towards which experiments are ex pected to evolve. These models and theories are then incorporated into numerical codes to simulate the present performance of experiments and to predict the hehavior of future, scaled-up experiments. Thu Computational Physics group serve's the entire MFE community. Its principal objective is to deselop detailed numerical models for investigating plasma phenomena and for simulating present and futur: magnetic confinement systems, with application to tokamaks, mirrors, and various alternative concepts

Under Experimental Plasma Research, researchers are studying the feasibility of using certain neutron-detection techniques for determining the characteristics of the plasmas in advanced thermontt. clear experiments.

The National MFE Computer Network was established in 1974 by the Department of Energy Division of Magnetic Fusion Energy: The NMFECC, headquarters of the network, is located at I.LNL; its purpose is to apply large-scale computational technology and computing techniques to the problems of controlled thermon iclear research. At the national center-available to the entire community-are two high-spered Cray-1 computers, each with one million words of memory, and the CDC 7600 central computer with 64,000 words of small semiconductor memory, 500,000 words of large-core memory, and disk slorage. Different levels of computer capability are provided according to research priority and anticipated com putational demand at the various remote locations. Selected universities and other laboratories engaged in MFE research have access by satellite or land links to the NMFECC at I.LNI, via six user service centers (USCs) equipped with PDP-10 computer systems. Dial-up capability is provided to approximately 30 other selected universities and laboratories.

\section{Fusion Flasma Theory}

\section{Simulation of Long-Timescale Plasma Phenomena}

\author{
(A. B. Langdon, A. Friedman, B. I. Cohen, \\ R. P. Freis, and I'. Thomas')
}

Our preliminary studies indicate that orbit averaging and implicit methods substantially improve particle-code efficiency.

\section{Implicit Simulation}

We have furthered our understanding of the properties of implicit plasma simulaticn in general

\footnotetext{
Electronics Research l.ahoratory, University of California at
} Burkeler: and of "direcl" methots in particular. In addition, we have studied orbit averaging to reduce particle statistics in combination with these implicit methods.

A brief discussion of the simplest direct method and its application to the electron. electron two-stream instability and to ion acoustic waves appears in Ref. 1 Our analyses of the stability and accuracy of implicit time-integration schemes, including our synthesis of new schemes with desirable properties, are described in detail in Ref. 2; this work is equally relevant to "moment" implicit methods described in Refs. 3 and 4. A detailed description of a generalized direct scheme, including discussions of prediction, iterative refinement, spatial difference representations, residual timestep limitations, and consistent spatial filtering appears in Ref. 5. Here, we briefly summarize our work appearing in Ref;. 2 and 5 . 


\section{Applied Plasma Physics}

and describe our progress in orbit-averaging methods.

A difference scheme should satisfy the following design criteria:

- High accuracy for modes with normalmode frequency $\omega_{0}<\Delta t^{-1}$; e.g., $\operatorname{Im}\left(\omega / \omega_{0}\right)$ should be minimal, where $\Delta t$ is the timestep.

- Substantial dissipation of modes with $u_{i},>\Delta t \quad{ }^{i}$ since these modes cannot be accurately represented.

- Minimal storage of past data.

- Minimal spurious numerical cooling and fatuling (secular accelerations, as described belming.

- Galilean invariance to prevent spurious diulabilization of fast or slow space-charge waves.

- Robustness with respect to an approximate solution of the implicit particle-field equations. which cannot be solved exactly for reasons of computational economy.

Wie have discussed all but this last issue in detail in our analysis of difference schemes in ief. 2; in addition, we have included our construclions of new schemes possessing the properties described above.

Our analysis of cold-plasma wave dispersion has led to a number of important conclusions. Relaxation of the $w_{r}$, st stability constraint in a plasma simulation requires implicitness without exception, $w$ here $\omega_{p}$ is the plasma frequency. The coefficients in our difference equations that both control the degree of implicitness and govern dissipation jointly determine stability. For $\omega_{1}^{2} \Delta t^{2} \gg 1$, implicit schemes can be stable, but the highfrequency oscillations are necessarily distorted; therefore, damping is generally desirable.

We have devised several schemes that effiriently damp high-frequency oscillations and compare then in Fig. 1, where the absolute value $|z| \equiv|\exp (-\omega \Delta t)|$ (for the least-damped normal mode) is plotted as a function of $\omega_{i j}^{2} \mathrm{t}^{2}$. C Cnversely, low-frequency oscillations can be simulated with high accuracy. The dissipacion rate can be removed to high order in $\Delta t$, for $\omega_{1} \Delta t \ll 1$, with the proper choice of coefficients.

In addition, we have generalized our implicit schemes to include a magnetic field to (1) reproduce the cyclotron gyration of single particles in a stable fashion but with no damping for any value of the product of cyclotron frequency $w_{c}$ or the timestep It, and (2) model collective modes (wav's's) in a numerically stable fashion for any wave frequency and timestep-with frequency error $\propto \Delta t^{2}$ and damping $\alpha \Delta t^{3}$ at low frequencyand with substantial dissipation at high frequency.

A second important aspect of numerical accuracy is illuminated by a calculation of the trajectory of a particle drifting tinrough a sinusoidally-varying electric field, as reproduced by finite difference equations. Unphysical modifications are introduced by finite timestep effects that depend on wavelength, timestep, and particle velocity. Because the particle is untrapped, it should interact adiabatically with the wave. However, we find that a drifting particle will experience a spurious time-averaged force and thus, accelerate.

The unphysical acceleration (drag) rates for second-order schemes are all proportıonal to $\Delta t^{3}$ for slow particles. This scaling and detailed dependence on the difference schemes correspond directly to those for the dissipation rates we found for low-frequency, simple, harmonic oscillations. Thus, the same mechanism that causes damping of low-frequency modes is responsible for the artificial cooling or heating of the plasma as it interacts with electric field structures. Use of higher-order schemes reduces both effects. The absolute cooling or heating rates we obtain depend on the strength of the electric field, as measured by $\omega_{t r} \Delta t$, where $\omega_{t r}$ is the "trapping" frequency of the oscillation of a particle near the bottom of a potential well.

In contrast, the plasma cooling/heating rates for the first-order schemes are generally much larger than those for the second-order accurate schemes; this argues strongly for the use of the higher-order algorithms. Drag rates of first- and second-order schemes can be compared in Fig. 2 where we plot the normalized accelerations

$-\left(a^{(2)}\right) /|a ̂|\left(\omega_{t r} \Delta t\right)^{2}=-\operatorname{Im}\left(\tilde{x} / \tilde{a} \Delta t^{2}\right)$,

which are functions only of $\mathrm{kv}^{(1)} \mathrm{t}$. Mason ${ }^{4}$ has observed numerical cooling of warm plasmas in simulations with a first-order dissipative-implicit algorithm. Significantly reduced cooling rates can be achieved by using the higher-order accurate integration schemes.

We have also directed our research toward developing improved schemes for solving coupled 


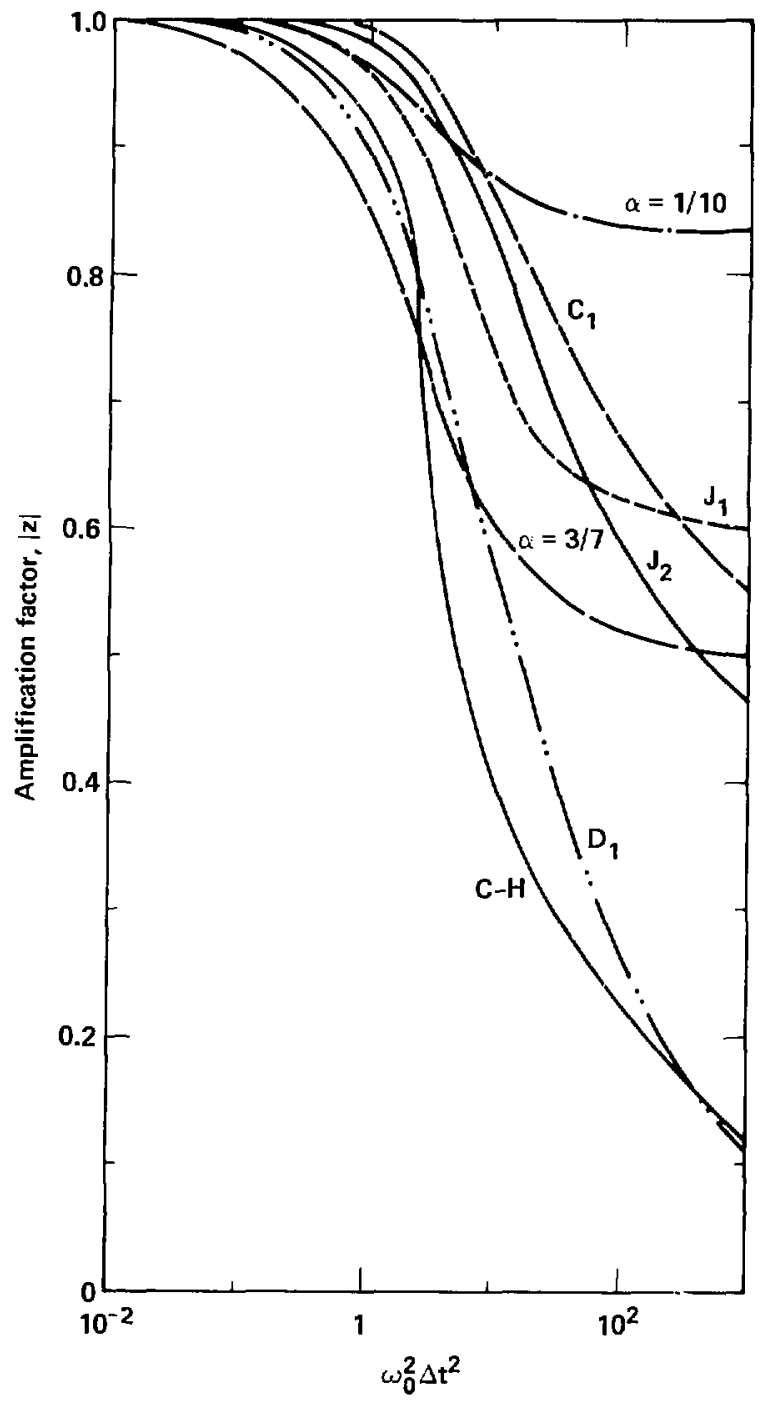

Figure 1. The absolute value $|z|=|\exp (-i \omega \Delta t)|$ of the least-damped, simple harmonic oscillator normal mode vs $\omega_{0}^{2} \Delta t^{2}$ for the $J_{1}$ and $J_{2}$ schemes of Denavit, ${ }^{3}$ the $\mathrm{C}-\mathrm{H}$ scheme of Curtiss and Hirschfelder, ${ }^{6}$ the first-order schemes with $\alpha=3 / 7$ and $1 / 10$, the optimized $c_{1}$ scheme $\left(c_{0}=0.302\right.$, $\left.c_{1}=0.04\right)$, and the $D_{1}$ scheme $\left(d_{0}=2, d_{1}=-1\right)$. 


\section{Applied Plasma Physics}

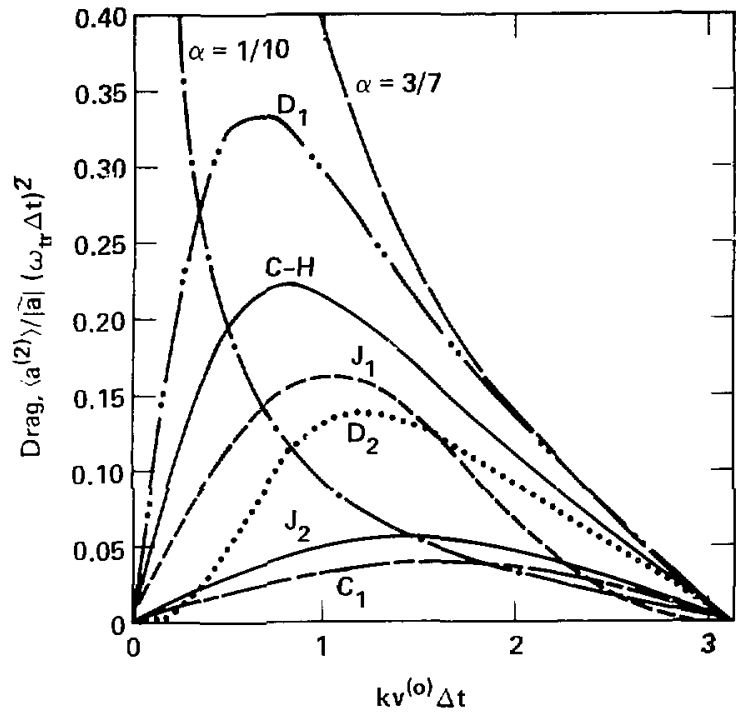

Figure 2. The normalized drag $\left\langle a^{(2)}\right\rangle /|a|\left(\omega_{1 t} \Delta t\right)^{2}=-\operatorname{Im}\left(\bar{x} / \bar{a} \Delta t^{2}\right)$ vs $\mathbf{k v}^{(0)} \Delta t$ for the $J_{1}$ and $J_{2}$ schemes of Denavit, ${ }^{3}$ the $\mathrm{C}-\mathrm{H}$ scheme of Curtiss and Hirschfelder, ${ }^{6}$ the firstrder schemes with $\alpha=3 / 7$ and $1 / 10$, the optimized $C_{1}$ scheme $\left(c_{0}\right.$ $\left.=J .302, c_{1}=0.04\right)$, the $D_{1}$ scheme $\left(d_{0}=2, d_{1}=-1\right)$, and the $D_{2}$ scheme $\left(d_{0}=5 / 2, d_{1}=-2, d_{2}\right.$ $=1 / 2)$. The drag rate has odd symmetry and is periodic with respect to $\mathrm{kv}^{(0)} \Delta t$ with period $2 \pi$.

implicit particle-field equations. A simple but approimate scheme has been described in Ref. 1 . We have devised (but not yet tested) a means of iterating toward an exact solution of the field equation at the advanced time level. This ability to iterate to an exact answer ensures that desirable features built into the time-differencing scheme can be realized in simulation, and provides a useful benchmark for inexact (but perhaps faster) schemes. We have studied a simplified scheme wherein a significantly simpler set of quantities needs to be accumulated from the particles, and the bandwidth of the resulting field equations is reduced to the point where, even in twodimensional magnetized problems, a solution is convenient with known methods. Iteration might be used to refine the resulting fields. We have also delineated residual timestep constraints arising from direct-impli-it schemes; these are noted helow.

The essence of our iterative scheme is the correction of an $\mathbf{r}^{\text {th }}$ approximation to the potential $\phi^{(\mathrm{rl})}$ by an amount $\delta \phi$, where

$-\Gamma \cdot(1+x) \Gamma \delta \phi=\rho^{(r)}+\Gamma^{2} \phi^{\mathrm{ert}}$. and

$\chi(x)=\beta u_{p}^{2}(x) \Delta t^{2}$.

Here, $\omega_{\gamma}(x)$ is the local plasma frequency, $x$ is the effective susceptibility, $\rho^{(n)}$ is the charge density, and $\beta$ (a positive constant $\leq 1$ ) is a function of the implicit difference scheme chosen. The particles are readvanced using $\left.\phi^{\prime}\right|^{\prime \prime}=\phi^{|r|}+\delta \phi$, and an improved $\rho^{i r \cdot 1 !}$ is computed. In our simplest scheme $\phi^{\{11 !)}=0$, and we take only one iteration.

Thers are three residual limits on the timestep in our simulation schemes; to some degree they coincide with the fundamental limits of steps small enough to resolve the physical processes under study. The first limitation is on the electron transit frequency $V_{1}, s t / L$, where $V_{t}$ is the thermal velocity, and $L$ is a scaie length of field variation. This is caused by the requirement that electrons reproduce Debye shielding and perhaps also Laniau damping. The implicit code shields too strongly at short wavelengths. Accurate shielding requires $k^{2} v_{1}^{2} \Delta t^{2} \leqslant 1$. When $\omega_{1}^{2} \Delta t \gg 1$, 
this restricts us to wavelengths large compared to a Debye length because

$k \lambda_{D}=\frac{k v_{1} \Delta t}{w_{1}, \Delta t} \ll 1$,

where $v_{t}$ is the thermal velocity and $\lambda_{D}$, the Debye length. Unfortunately, this eliminates applications such as ion-acoustic turbulence for which $k \lambda=1 / 2$.

At short wavelengths, the implicit algorithm is at least stable, and errs in the direction of making the change in the electric field too small. Thus, it appears that the presence of silort wavelengths may not interfere with the longer wavelengths that are simulated accurately. Finite $k v_{1} \Delta$ t does not appear to affect convergence of our solution process, whereas $k v_{\mathrm{t}} \mathrm{s} t \geq 1$ does upset convergence of the moment-implicit method. 2.4

The second residual $\Delta t$ limit is a restriction on $\omega_{t r} \Delta t$, where $\omega_{t r}$ is the trapping or oscillation frequency of a particle in an electrostatic potential well. It arises from the negiected field-gradient term in the equation for the particle displacement at the advanced time; the neglected term is important when $\Delta t$ is too large to resolve trapping oscillations.

The final limitation on the timestep, nonphysical secular acceleration, has been described ahove.

\section{Orbit Averaging}

Long-timescale plasma simulation has been enhanced with orbit-averaged particle $\operatorname{codes}^{7}$ as well as with codes in which implicit and orbitdveraging methods have been merged. ${ }^{4}$ We have employed a two-dimensional, orbit-averaged, magneto-inductive particle code to produce simulations of the neutral-beam-driven, high- $\beta$ experiments in the 2 XIIB device, using fully realistic plasma parameters. '

Merging orbit averaging with implicit methods should further increase the power of the orbit-averaging technique and extend particle simulation to longer timescales, while preserving numerical stability and accuracy. Reference 8 reports our synthesis and analysis of difference equations for an implicit orbit-averaged electrostatic model and gives simulation examples. We have constructed schemes that are stable at large timesteps $\left(\omega_{\mathrm{pu}}, \Delta \mathrm{t} \gg 1\right)$, require fewer particles, and hence reduce input/output and memory requirements. However, the orbit averaging in the implicit unmagnetized electrostatic models we have tested so far has not been as successful as in cases where a magnetic field existed. Orbit averaging can achieve more significant improvements in code efficiency ${ }^{8}$; however, such improvement depends primarily on the existence of a natural separation between particle-orbit timescales and the longer timescales for the evolution of self-consistent electromagnetic fields.

\section{Analytic Model of the Radiation-Dominated Decay of a Compact Toroid}

\section{(S. P. Awerbach)}

Recent theoretical calculations demonstrate that several striking features of the Beta-II experiment are correlated with the observed dominance of the energy balance by impurity radiation. These calculations thus support the hope that decreasing the impurity levels will significantly improve the performance of Beta-II and similar devices.

The coaxial-gun, compact-torus experiments at Lawrence Livermore National Laboratory (LLNL) and Los Alamos Scientific Laboratory (LASL) are believed to be radiation-dominated ${ }^{9,10}$ in the sense that most or all of their input erargy is lost by impurity radiation. This paper presents a simple analytic model of the radiation-dominated decay of a compact torus (CT), and demonstrates that several striking features of the experiments (finite lifetime, linear current decay, and insensitivity of the lifetime to density or stored magnetic energy) can also be explained by the hypothesis that impurity radiation dominates the energy loss. Based on the analytic results, a simple criterion for the maximum tolerable impurity density is established.

The model assumes that power flow in the decay of a compact torus is dominated by two processes: magnetic energy is transferred to the electrons by ohmic heating; the electrons then lose their energy by radiation. Given the observed temperatures and densities, neglecting other loss 


\section{Applied Plasma Physics}

channels is justified. The power flow equations are then

$$
\frac{d W_{B}}{d t}=-P_{\text {nh }},
$$

and

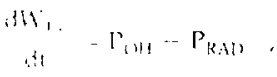

where $\mathbb{H}_{13}$ is the magnetic energy, $W_{T, k}$ the elecinm thermal energy. Pou the ohmic heating pomer, and $\Gamma_{R A[}$ the radiated power. Model expresisions for $W_{B}, \Gamma_{(1)}$, and $\Gamma_{\mathrm{BA} D}$ will be discussed next.

The plasma is in magnetohydrodynamic (MIHD) equilitrium inside the flux conserver. This equilibrium is modeled by the spherical, forcefree spheromak equilibrium of Morikawa, ${ }^{11}$ and Rosenbluth and Bussac. ${ }^{12}$ (Essentially identical results would be obtained if the force-free cylindrical equilibria of Bondeson et al. ${ }^{13}$ were employed.) For the spheromak equilibrium, the magnetic energy is $W_{13}=b l^{2} R$, where $b$ is a constant, $\mathrm{I}$ is total toroidal current, and $\mathrm{R}$ is the separatrix radius. For this equilibrium, the current is parallel to the magnetic field. Thus, using the Spitzer parallel resistivity,

$P_{\text {(H) }}=\int \eta J^{2} d^{i} x=\bar{\eta} \int J^{2} d^{3} x$

where $J$ is the current density, and $\bar{\eta}$ is an average parallel resistance. For the spheromak equilibrium, $\mathrm{P}_{\mathrm{OH}}$ is then $\mathrm{P}_{\mathrm{OH}}=\mathrm{al}^{2} /\left(\mathrm{RT}^{3 .}\right)$, where $\mathrm{a}$ is a constant, and $T$ is electron temperature. If $I$ is ineasured in amperes, $R$ in centimeters, and $T$ in - Hectron volts, then the constants become: $a=0.6$, . $\mathrm{b}=1.8 \times 10^{-9}$.

The radiated power is modeled by a $\therefore$ : vil hw fit to the coronal-equilibrium radiation ... cilations of D. E. Post et al. ${ }^{1+}$ Thus, the radiated $\because \cdots$, in taken to be $P_{R A D}=c n_{e} n_{1} V T^{k}$, where $c$ . . . comstants, $n_{e}$ and $n_{1}$ are the electron and (i) :ai: densities, respectively, and $V$ is the plasma volume. As an example, for oxygen radiation in the range $5 \leq \mathrm{T} \leq 20 \mathrm{eV}$, a decent fit to the coronal-equilibrium calculations is $c=4.2 \times 10^{-28}$, and $k=1.92$ (if $P_{R A D}$ is measured in watts, $V$ in cubic centimeters, and $T$ in electron volts).

To derive soluble equations, three further assumptions will be made:

(1) The separatrix radius $R$ is constant. Indeed, this is approximately true for the decay of plasma in a flux conserver for which $R=$ flux conserver radius.

(2) Both $n_{t^{\prime}}$ and $n_{1}$ are constant during the discharge. This is certainly true classically because the particle loss rate is of order $\beta$ times the field decay rate $\left(\beta=8 \pi \mathrm{P}^{2} \mathrm{~B}^{2}\right)$.

(3) $P_{0 I 1}=P_{\text {RAD }}$. This is also reasonable because, in a low- $\beta$ plasma, the electron heat capacity is so small that the electron energy sources and sinks must very closely balance. All of these assumptions agree with numerical simulations. ${ }^{15}$

As a result of these three assumptions, Eqs. (5) and (6) become, respectively.

$\mathrm{bR} \frac{\mathrm{dI}^{2}}{\mathrm{dt}}=-\frac{\mathrm{al}^{2}}{\mathrm{RT}^{32}}$

and

$\frac{\mathrm{al}^{2}}{\mathrm{RT}^{12}}=\mathrm{cn}_{\mathrm{c}} \mathrm{n}_{1} \mathrm{VT}^{\mathrm{h}}$

Equation (9), the electron power-balance equation, determines the electron temperature:

$\mathrm{T}^{32}=\left(\frac{\mathrm{al}^{2}}{\mathrm{cRVn_{ \textrm {c } } \mathrm { n } _ { 1 }}}\right)^{\prime \prime}$

where $\alpha=3 /(3+2 k)$. By corribining Eqs. (8) and (10), and solving the resulting differential equation, the toroidal current is found to be

$I(t)=I(0)\left(1-\frac{t}{t_{1}}\right)^{I / 2 t}$ 
where the "extinction time" $t_{F}$ is

$t_{1}=\frac{[1(0)]^{2 n}}{\gamma}$

$\gamma=\frac{a \alpha}{b R^{2}}\left(\frac{c n_{a} n_{1} R V}{a}\right)^{\prime \prime}$.

The magnetic-field components will also obey an equation like Eq. (11) because, for fixed $R$, the fields are proportional to the current I. Equations (11) and (12) have the following consequences:

(1) Finite lifetim-Obviously, the currents and fields are extinguished in a finite time $t_{\mathrm{l}}$ :

(2) Lifalime scaling-Because $\mathrm{W}_{\mathrm{M}}=\mathrm{bl}^{2} \mathrm{R}$, the extinction time scales as

$t_{1}=\frac{\left(W_{B}\right)^{(2}(R)^{2}}{\left(n_{B} n_{1}\right)}-$

For oxygen, $\alpha=0.44$, and so $t_{E}$ is only weakly sensitive to the magnetic energy, the impurity level, or the radius $(2-5 \alpha=-0.19)$.

(3) Essentially linear current decay-For oxygen, $1 / 2 \alpha=1.14$, so

$l(t)='(0)\left(1-\frac{t}{t_{1}}\right)^{1.14}$

which is almost indistinguishable from linear decay.

These theoretical results are in good qualitative agreement with the experiments, which indeed exhibit finite lifetimes, apparently linear current decay, and insensitivity to $W_{B}$. (The impurity levels in the experiments are not known; thus detailed comparisons with the theory are difficult.) The analytic results are in good quantitative agreement with the 1-1/2-D simulation performed by Shumaker et al. ${ }^{15}$

The results of this analysis demonstrate that several features of the coaxial-gun, CT experiments at LLNL and Los Alamos, viz., finite life- time, linear decay, and insensitivity to magnetic stored energy and density, can be simply explained by impurity radiation. This supports the hope that the performance of these CT devices will improve if the impurity level is decreased sufficiently.

With this in mind, it is useful to derive a criterion for the tolerable impurity density. Clearly, the plasma will burn through the peak of the oxygen radiation curve at approximately $20 \mathrm{eV}$ if the equilibrated electron temperature is greater than $20 \mathrm{eV}$, i.e., if the temperature derived from Eq. (10) exceeds $20 \mathrm{eV}$. This requires:

$\mathrm{n}_{1} \mathrm{n}_{1 \ldots \ldots+n)}<2.6 \times 10^{22} \frac{\mathrm{B}_{6}^{2}}{\mathrm{R}^{2}}$

where $B_{1}$ is the magnetic field at the geometric center $\mathrm{r}=\mathrm{z}=0$ measured in Gauss, $\mathrm{R}$ is the separatrix radius measured in centimeters, and $n$ is measured in inverse cubic centimeters. As an example for $\mathrm{n}_{\mathrm{a}^{\mathrm{i}}}=2 \times 10^{14} \mathrm{~cm}^{3}, \mathrm{~B}_{\mathrm{i}}=5 \mathrm{kG}$, $R=40 \mathrm{~cm}$ (typical of the low-density, higher current Beta-11 experiments at LLNL) burn-through requires $n_{1}<2 \times 10^{12} \mathrm{cr}$. ${ }^{3}$, i.e., less than $1 \%$ oxygen. Burning through the carbon peak at approximately $10 \mathrm{eV}$ requires $n_{\mathrm{c}} \mathrm{n}_{\mathrm{c} \text { arhom }}<3.6 \times$ $10^{22} \mathrm{~B}^{2} / \mathrm{R}^{2}$. Caramana and Perkins have derived a similar criterion. ${ }^{16}$

\section{High-Frequency Microinstabilities in Hot-Electron Plasmas}

(G. R. Snith, W. M. Norins, and Y. Chen)

Our initial research indicates that two weakly growing instabilities - the whistler and upper-hybrid loss-cone modes-occur in a plasma with an electron distribution function similar to that produced by ECRH.

The electron-cyclotron-resonant-heated (ECRH) plasmas that will be produced in the next generation of tandem-mirror experiments may suffer from instabilities at frequencies comparable to the electron-cyclotron frequency $\Omega$. Previous work $^{17}$ has led us to study two of these instabilities, the whistler and upper-hybrid loss cone 


\section{Applied Plasma Physics}

(UHiC). In this article we describe our numerically efficient modeling of the electron distribution function of an ECRH plasma and give some of our initial results on these instabilities.

Fokker-Planck studies of ECRH plasmas have found distributions $f(v)$ as the one shown in Fig. 3. ${ }^{18.19}$ The moments $f_{\perp} \equiv \int d v_{\| i} f(v)$ and $f_{\|}$ $\equiv \int \mathrm{v} d v \mathrm{f}(\mathrm{v})$ are monotonically decreasing functions of perpendicular and parallel energy, respectively. The conclusion that loss-cone instabilities are absent does not follow, however, because the distribution in Fig. 3 is poorly approximated by $f$. f i.e., $f(v)$ is not a separable function of the perpendicular and parallel energies. Loss-cone instabilities with finite $k$ can be driven by waveparticle interactions at $\mathbf{v}_{\mid}=(\omega-n \Omega) / \mathbf{k}_{i}$, along which the perpendicular-velocity distribution is inverted for appropriate $n, \omega$, and $k_{\mid k}$. Here $n$ is an integer, $\omega$ is the wave frequency, and $k_{\|}$is the parallel component of the wave vector. Failure to recognize the nonseparability of $f(v)$ would lead to overly optimistic stability assessments for loss-cone instabilities. Therefore, we have developed the following nonseparable model for the distribution function of an ECRH plasma.

We superpose a number $N$ of electron "species" with various parameters:

$$
f(v)=\sum_{-1}^{N} f_{N}(v)
$$

Each species has a separable distribution

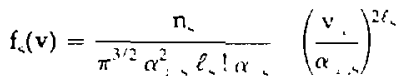

$$
\begin{aligned}
& x \exp \left(-\frac{v^{2}}{\alpha \ldots}-\frac{v^{2}}{\alpha^{2}}\right) .
\end{aligned}
$$

By approp: ate choices of the densities $n_{\mathrm{s}}$, thermal speeds $\alpha_{\perp, s}$ and $\alpha_{\|, s}$, and indices $\ell_{s}$, we achieve a good reproduction of Fig. 3, as shown in Fig. 4.

Superposing separable distributions to model a nonseparable distribution avoids numerical velocity-space integrations-a considerable computational advantage. The distribution given by Eq. (16) is precisely that used by Callen and Guest ${ }^{20}$; they provided all the formulae necessary for numerical calculation of the dielectric function $D(\omega, \mathbf{k})=\operatorname{det}[D(\omega, \mathbf{k})]$, whose roots describe the small-amplitude waves with wave vector $\mathbf{k}$ of a collisionless plasma in a uniform magnetic field $\mathbf{B}_{0}$.

We have written a computer code that solves the fully electromagnetic dispersion relation

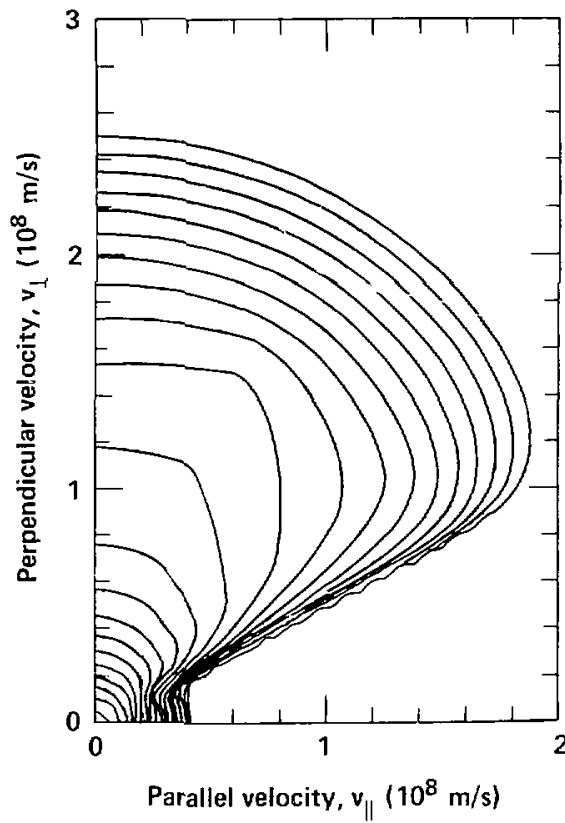

Figure 3. Contour plot of the electron distribution found in Fokker-Planck studies of the ECRH plasma in TMX Upgrade. The total electron density is given by $\omega_{p}^{2} / \Omega^{2}=1.55$. Contours are logarithmically spaced with a factor of two separating adjacent contours.

$D(\omega, \mathbf{k})=0$ for the nonseparable nodel distribution given by Eqs. (15) ar.d (16). The direction of wave propagation $\mathbf{k}$ with respect to $\mathbf{B}_{0}$ can be arbitrary, bu: $i$ the plasma is assumed to be spatially uniform and nonrelativistic.

This uniform-plasma approximation is a reasonable first approximation because high- 
frequency instabilities have wavelengths much shorter than typical equilibrium scale lengths of the plasma. The nonrelativistic approximation is known to be pessimistic for the whistler instability: Gladd ${ }^{21}$ has found growth-rate reductions of a

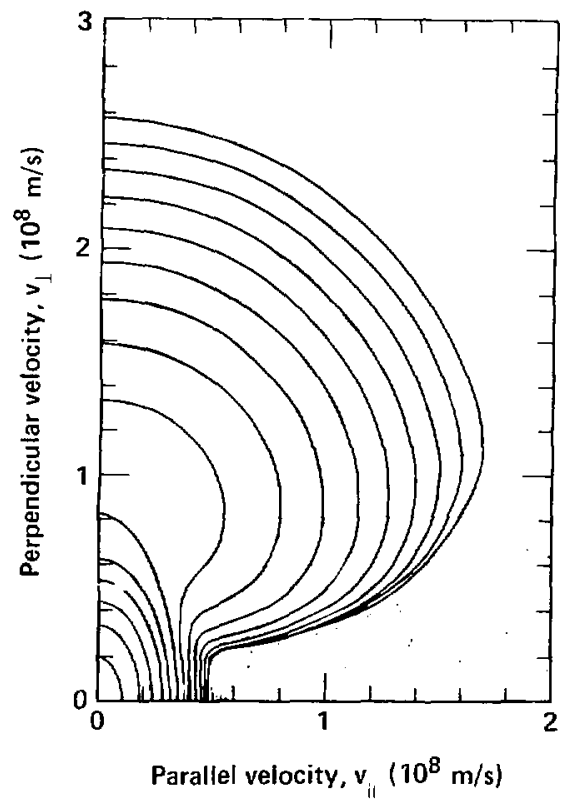

Figure 4. Model electron distribution for TMX Upgrade formed by superposing five separable distributions [Eq. (16)]. A factor of two separates the logarithmically spaced contours. The plasma frequencies $\omega_{p}$, perpendicular temperatures $\mathbf{T} \equiv(\ell+1) \mathrm{m} \alpha^{2} / L$, parallel temperatures $\mathrm{T} \equiv \mathrm{m} \alpha^{2} / 2$, and indices $\ell$ are given for all five distributions by $\omega_{p}^{2} / \Omega^{2}=0.64,0.92$, $-0.037,0.046$, and $-0.018 ; \mathrm{T}=3,40,12,12$, and $4 \mathrm{keV} ; \mathrm{T} / \mathrm{T}=0.3,0.35,4,2$, and 6 , and $\ell=0,1,1,1$, and 1 . The dotted contours (lower right) give unphysical negative values of the distribution functicn. Separation between adjacent dotted contours is also a factor of two, and the most negative value of the distribution function has a magnitude $<1 / 2000$ of the most positive value. factor of two or more for mean electron energies of $50 \mathrm{keV}$, one-tenth the rest energy. Relativistic effects are strong only for instabilities with $\omega<\Omega$. Therefore, the nonrelativistic approximation is probably accurate at the design energy $(50 \mathrm{keV})$ of the Tandem Mirror Experiment Upgrade (TMX Upgrade) for the U:HLC instability, which has $\omega^{\prime}>\Omega$.

We have used our computer code to calculate temporal growth rates $I m \omega$ of the whistler and UHLC instabilities for the distribution shown in Fig. 4. For the whistler instability, the maximum growth rate occurs at $\mathrm{k}=0$ and $\mathrm{k} c / \Omega=1.41$, where $\omega / \Omega 2=0.55+\mathrm{i} 0.025$.

For the UHLC instability, we show in Fig. 5 a contour plot of $\operatorname{lm} \omega$ in the $k, k$ plane. The maximum growth rate occurs at $\mathrm{k}: \mathrm{c} / \Omega=9.9$ and $k / k=0.071$, where $\omega / \Omega=1.15+i 0.0064$. These values of $k$ and $k$. for the most unstable mode are in line with estimates presented by Guest and Sigmar ${ }^{17}$ We note that the growth rate of the UHI.C mode goes to zero as $k$ goes to zero; this is as expected for our monotonically decreasing $f$.

Our work to date has found two weakly growing instabilities, the whistler and UHLC modes, in a plasma with an electron distribution function similar to that produced by ECRH. To prevent deleterious effects in future experiments, we continue to study these instabilities, both in the uniform-plasma approximation discussed here and in terms of the effects of spatial nonuniformity.

\section{Improved Heating with Two-Frequency ECRH}

\section{(T. D. Rognlien)}

Improved ECRH with two applied frequencies, as observed in a recent symmetric mirror experiment, is attributed to overlapping resonances that increase stochasticity. This effect is negl $\mathrm{i}_{\mathrm{i}}$ ible for TMX Upgrade.

Recent results from the Symmetric Mirror-1 (SM-1) experiment $\mathrm{t}^{22}$ at TRW, Inc., have indicated more than a doubling of hot-electron beta when two or more closely-spaced electron-cyclotron resonant heating (ECRH) frequencies are used instead of one. It is important to understand this 


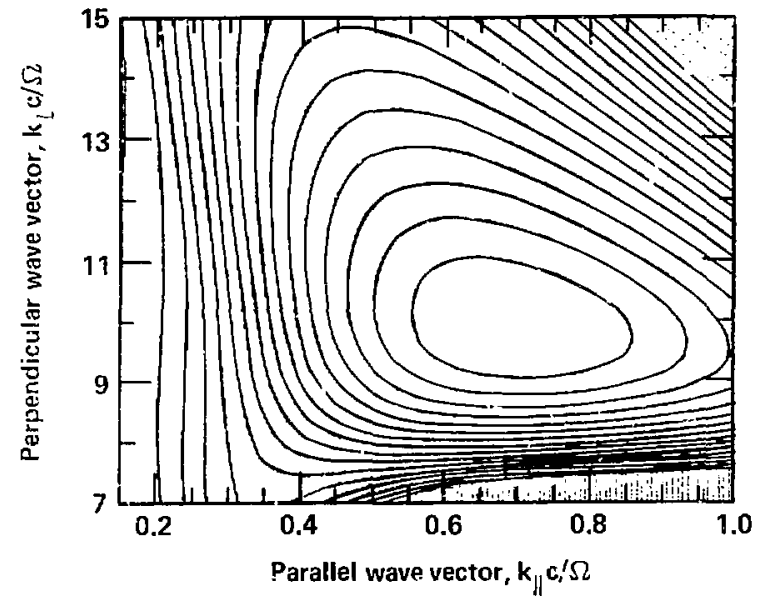

Figure 5. Temporal growth rate of the upper-hybrid loss-cone (UHLC) instability for the electron distribution for TMX Upgrade shown in Fig. 4. Solid contours give Im $\omega \geq 0$, dotted contours (upper right) give Im $\omega$ $<0$. The interval between adjacent contours is $4 \times 10^{-4} \Omega$. increased heating efficiency because ECRH will be used for thermal barriers in tandem mirrors and for Elmo Bumpy Torus (EBT) devices as well. We usea a test particle-simulation code to study two-frequency heating in both SM-1 and the Tandem Mirror Experiment Upgrade (TMX Upgrade) at Lawrence Livermore National Laboratory (LLNL). In SM-1 we have concluded that the increase in heating efficiency with multiple freouiencies is due to extending the superadiabatic heating barrier to higher energy. ${ }^{23}$ Our calculations for TMX Upgrade show that the superadiabatic barrier energy is greater than the expected operating energy of $50 \mathrm{keV}$; thus, multiple frequencies will not improve the heating efficiencies there.

The test particle-simulation code used for our SM-1 and TMX Upgrade calculations follows electron orbits along a magnetic field line in the presence of one or two 1.:onochromatic ECRH waves. We can advance the electrons using guidingcenter equations together with an equation for the gyrophase; we thus retain phase information that can lead to superadiabatic motion. We modeled Coulomb collisions with electrons and ions, employing Monte Carlo drag and diffusion terms in the equations of motion.

Calculation of the of diffusion coefficient, or heating rate, proceeds in the following manner. An ensemble of test electrons is injected at a given energy with a unform distribution between pitch angles $\theta_{\max }$ and $\theta_{\min }$. Each time these electrons bounce across the midplane, their total velocity (v), is recorded. The diffusion coefficient is givein by

$\mathrm{D}=\left((\langle\mathrm{v})-\mathrm{v})^{2}\right) / 2 \mathrm{t}$

where () denotes average over the ensemble, and $t$ is the time. Collisional contributions to the diffusion coefficient D are negligible.

The quasilinear diffusion coefficient $D_{q}$, the standard to which the measured diffusion coefficient is compared, is obtained by assuming that perturbations received on successive bounces are uncorrelated. An expression for $D_{q}$ is given in Ref. 24.

If, in contrast to the quasilinear assumption, successive perturbations are correlated, a series of bounce resonances appear. The resonance condition for a quadratic magnetic weil is ${ }^{24}$

$\omega_{1}=\ell \omega_{\mathrm{v} 0}\left(1+\mathrm{v}_{0}^{2} / 2 \mathrm{v}_{\perp 0}^{2}\right)-2 \mathrm{p} \omega_{\mathrm{b}}$

with $\omega_{1}$, the wave frequency; $\omega_{c 0}$, the midplane cyclotron frequency; $v_{i 0}$ and $v_{\perp n}$, the midplane parallel and ferpendicular velocity, respectively; $\ell$ 


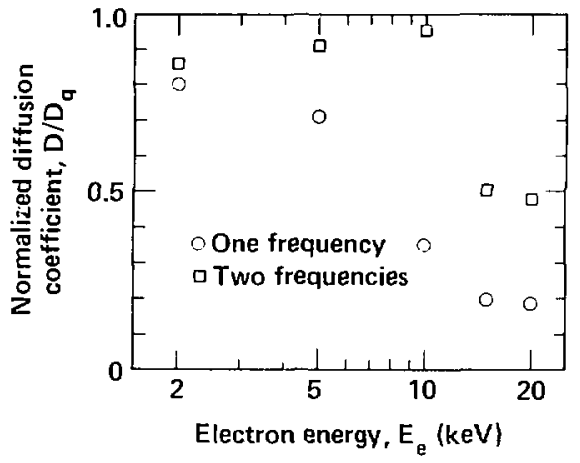

Figure 6. Ratio of the calculated (or normalized) diffusion coefícient to quasilinear value at various electron energies for $S M-1$ paramefers. Both the one- and two-frequency cases have the same total applied power. For two frequencies, $\Delta \omega=1.5 \times 10^{8} \cdot \mathrm{s}^{-1}$.

and $p$, integers; and $\omega_{l,}$ the axial bounce frequency. If the resonances are sufficiently close together so that the rf kicks can move an electron from one resonance to another (resonance overlap), stcchasticity results, ${ }^{27}$ and $D$ approaches $D_{4}$. If the resonances do not overlap, the electron motion is superadiabatic, and no net diffusion results.

With this background we considered the results of a code calculation applied to the SM-1 experiment. Fundamental heating with $\mathrm{E}=5 \mathrm{~V} / \mathrm{cm}$ is applied with the resonance at a mirror ratic of 2 ; the total mirror ratio is 2.2 . The ion and electron densities are $2 \times 10^{11} \mathrm{~cm}^{-3}$. We average $D$ between the mirror ratios of 2 and 2.2 , or pitch angles $45^{\circ}>\Theta>42.4^{\circ}$. The normalized diffusion cuelficient $D / D_{4}$ is shown in Fig. 6 for various energies for both one frequency and two frequencies with $\omega_{1}-\omega_{2}=\Delta \omega=1.5 \times 10^{8} \cdot \mathrm{s}^{-1}$. For the two-frequency case, the electric field is reduced by $2^{1 / 2}$ to maintain the same total power. The onset of superadiabatic reduction of $D$ is extended to higher energy for the two-frequency case. In Fig. 7, we show the variation of $\mathrm{D} / \mathrm{D}_{\mathrm{q}}$ at $10 \mathrm{keV}$ for two frequencies for various $\Delta \omega$. Note that $D / D_{4}$ maximizes (minimizes) for $J \omega$ equal to cdu (even) multiples of the bounce frequency $\omega_{\mathrm{b}}$.

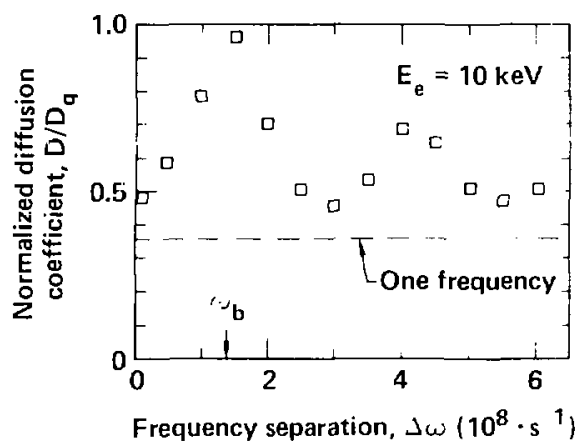

Figure 7. For SM-1, variation of the normalized diffusion coefficient at $10 \mathrm{keV}$ with frequency separation $\Delta \omega$ for the two-frequency case.

Figure 7 can be interpreted using Eq. (18). When $j w=\omega_{1}-\omega_{2}$ is an odd multiple of $\omega_{1}$, the two sets of resonances interlace, thus halving the distance between them. Since $E$ is reduced by $: 1$, the oscillation width about a 1 sonance is only reduced by $2^{1 / 4}$ (Ref. 24). The $n \cdot t$ effect is to make it easier fo the interlaced reso' ances to overlap. For $J \omega=2 n \omega_{w}$, the two sets of resonances nearly $c 0$ incide, and the one-frequer, $y D$ is approached. Figure 6 shows the same basic fifect: $D / D_{1}$ will increase when using twc frequencies instead of one if $j \omega=(2 n+1) \omega_{j}$.

In using these results to explain the increase in hot-electron beta in $S \mathrm{~S} M-1$, we have determined that the heating at the fundamental resonarice produces an increased source of moderate-energy electrons, and we assume that these can then be heated by the second harmonic to higher energies. For optimum heating, one should choose $\lrcorner \omega=\omega_{6}$ at the energy where superadiabatic motion reduces $D$ to increase the rtrength of this source. The optimum $\Delta \omega$ found in our calculation for $5 M-1$ is approxmateiy $25 \mathrm{MHz}$, whereas in this experiment it is about $40 \mathrm{MHz}$.

We have also used the code to determine if two frequencies might improve the heating efficiency for TMX Upgrade. We have concluded that $D / D_{4}=1$ for even one irequency for $E_{\mathrm{e}}$ $\leqslant 50 \mathrm{keV}$; thus, no advantage is gained by using 
two freplutucies. The difference with $5 M-1$ can be attributed to higher collisionality. larger electric liend fopuromately $100 \mathrm{~V} /(\mathrm{m})$, and smaller $\mathrm{w}_{\mathrm{w}}$ (loipger $u$ intem).

\section{Fixact and Approximate Configurational Invariants}

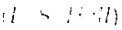

lismulation of a general theory of integrahle whems in two dinensions has yielded a priverful new tool for the construction of mactomoupic invariants. This work complements the theory of microscopic (adiabatic) invariants becaune the new invariants can supplement or replace the latter (such as the magnetic moment in configurations that are not everywhere adiabatic.

what hafuene when the magnetic moment is

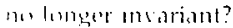

hometimen a confinement configuration in Guken nomatiabalio reguens. for cxample, trapped partictim iat aprobeh the null points in a general

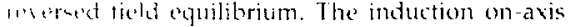
11 tertaln a distmmetric, tandem-mirror. "ntoldedl nonfipurations can also vanish. It is lememing much more important to know what hapiens when faticles lose theje conventional actiabatic ins arsate. Ace such particles scattered ard liat to the sistent-ers can confinement be maintained? It de'pends

He want la tind oul when it is that nther invariats exist, be thesexact or approximate. When alterative invariants can be found, we can make an allermative asecesment of confinenent propertios-cyen whon the nagnetio monrent fails.

Here, we are searching for configurational invariants. Such inwariants tepend upon the nature of the confinement contiguration itself-its symmetry and its "smoothness." The simplest example occurs for an axisymmetric system. Motion is independent of the toroidal angle $\theta$; the angular monientum $p_{n}$ is an exact invariant. But this same overall example also leads us much further

In the axisymmetric system, the theedimensional motion reduces in the usual way to a two-dimensional problem when the centrifugal polential is introduced. But that is still not sufficie'nt to guarantee confinement. Does a last invari- ant (in addition to the total energy) airo exist? To progress, we have to go beyond a priori symmetry arguments. Except for the existence oi a symmetry arjs, there is not nuch obvious symmetry in the poloidal projection. Yet we shall find that often the comfigaration admits a robust, hroadly appli(able) approximate imariant. Occasionally, the invariant is eren exact.

\section{Magnetized Particle Motion}

Vie bygin with se equations of motion in tove dimencion?

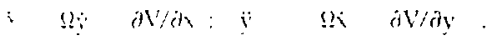

for esample, the axismmele problem ? is 3 ind mesures the torridal induction.

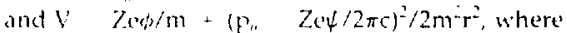
$f$ is the olererstatif potential and $\psi$ is the poloidal flux If $(r, r)$ are the ordinary poloidal coordinates of a cylindrical sistons.

$$
\begin{aligned}
& -1 / \quad \int_{1} \cos \theta \cdot r \quad \mathrm{r}_{1} \sin \delta .
\end{aligned}
$$

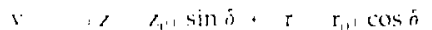

with $r_{1,} \cdot$ and $i$ chosen for appropriateness. If there is a simmelrs axis at $r=0$. we would normally chume,$-i=0$, and $r=r_{19}$ at a minimum of $r$.

\section{A General Form of Invariant}

Suppose first of all that an invariant I exists, suck that $:=(\Gamma / \mathrm{Q})$ tep $(-\mathrm{R} / \mathrm{S})$, where $\Gamma, Q, \mathrm{R}$, and $S$ are each finite-order polynomials in $x$ and v. That is,

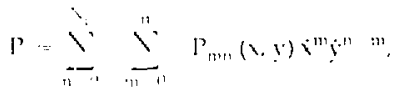

etc. It is remarkable that the existence of an invariant of the general form of $f$ implies that a nuch simpler invariant exists. That is, if $y$ exists, another invariant also exists that is merely a simple series of rmbs orcter in $\dot{x}$ and 5 Indeed, we can now use conservation of energy repeatedly in order to sliminate the combination $\dot{x}^{2}+\dot{y}^{2}$ in terms of spatial coordinates wherever the combination appears. The result is that the double-sum in a

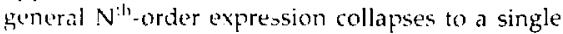


sum, a Fourier-series in the velocity pitch-angle. (Remember, the order to which we refe- is the order to which the relocitics appear in the invariant.)

In convenient form, the general $\mathrm{N}^{\text {th }}$-order invariant is

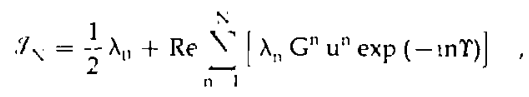

where $\lambda_{11}$ is real and $\lambda_{x}=1 / \mathrm{N}$. Otherwise, $\lambda_{n}$ is a general complex field-a function of $x$ and $y$. The normalization of $\lambda$, was accomplished by introducing another complex quantity $G$. However, $G$ has the special feature that it is an arbitrary amalitic function of $z=\because+$ iy. Finally, $u(x, y)$ and $\gamma$ are cylindrical velocity coordinates

$\dot{x}=u \cos \gamma ; \dot{y}=u \sin \gamma ; u^{2}=2(\varepsilon-v)$,

where $\delta$ is the total energy.

\section{The Necessary and Sufficient Constraint Condition for Existence of $\mathcal{I}_{\mathrm{N}}$}

It 's convenient to introduce a point transformation related to the analytic function $G(z)$. Thus, $d \xi=\mathrm{d} \xi+\mathrm{id} \eta=\mathrm{Gdz}$, where $\xi$ and $\eta$ are real and form the complex differential operators

$D=\frac{\partial}{\partial \xi}-\mathrm{i} \frac{\partial}{\partial \eta} ; D^{*}=\frac{\partial}{\partial \xi}+\mathrm{i} \frac{\partial}{\partial \eta}$.

(An asterisk denotes the complex conjugate.)

The transformation $\zeta=\int \mathrm{Gdz}$ generates a conformal mapping of the complex z-plane into the complex $\zeta$-plane. Notice that $D^{*} \mathrm{G}=0$ $=D^{*}$; either relation reproduces the ordinary Cauchy-Riemann conditions. In addition, for any analytic function, $D \mathrm{G}=2 \mathrm{dG} / \mathrm{d} \zeta$.

Finally, we also define the real functions

$B=2 \mathrm{GG}^{*} \Omega ; \mathrm{T}=\mathrm{GG}^{*} \mathrm{u}^{2}=2 \mathrm{GG}^{*}(\mathscr{E}-\mathrm{v})$.

Hence, if $G=$ const $\left(=2^{-1 / 2}\right.$, say), $T$ is the kinetic energy: Also notice that in general, since $G$ is analytic,

$\mathrm{GG}^{*}=|\Gamma \xi|^{2}=|\Gamma \eta|^{2}$.
With this preparation, the necessary and sufficient condition for the existence of an invariant of order $\mathrm{N}$ in the velocities is that

$$
\mathcal{D}^{*} \lambda_{n}{ }_{1}+n i \beta \lambda_{n}+T " \mathcal{D}\left(T^{n+1} \lambda_{n: 1}\right)=0
$$

$$
\text { for } 1 \leq \mathrm{n} \leq \mathrm{N} \text {, }
$$

supplemented at the lower end by the degenerate constraints

$\left.\operatorname{Im}\left(\lambda_{13}\right)=0 ; \operatorname{Im} \mid D\left(\mathrm{iT} \lambda_{1}\right)\right\}=0$.

At the upper end, $\lambda_{N}=N^{1}$, and $\lambda_{N+1}=0$.

Equations (27a) and (27b) are complete. There are $2 \mathrm{~N}+2$ real equations for $2 \mathrm{~N}+2$ unknowns: $\operatorname{Re}\left(\lambda_{n}\right), \operatorname{lm}\left(\lambda_{n}\right), 0 \leq n \leq N-1, \beta$, and $T$. The class of solutions admits the entire class of magnetic fields $\Omega$ and potentials $V$ for which an invariant of order $\mathrm{N}$ exists.

\section{Solutions of the Constraint Equations: Recovery of Known Results}

The solutions of Eqs. (27a) and (27b) for $N=1$ and for $N=2$ reproduce virtually all that is known about systems with exact invariants in two dimensions. Thus, if $\phi(\eta)$ and $K(\eta)$ are arbitrary functions of an arbitrary solution of La. place's equation, viz., functions of some coordinate obtained by an arbitrary mapping of the complex plane (arbitrary G), and if

$\varepsilon-\mathrm{V}=-(\mathrm{d} \phi / \mathrm{d} \eta)|\nabla \eta|^{2}$

$$
\Omega=-(\mathrm{d} K / \mathrm{d} \eta)|\nabla \eta|^{2} .
$$

then

$\left.g_{1}=\mathcal{K}+|\Gamma \eta|=\mid \dot{x}(\partial \eta / \partial y)-\dot{y}(\partial \eta / \partial x)\right\}$.

For example, if $\mathrm{G}=\mathrm{a} \mathrm{e}^{\mathrm{i} \zeta}$, then $\eta=\ell \mathrm{n}$ $\left[a /\left(x^{2}+y^{2}\right)^{1 / 2}\right]$. Hence, the invariant exists for an arbitrary central potential, provided $\Omega$ also depends only upen $\left(x^{2}+y^{2}\right)^{1 / 2}$. In this case, $\mathcal{J}_{1}$ is just the angular momentum. Likewise, if $\Omega=0$, the system is satisfied at $N=2$ if

$\xi-\mathrm{V}=\mathrm{f}(\xi)|\nabla \xi|^{2}+\mathrm{g}(\mathrm{n})|\nabla \eta|^{2}$.

This solution corresponds to a general separable system. 


\section{Applied Plasma Physics}

Notice that the existence of a last invariant riay or may not depend upon the value of $E$, depending upon whether or not the expression for $V$ can he kept fixed as $E$ is changed. If $G$ is constant, this is easily seen to work out by extracting an additi $\because$ constant from $f$ or $g$; that is, $V=f(x)$ - $g(y)$ admits a second-order invariant. Likewise. the mapping to confocal coordinates generated by $z=a c^{2}, 5$ gives another well-known separable

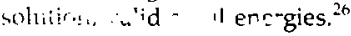

\section{lfigher-Order Solutions}

We have aiso obtained solutions to our equawhin for invariants of orders $N=3$ and $N=4$ when! $!=0$. At third order a number of systems with exact invariant can be found. In particular, the equations lead naturally to the Toda potential and its associated invariant, discovered a few years ago by Ford and co-workers. ${ }^{27}$ We also find an approximate third-order invariant for the Benon-Heiles potential, ${ }^{24}$ a system which is related, in fact, to the Toda potential. ${ }^{27}$

At fourth order, we find that the system

$V=\frac{1}{2} x^{2}+16 y^{2}+4 x^{2} y+\frac{64}{3} y^{3}$

atso admits an exact invariant, evidently previmuly unknown.

Our cyuations are quite suited to the discovery of approximate invariants. Indeed, at both third and fourth order, we have investigated tine general cubic potential with a symmetry plane at $x=0$ :

$V=\frac{1}{2} A x^{2}+\frac{1}{2} B y^{2}+C x^{2} y+\frac{1}{3} D y^{3}$

(Only the ratios $\mathrm{A} / \mathrm{B}$ and $\mathrm{C} / \mathrm{D}$ are significant; the other coefficients can be taken into the dimensions. We keep all four here for convenience.) In particular,

$I=\frac{1}{4} \rho \dot{x}^{+}-U \dot{x}^{2}-F \dot{x} \dot{y}+\frac{1}{8} G x^{2}$,

is generally an approximatc fourth-order invariant, accurate when the energy is not too large. (1 has quatratic terms, and $\dot{I}$ is sixth order in the coordinates and velocities.) When [ is not an exact in- variant, $\dot{I}=f \dot{g}-g \dot{f}$. The functions appearing in Eqs. (33) and (34j are

$$
\begin{aligned}
& \mathrm{U}=\theta \mathcal{E}-\| \mathrm{A} y-\frac{1}{2}(\rho-\lambda) \mathrm{Ax} \mathrm{x}^{2}-\frac{1}{2} \lambda \mathrm{Ay}^{2} \\
& -(\rho-\mu) C x^{2} y-\frac{1}{3} \mu C y^{3}, \\
& F=" A x+\lambda A x y+\frac{1}{3}(\rho-\mu) C x^{3}+\mu C x y^{2} . \\
& \mathrm{C}=8(\lambda-\theta) \mathrm{A} E+2[4(\mu-\theta) \mathrm{C} E-\| \mathrm{AB}] \mathrm{y} \\
& -2(2 \lambda \mathrm{A}+\mu \mathrm{C}-\rho \mathrm{A}) \mathrm{Ax^{2 }} \\
& -2[2 \lambda B-m(2 C-D)] A y^{2} \\
& -\left\lfloor 5 \lambda A+\frac{1}{3}(p-\mu)(B-8 A) \mid C x^{2} y\right. \\
& +\left\lfloor\frac{4}{3} \lambda \mathrm{AC}-\frac{10}{3} \lambda \mathrm{AD}-6 \mu \mathrm{BC}\right\rceil \mathrm{y}^{3} \\
& -\frac{4}{9}(\mu-\mu) C^{2} x^{4}-\left[8 M-\frac{1}{3}(8 \rho-23 \mu) C^{2}\right. \\
& +\frac{1}{3}(\rho-\mu) \mathrm{CD} \mid x^{2} y^{2} \\
& -\left|8 N-\frac{2}{3} \mu(C-7 D) C\right| y^{4} \text {. }
\end{aligned}
$$

$f=\frac{1}{2}\left(M x^{2}+N y^{2}\right)$

$g=4 x^{2} y^{2}$

and

$$
\begin{aligned}
& \theta=\mu+(B-A)(4 A-B)(16 A-B) \\
& \times(9 B-4 A) / 108 \\
& v=2(\mathrm{~B}-\mathrm{A})(16 \mathrm{~A}-\mathrm{B})(9 \mathrm{~B}-4 \mathrm{~A}) \mathrm{C} / 5 \mathrm{~A}, \\
& \rho=(6 C-D)[(16 A-B)(2 C-D) \\
& +3 C(9 B-4 A)] \text {, } \\
& \lambda=(16 A-B)(9 B-4 A) C(6 C-D) / 5 A \text {, }
\end{aligned}
$$




$$
\begin{aligned}
& \mu=(16 A-B)(2 C-D)(6 C-D) \\
& M=\left(C^{2} / 8\right)[5(16 A-B)(2 C-D) \\
& \quad-(9 B-4 A)(16 C-D)](6 C-D) \\
& N=\left(\frac{7}{2}\right) C(C-D)(2 C-D)(6 C-D) \\
& \quad \times(16 A-B) .
\end{aligned}
$$

Numerical calculations show that indeed I is a surprisingly good invariant. (The numerical work, with B. McNamara and Ki. White, has only recently begun.) $I$ is exact ( $I=0$ ) for the cases (a) $16 \mathrm{~A}=\mathrm{B}, 16 \mathrm{C}=\mathrm{D}$; (b) $\mathrm{A}=\mathrm{B}, \mathrm{C}=\mathrm{D}$; (c) $C=0$; and (d) $6 C=D$. Only for case (a) do we have a true example of a fourth-order invariant; the others are reducible to second order. An account of the initial development of this work is in Ref. 29

\section{Characteristic Behavior}

An invariant of order $\mathbb{N}$ owns a characteristic signature that can be seen in the behavior of the particle trajectories. The simultaneous solution of $I_{V}=$ const, $\mathscr{E}=$.onst is multivalued in the velocity pitch angle; in general, there are $N$ solutions for a nondegenerate invariant of order $\mathrm{N}$. The orbits return and cross each other-in $N$ different directions. A particle with a first-order invariant tends always to move in a given sense, second-order patterns have two-way crosings, and for $3_{i}$, the vectors along the trajectory at a given point superimpose to form an $\mathrm{N}$-pointed "star." Figure 8 illustrates our argument. Various orbits have been computed showing second-, third-, and fourth-order invariant behavior. The last frame of Fig. 8 is an example of a stochastic orbit.

Sometimes, invariant behavior of differing orders can be observed for different orbits in the same configuration-even for fixed particle energy. Figure 9 is an example. Some of the crbits behave as if governed by a third-order invariant; some of the orbits correspond to fourth order. This peculiar behavior could be explained, for example, by a varying dominance of degenerate terms like $7_{3}^{2}$ and $6.7_{4}$, which can show up in an overall sixth-order invariant $\mathfrak{J}_{t}$.
Low-order-crossing behavior, as shown in Figs. 8 and 9 , is a useful gujde for finding approxi mate invariants of a given dynamical system.

\section{Summary}

A general theory of integrable systems in two dimensions has been formulated and applied. (The theory also has applications to more dimensions.) Constraints are found that admit to genera] integrability of the orbits when there are magnetic forces as well as forces derivable from a scalar potentiai. When a system admits a given invariant, the invariant is found. A number of examples, including both known and apparently previously unknown invariaris, have been worked out. The theory of exact integrals of mution can also be extended to the derivation of approximate invariants. A variational principle has been found. The problem of the general cubic potential with one symmetric coordinate, Eq. (32), has been examined in detail.

\section{Slosling Ions for Microstability}

\section{(M. E. Rensink)}

Through the bouns 2-average Fokker-Plank code, we have determint 1 that the simple addition of low-energy ions to a sloshing-ion plasma with thermal electrons does not necessarily produce a stable distribution.

High-level rf fluct'dations degrade ion confinement. This $r$ activity is caused by ioncyclotron instabilitiec ${ }^{30}$ that are drisen by the ambipolar hole in the velocity-space distribution function for mirror-confined ions. However, researchers have found that stability can be achieved by partially filling this hole with unconfined ions flowing through the device; stability can also he gained by creating a dip in the ambipolar potential at the midplane to electrostatically confine low-energy ions. ${ }^{31.32}$

The first method was initially demonstrated by stream stabilization $i_{\text {. }}$ the single-cel! 2 XIIB experiment at Lawrence Livermore National Laboratory ${ }^{33}$; it was verified six years later by escaping solenoid ions flowing through the Tandem Mirror Experiment (TMX) end plugs. ${ }^{3+}$ The second method was demonstrated by Ioffe et al. ${ }^{35}$ in the PR-6 experiment in 1974; the Soviet team used 


\section{Applied Plasma Physics}

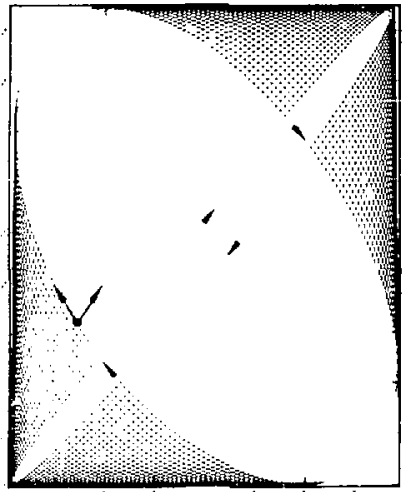

(a)

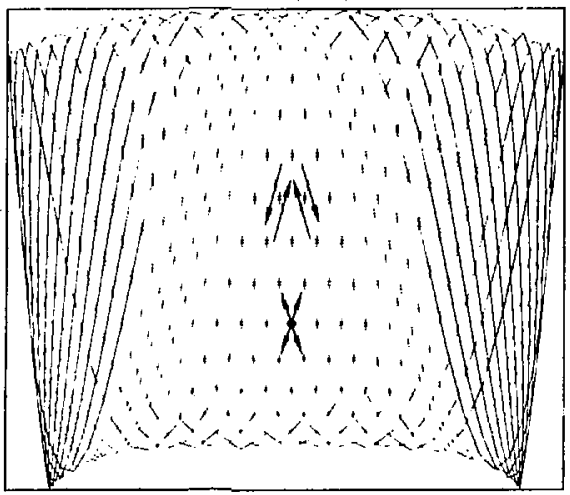

(c)

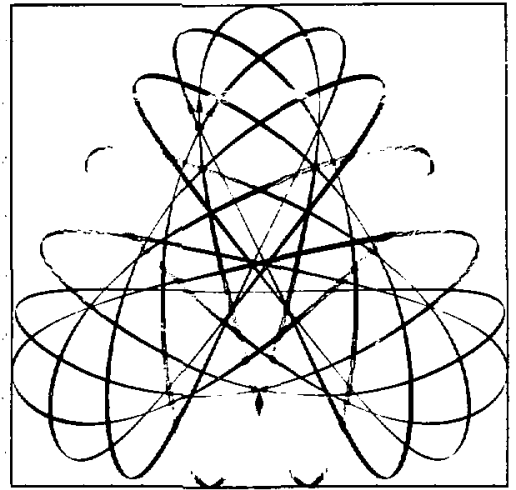

(b)

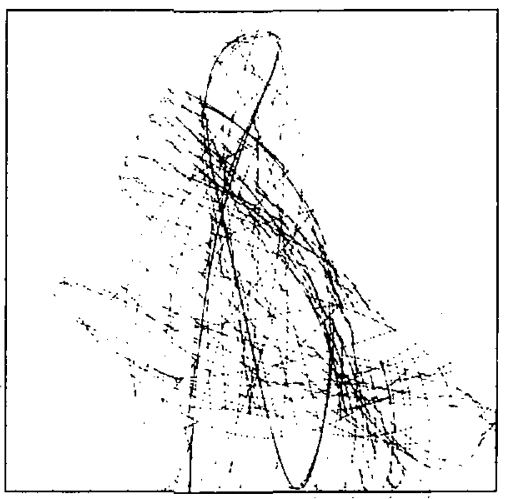

(d)

Figure 8. Configuration-space trajectories for (a) second-order invariant $(1,1,1,6)$; (b) third-order invariant $(1,1,1,-1)$; (c) fourth-order invariant $(1,16,4,64)$, and (d) stochastic orbit $(1,1,1,-1)$. Here $(A, B, C, D)$ are the coefficients of the general symmetric cubic potential $V=(1 / 2) A x^{2}+(1 / 2) B^{2}$ $+\mathrm{Cx}^{2} \mathrm{y}+(1 / 3) \mathrm{Dy} \mathrm{y}_{3}$. Arrows indicate the direction of motion along a trajectory.

magnetically-confined electrons at the midplane 10 create the potential dip.

Employing the first method that utilizes "sloshing ions" to create a potential dip" has been proposed for current mirror experiments like
TMX Upgrade, the tandem Magnetic Fusion Test Facility (MFTF-B) and TARA, as well as various reactor-like mirror confinement devices. Specifically, Kesner ${ }^{36}$ recommends forming a hot-ion density profile that peaks axially off the midplane 


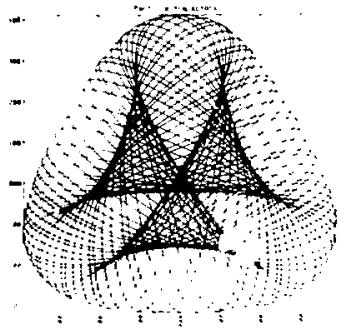

(a)

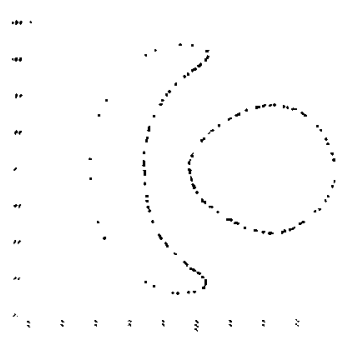

(d)

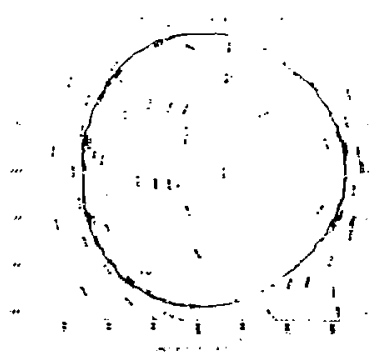

(g)

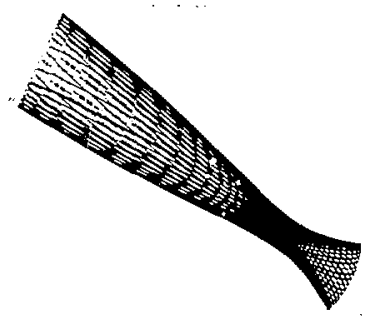

(b)

(e)

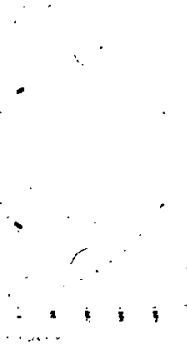

(h)

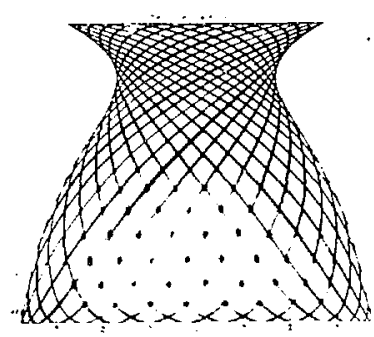

(c)

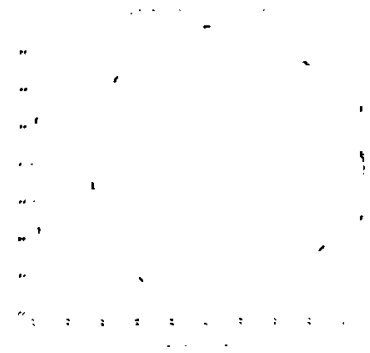

(f)

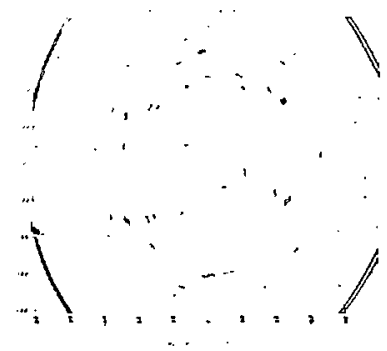

(i)

Figure 9. Configuration-space trajectories (a,b,c), corresponding surfaces-of-section (d,e,f), and composite surfaces-of-section $(\mathrm{g}, \mathrm{h}, \mathrm{i})$, corresponding to $(\mathrm{g})$ arialytic third-order invariant, $(\mathrm{h})$ computed orbits, and (i) analytic fourth-order invariant. The potential is a symmetric cubic approximating Hénon-Heiles, $v=(1 / 2) x^{2}+(1 / 2) y^{2}+x^{2} y-(11 / 30) y^{3}$, and the energy is fixed $(\delta=0.06887)$. The dots on the surfaces-of-section $(d, e, f)$ are from computed orbits, and the solid curves are from the analytic fourth-order invariant. Separately, the different orbits show definite third-order (a,d) and fourth-order ( $b, e$ and $c, f)$ invariant structures that contribute to the mixed island structure of the composite surface-of-section plot $(h)$. Note: the contours outside the' level-zero curves in the analytic approximation of the third-order (g) and fourth-order (i) should be ignored; they are an idiosyncrasy of the plotting routine. 


\section{Apolied Plasma Physics}

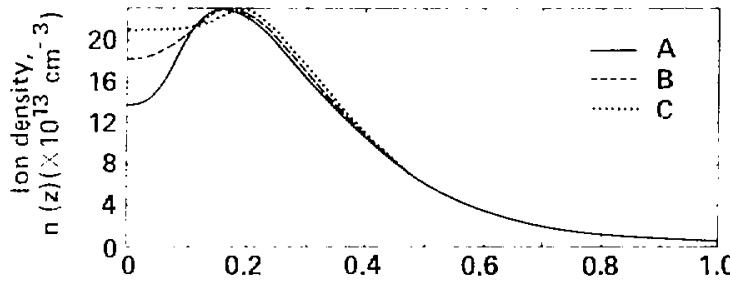

Figure 10. Axial density profiles. Case $A$ has sloshing ions only; Case $B$ has sloshing ions plus warm ions; Case $C$ has sloshing ions and warm ions plus if diffusion.

Normalized distance from midplane, $z / z_{m}$

i) anjecting anergetic (sloshing-ion) neutral $10.3 m 5$ at an acute angle with respect to the magInis ield. This could also be accomplished by perperticular injection at some point between the midplane and the mirror.

We are now investigating sloshing-ion distributions. Here we give some illustrative results of our work on the tandem-mirror-reactor anchor (c)ll. "Since the axial variations of the ion density, anbipolar potential, and magnetic field play a key role in this configuration, we have used the bounce-average Fokker-Planck code ${ }^{3 *}$ to study this problem.

Results from three Fokker-Planck runs are uhowin in ligs. 10 to 12 . The axial variation of the ambipolar potential is given by the Naxwell-Boltzmann relation,

$J d(x)=T_{1}(\mathrm{n}|\mathrm{n}(\mathrm{z}) / \mathrm{n}(0)|$.

where $T_{1}=36 \mathrm{keV}$ for these runs. Hot, magnetically confined electrons can significantly enhance $\Delta \phi$, as proposed for TMX Upgrade and MFTF-B, but we do not consider such a possibility here. Other physics parameters are defined in Table 1.

For Case A the only ion source is an energetic neutral beam injected at the midplane at an angle $\theta_{\text {ini }}=55^{\circ}$. The resulting density profile has $\mathrm{n}_{\text {roik }} / \mathrm{n}_{\text {madplane }}=1.7$ as shown in Fig. 10 . The low-energy hole in the $F(v$. $)$ distribution is shown in Fig. 11.

In Case B a low-energy source is added to partially fill in the hole but the resulting $F\left(v_{+}\right)$ Jistribution is still unstable. The warm-ion denuity is limited to about $20 \%$ of the total density at the midplane because the confining potential de- creases as the density dip is filled with warm ions. For the warm ions to stabilize the plasma, they should have a perpendicular energy spread $T$. of the order of the hole size $\mathrm{E}_{\text {hull }}$; their parallel energy sread $T$ should be less than the confinin: potential dip $J \phi_{p \cdot \text { in }}$ for good axial confinement. With $\Delta \phi_{\text {perak }} \leqslant T_{\text {re }}$ and $E_{\text {hole }} \approx E_{\text {inj, }} T_{+}$must te greater than $T$ for warm ions. Thus, in Case $C$. we add a fixed perpendicular diffusion in velocity space to simulate the low level of if fluctuations that might occur spontaneously due to instability or might be created intentionally by ion-cyclotron resonant heating (ICRH). The resulting $v$, distribution show' $n$ in Fig. 11 is not quite monotonedecreasing as required for stability, but a fine tuning of the parameters for this case would most likely produce a stable distribution.

Figure 12 illustrates a possible problem with this configuration in the development of a double-humped distribution for $F(v)$ that can give rise to an ion two-stream instability. Obviously, more runs are needed for any quantitative conclusions, but it is clear that the simple addition of low-energy ions in a sloshing-ion plasma (with thermal electrons) does not necessarily produce stable distribution functions.

\section{Negative Ion Formation in Hydrogen Discharges and Vibrational Population Distribution for Hydrogen Molecules in a Hydrogen Discharge}

\section{(J. R. Hiskes)}

We have investigated vibrational population distributions for hydrogen molecules in a 
Figure 11. Midplane distribution function for perpendicular velocities, $F\left(v_{,}\right)=\int_{x}^{+x} d v f\left(v_{\perp}, v\right)$. Case $A$ has sloshing ions only; Case $B$ has sloshing ions plus warm ions; Case $C$ has sloshing ions and warm ions plus rf diffusion.
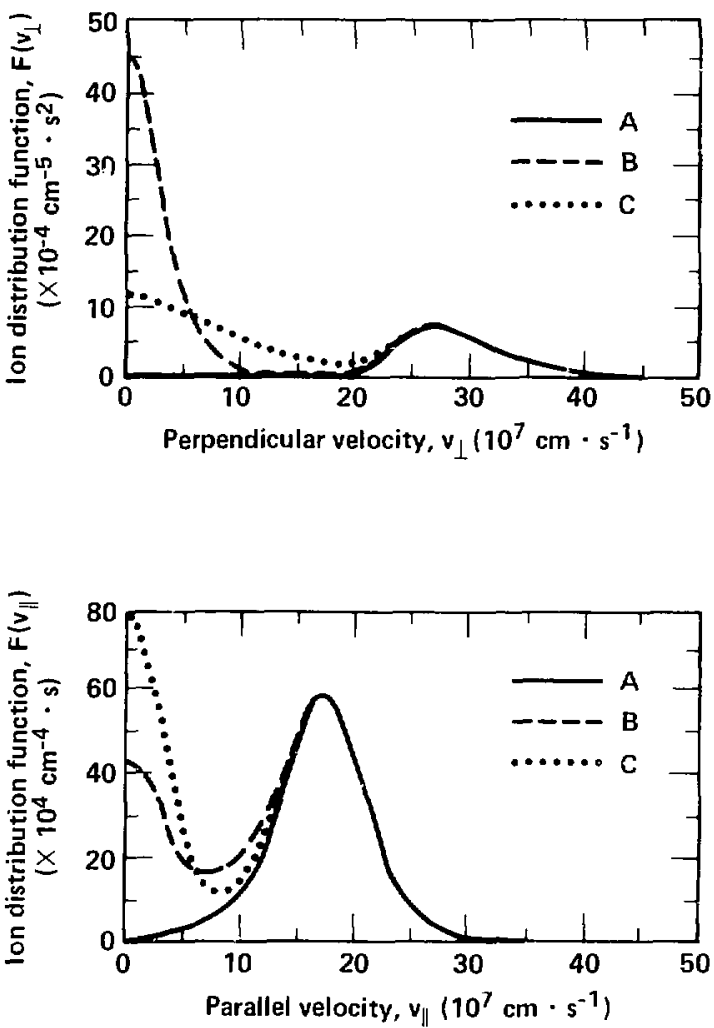

hydrogen discharge; our results show that wall collisions are the major cause of depopulation.

We have folind that the generation of negative ions in the volume of a hydrogen discharge is dominated by the dissociative attachment of low-energy $(1-\mathrm{eV})$ electrons to vibrationally excited molecules, according to

$\mathrm{e}+\mathrm{H}_{2}\left(v^{\prime \prime}\right) \rightarrow \mathrm{H}_{2} \rightarrow \mathrm{H}+\mathrm{H}^{\cdot}$.

Negative ion formation is due principally to the attachment of molecules with a vibrational level of $v \geq 6$.

A major problem is to determine the magnitude and the details of the vibrational population distribution. Figure 13 shows the results of our

$I_{\text {cold }} / I_{\text {hot }}=0$ (Case A), 0.07 (Case B), 0.17 (Case C) 


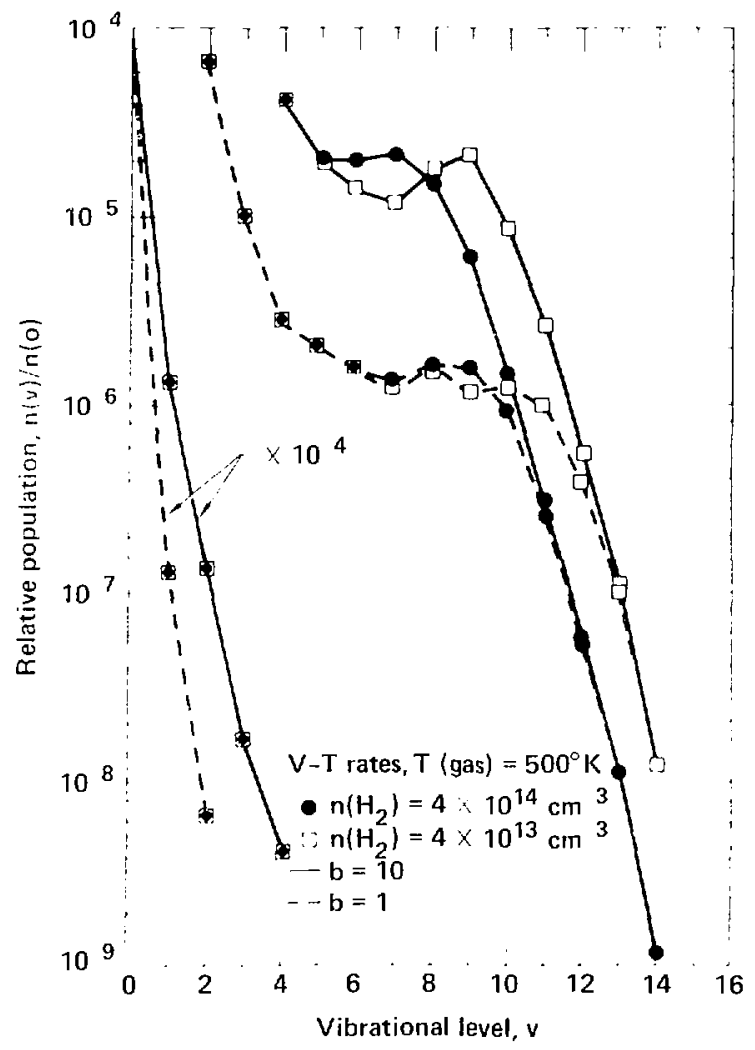

Figure 13. $\mathrm{H}_{2}$ vibrational distribution vs vobrational level v. Vibration-translation rates are indicated by V-T and wall-bounce number by $b$.

calculations for a population distribution that takes into account those processes believed to be dominant in a medium-density hydrogen distharge. Included are low-energ! $\left(\mathrm{k} T_{1}=1 \mathrm{eV}\right)$ electron excitations

$e+H_{2}\left(v^{\prime \prime}=0\right)-H_{2}\left(v^{\prime \prime}\right)+e$, for all $v^{\prime \prime}$ :

$e+\mathrm{H}_{2}\left(v^{\prime \prime}\right)-\mathrm{H}_{2}\left(\underline{v}^{\prime \prime}\right)+e$, for $J v= \pm 1$.

The transition rates for these processes, which dominate the distribution for $v \leq 5$, have heen calculated by Wadehra and Bardsley, "“+11

The population of high-energy electrons in a hydrogen discharge ( $E>20 \mathrm{eV}$ ) can populate the vibrational levels through the internediary of singlet electronic excitations. which then undergo radiative decays to the different vibrational levels of the ground alectronic state ${ }^{+1}$.

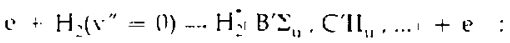

$\mathrm{H}_{2}^{*}-\mathrm{H}_{2}\left({ }^{\prime \prime}\right)+h{ }^{\prime}$

These excitations are the principal mechanism for populating the uppermost vibrational levels.

This population distribution is substantially modified through the action of the $\mathrm{V}-\mathrm{T}$ processes:

$\mathrm{H}^{2}\left(\mathrm{u}^{\prime \prime}\right)+\mathrm{H}_{2}-\mathrm{H}_{2}\left(\mathrm{I}^{\prime \prime}\right)+\mathrm{H}_{2}$. 
In these collisions, internal vibrational excitations are relaxed through transfer of vibrational energy into translational motion (the V-T process). These processes transfer the populations of the upper ( $v>9)$ levels to the lower levels $(v=5$ to 9$)$ through de-excitation.

We believe the principal mechanism for depopulating the levels is wall collision. Some evidence exists to suggest the $v=1,2$ levels can survive as many as 5 to 15 wall bounces. This problem is under theoretical ${ }^{12}$ and experimental ${ }^{4.3}$ investigation; for our calculations we have considered the wall-bounce number (b) to be an exploratory parameter with values of 1 and 10 .

ln Fig. 13, note the characteristic hump in the distribution in the $r=5$ to 9 range. This develops because Eq. (39) populates the upper levels almost uniformly; before the rapid transfer of population levels $v=10$ to 14 to the levels $v=5$ to 9 via Eq. (40).

The rate of formation of negative ions by dissuciative attachment is given by the equation

$$
\frac{d N}{d t}=N_{1} \searrow_{11}^{H+} N(v) \overline{\sigma v}(v)-N \quad N \cdot \overline{\sigma v}(i i) \text {. }
$$

Here $\overline{\sigma r}(i i)$ is the positive-ion, negative-ion attachment rate.

In equilibrium

$$
\frac{N}{N_{c}}=|N, \sigma v(i i)| \quad \sum_{11}^{14} n(v) \overline{\sigma v}(v)
$$

We insert numerical values from Fig. I3 for $\mathrm{b}=10$ and for $\mathrm{N}\left(\mathrm{H}_{2}\right)=4 \times 10^{14} \mathrm{~cm}^{3}, \mathrm{~N},=2$ $\times 10^{1 \mathrm{it}} \mathrm{cm}$, using values that are appropriate to the experiment at the Ecole Polytechnique ${ }^{4 t}$ and the calculated $\sigma v(v)$ rates. ${ }^{34 .+11}$ In this way we obtain the ratio $\mathrm{N} / \mathrm{N}^{\prime}=7 \%$. Because the cross sections from Eq. (39) may be underestimatred by as much as $40 \%$, the calculated ratio $\mathrm{N} / \mathrm{N}$. may be as large as $10 \%$. This is to be compared with the observed $^{+4}$ values fí 10 to $20 \%$. However, if we use the $b=1$ valu $\therefore$, from Fig. 13 , the $N / N_{\text {, }}$, ratio $\simeq 1 \%$.

In conclusion, it appears that the processes considered here regarding hydrogen discharge yield approximately the observer values, provided that $b$ is at least as large as 10 . 


\section{Confinement Systems}

i.awrence Livermore National Laboratory (LLNL) has the primary national responsibility for magrietic-mirror programs, an approach pioneered here since the early 1950s. A goal of LLNL's Magnetic Fusim Energy (MFE) Program is to provide the technology to develop a continuously operating fusion rtistor. The heart of this reactor will be a plasma confined by magnetic-mirror geometry and continuously - intuined by the injection of beams of energetic neutral atoms (such as deuterium).

In 1976, LLNL scientists proposed a new idea: the tandem mirror corcept. A tandem mirror reactor : $:$ uld contain a long solenoidal magnet terminated at both ends by conventional mirror cells. These cells $\therefore$ nuld act as "end plugs" to; revent plasma leakage out the ends of the solenoid. TMX was constructed to tew the principles of th:s conc.pt. After a successful 16-month demonstration of basic tandem mirror wmepts. the TMX experiment $u$ ss dismantled in Octe 1980. Major modifications to the TMX facility .M nunderway as described in the TMX Upgrade section. Present TMX activities include further data min m, publication of results, and basic physics program activities such as the development of diagnosit utrom-cycloton resonant heating $(E C R H)$, and neutral-heam studies that are not part of the TMX Liste construction. TMX Upgrade, a major improvement to the successful TMX, will allow generation "1 :hemal barriers and thereby, with concomitant microstability, permit an increase in the plasma temferature and improvement in plasma confinement. Its construction was completed in December 1981.

\section{Magnetic Mirror Systems Experiments}

\section{Tandem Mirror Experiment Upgrade (TMX Upgrade)}

The Tandem Mirror Experiment (TMX) sucinfully demonetrated:

- The tandem-mirror configuration could be senerated and sustained by noutral-beam injution.

- Confinement of both ions and electrons in a tandem mirror could bo improved over that in aingle mirrors.

IMx Uporade will be the first complete andem-mirror, thermal-barrier system: by verify An that the addition of thermal barriers to the mudem mirrer will improse potential confinem.1t. TMix Lipgrade will increase the atractiveness of the tandem-mirror-reactor concept. An rhaled and necessary ceature of TMX Upgrade is that it is designed to avoid microinstabilities in the plasma.

\section{Introduction}

\section{(T. C. 5 (m)}

The advantage of the thermal-barrier tandem over a basic tandem such as TMIX is illustrated by the relative magnitudes of the confining potential wells. In TMX Upgrade a depression in plasma potential $\phi_{p}$, isolates the plug electrons (with den- sily and temperature $n_{p}$ and $T_{r .}$ ) from the centralcoll alectrons (with density and temperature $n_{\text {a }}$ and $T_{n}$ ). If the density $n_{1}$, of electrons passing between these two regions is sufficiently small, a large electrostatic potential $\phi$, can be generated by using ECRH to raise $T_{1} .$. As $\phi$, is increased, higher-energy central-cell ions are electrostatically confined. Central-cell confinement improves with higher sentral-cell temperatures.

Figure 14 shows the TMIX Lpgrode magnet set and the corresponding density, magnetic tield, and potential profiles. To carry out the TMX Upgrade physics abjectives, we are making modifications and improvements to TMX as described in a previous (Datarly report.

\section{Final Assembly of TMX Upgrade}

\section{(A. K. (harsin)}

During this quarter, the Jandem Mirror Experiment (TMX) Upgrade experimental facility was assembled. The Major Device Fabrication phase of the project was completed December 4, and the checkout phase, which started even before all subsystems were assembled, is proceeding. Upon successful completion of the checkout near the end of next quarter, the first plasma experiment; are expected to begin. 


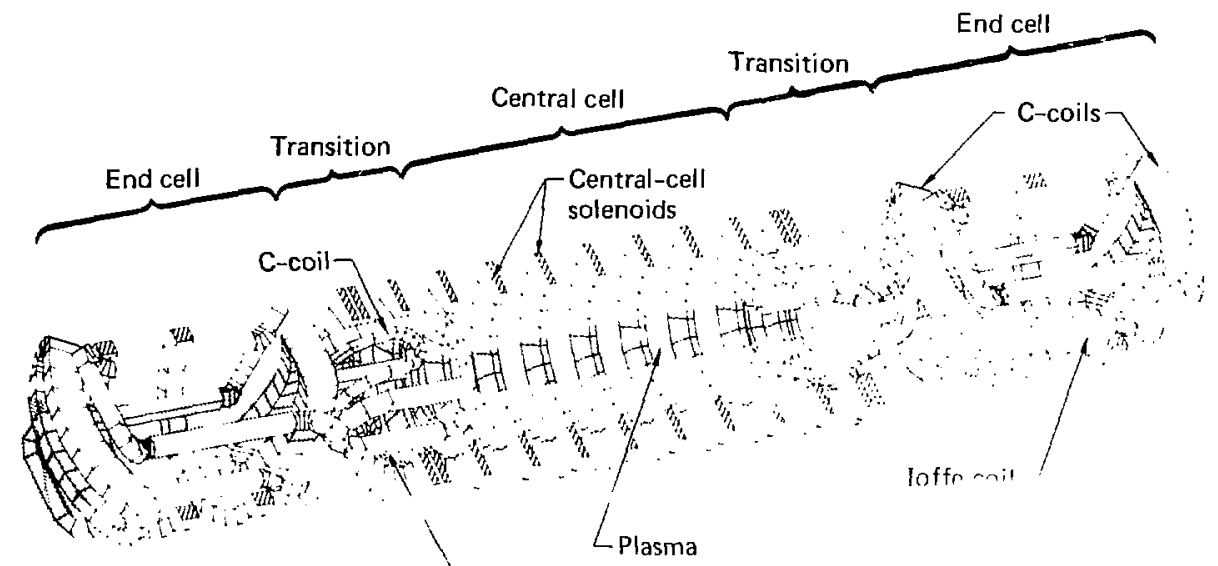

Transition loffe bar

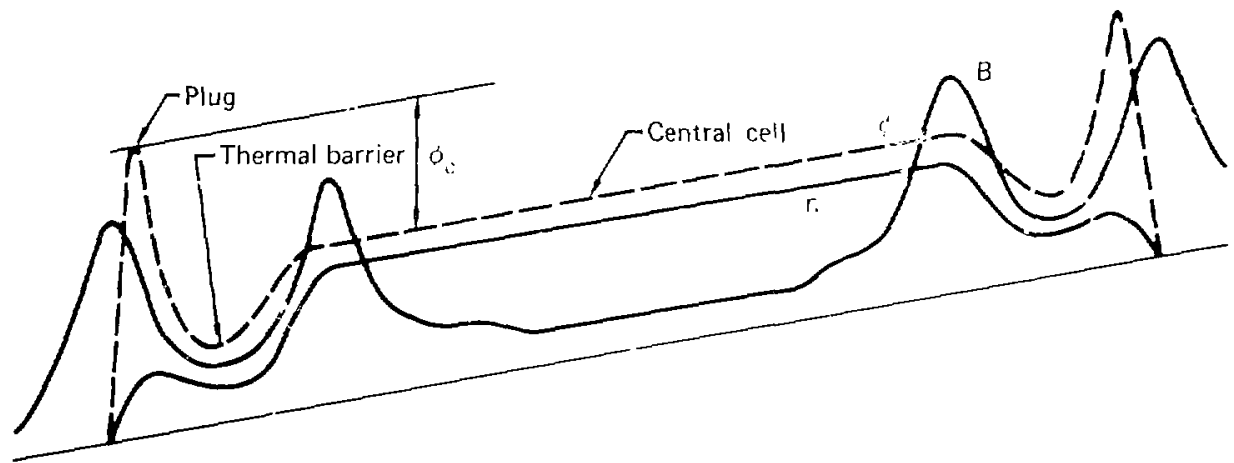

Figure 14. Computer drawing of TMX Upgrade magnet set with corresponding axial profiles of magnetic field $B$, plasma potential $\phi$, and density $n$. The confining potentials is $\phi_{c^{*}}$.

Highlighting this quarter was the feverish pace of assembly activities of the TMX Upgrade facility. The vacuum containment vessel of the device is subdivided into 11 sections. We set up nearby work areas, in which men of these sections was preassembled with it, associated magnets, liquid-nitrogen liners, internal plumbing, and titanium getters. At least four of these sections were in preassembly at any one time, and as each was completed, it was brought in the machine support structure for final assembly work Table 2 shows each machine section, its components, and the date of its installation on the machine support structure.

Because the transition and end-plug sections exceeded the lifting capacity of the existing building crane, we devised new assembly procedures. To handle the east transition section, we used the 


\section{Confinement Systems}

Table 2. Machine components of TMX Upgrade.

\begin{tabular}{|c|c|c|c|c|c|c|c|}
\hline \multirow{2}{*}{$\begin{array}{c}\text { Section } \\
\text { No. }\end{array}$} & \multirow[b]{2}{*}{ Vesse! section } & \multicolumn{2}{|c|}{ Magnets } & \multirow{2}{*}{$\begin{array}{l}\text { LN } N^{d} \text { liners } \\
\left(\mathrm{m}_{2}\right)\end{array}$} & \multirow{2}{*}{$\begin{array}{c}\mathbf{T i}^{\mathbf{b}} \\
(\mathrm{No})\end{array}$} & \multirow{2}{*}{$\begin{array}{c}\text { Getters } \\
(\mathrm{m})\end{array}$} & \multirow{2}{*}{$\begin{array}{l}\text { Date moved } \\
\text { to pif (1981) }\end{array}$} \\
\hline & & No. & Type & & & & \\
\hline 1 & East solenoid tank & 3 & Solenoid & 45 & 20 & 34.2 & $5 / 31$ \\
\hline 2 & Central-cell tank & & - & 19 & 7 & 11.9 & $7 / 10$ \\
\hline 3 & West solenoid & 3 & Solenoid & 46 & 20 & 34.2 & $6 / 5$ \\
\hline \multirow[t]{3}{*}{4} & East transition tank & 2 & Solenoid & 93 & 25 & 42.5 & $8 / 25$ \\
\hline & & 1 & C-coil & & & & \\
\hline & & 1 & loffe & & & & \\
\hline \multirow[t]{3}{*}{5} & West transition tank & 2 & Solenoid & 93 & 24 & 40.8 & $9 / 16$ \\
\hline & & 1 & C-coil & & & & \\
\hline & & 1 & Ioffe & & & & \\
\hline \multirow[t]{3}{*}{$"$} & East plug tank & 2 & Solenoid & 88 & 26 & 44.2 & $10 / 06$ \\
\hline & & 2 & C-coil & & & & \\
\hline & & 1 & Ioffer & & & & \\
\hline \multirow[t]{3}{*}{7} & West plug tank & 2 & Solenoid & 88 & 26 & 44.2 & $10 / 30$ \\
\hline & & 2 & C-coil & & & & \\
\hline & & 1 & loffe & & & & \\
\hline 8 & East dome & & - & 41 & 8 & 13.6 & $11 / 17$ \\
\hline 9 & West dome & & - & 41 & 8 & 13.6 & $11 / 24$ \\
\hline 10 & East end fan & & - & 19 & 5 & 8.5 & $11 / 17$ \\
\hline 11 & West end fan & & - & 19 & 5 & 8.5 & $12 / 02$ \\
\hline
\end{tabular}

building crane plus an external crane. For the east plug. we lifted the plug magnets and the plug tank separately, and then, using special fixtures, we assembled them together on the machine support structure. For the west transition and plug sections, we also used the external crane.

As the photographs depict chronologically (Figs. 15 to 20), the logistics of the final assembly culminated an effort that began in May 1980 when the Department of Energy approved the project for $\$ 14.5$ million. However, the start of the project was delayed to July due to the required redesign of the magnet system. The actual construction phase of the project took 17 months; the initial goal was to complete the project construction in 18 months. In addition, we met the budgeted cost.

So far, the checkout is proceeding on schedu.le. We established the following checkout sequence for subsystems: vacuum, magnets, magnet power, injectors, and diagnostics. At the end of this quarter, the external vacuum system was fully operational, and the tank pressure was at $2 \times 10^{5}$ Torr. The magnets have been mechani- cally and optically aligned and electrically checked. The magnet power circuits have all been through checkout, and with some additional calibration work, their full power operation will be achieved early in the next quarter. All of the neutral-beam-power-supply systems have undergone full dummy load tests; their operation in the vacuum system will also begin in the next quarter. The checkout of diagnostic components is on a similar schedule and will be completed in time for the first plasma experiments.

Overall, the checkout procedure is planned through several air-vacuum cycles. The air time allows fixing any inoperative components as well as completing installation of those items that would have precluded the possibility of checking out previously installed components. The vacuum time allows the necessary exercise of components to make them operational under the real conditions. At the end of these air-vacuum cycles, we expect to have all subsystems fully operational and begin plasma experiments. This should occur by the end of the next quarter. 


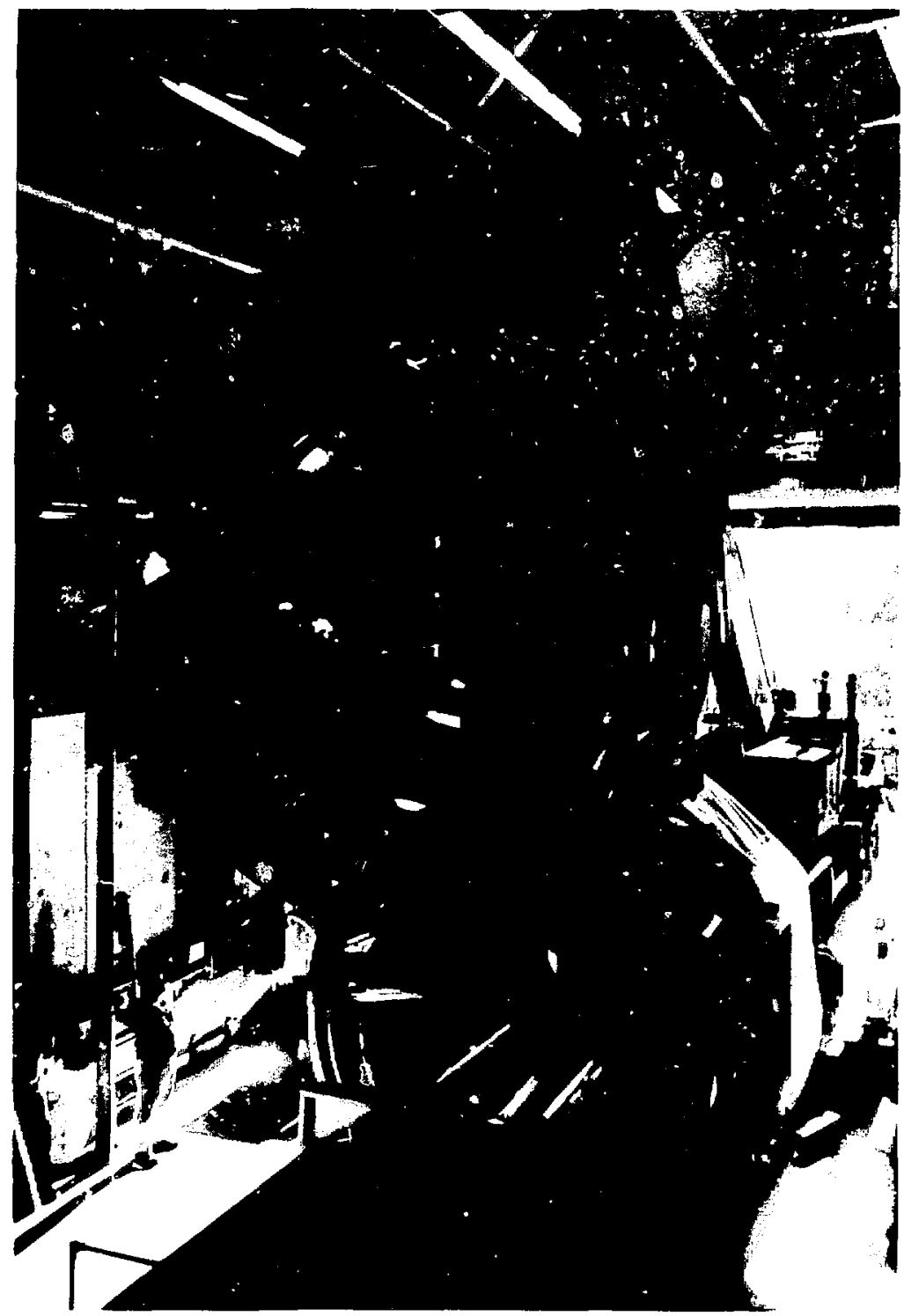

Figure 15. Instailation of $t^{\prime}: 25-t o n$ east transition section next to the central cell of TMX Upgrade. Two cranes are employed-one is the building crane (out of view); the other is the mobile crane seen in the background. 


\section{Confinement Systems}

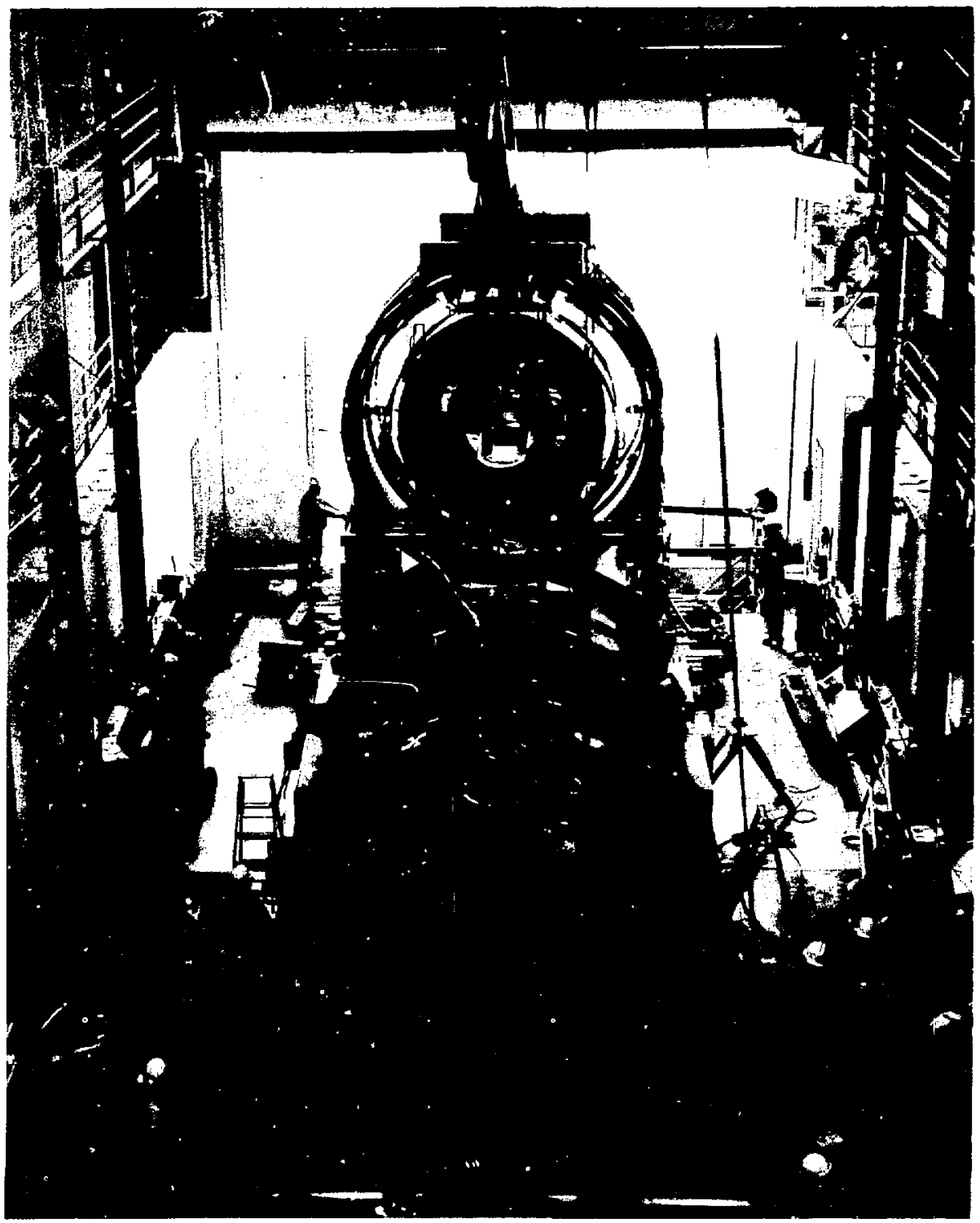

Figure 16. Overview of TMX Upgrade in construction. While workers install components in the east transition section, others lower the west transition section into position. 


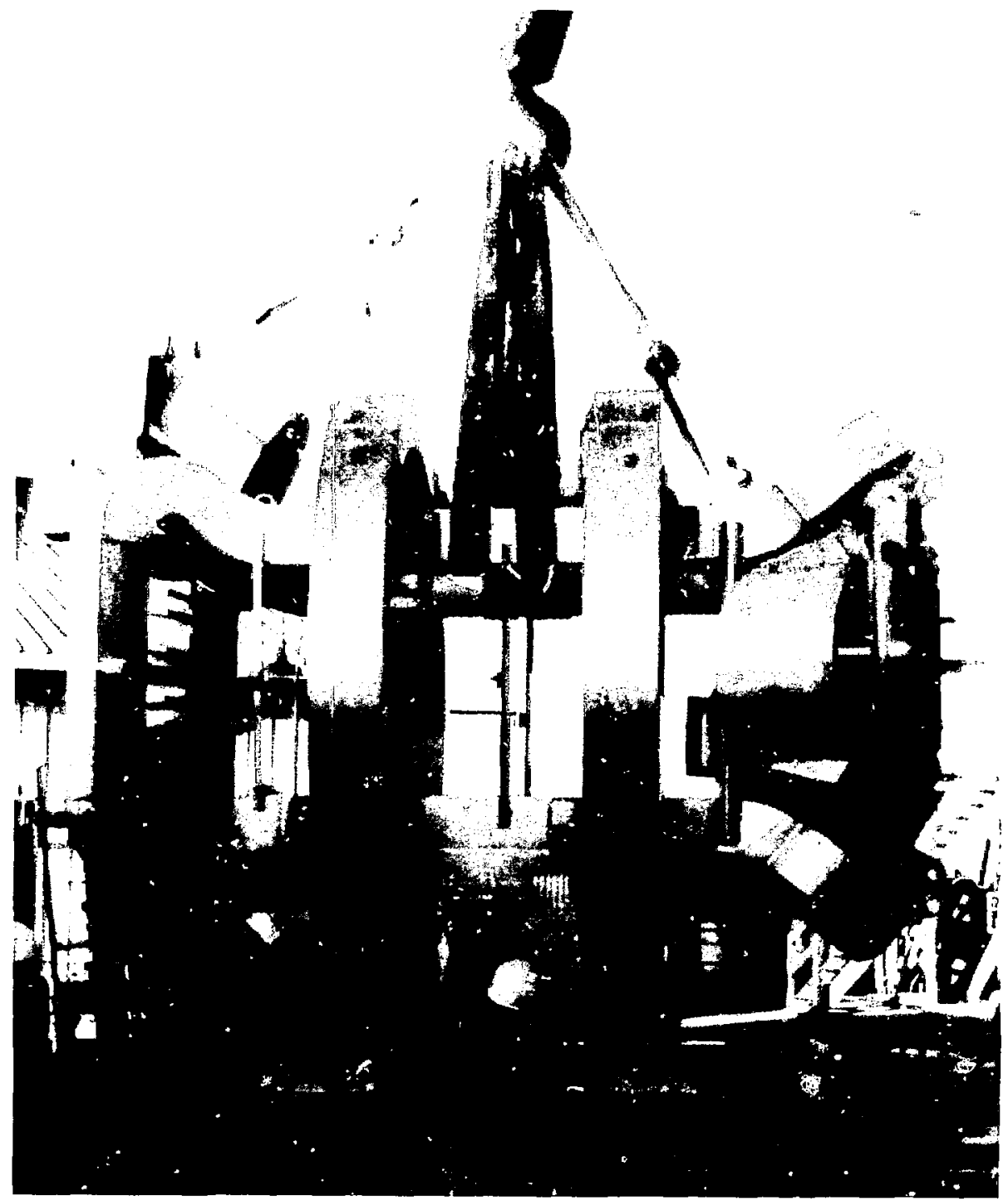

Figure 17. Preparation of the TMX Upgrade magnets for assembly within the west end-plug tank. This end-plug magnet set consists of two C-shaped coils for peak mirror fields up to $20 \mathrm{kG}$, two solenoids for the field in the magnetic well at $5 \mathbf{~ k G}$, and a loffe coil for the overall quadropole field. The distance between mirror peaks is $3 \mathrm{~m}$, and the coil set weighs 22 tons. 


\section{Confinement Systems}

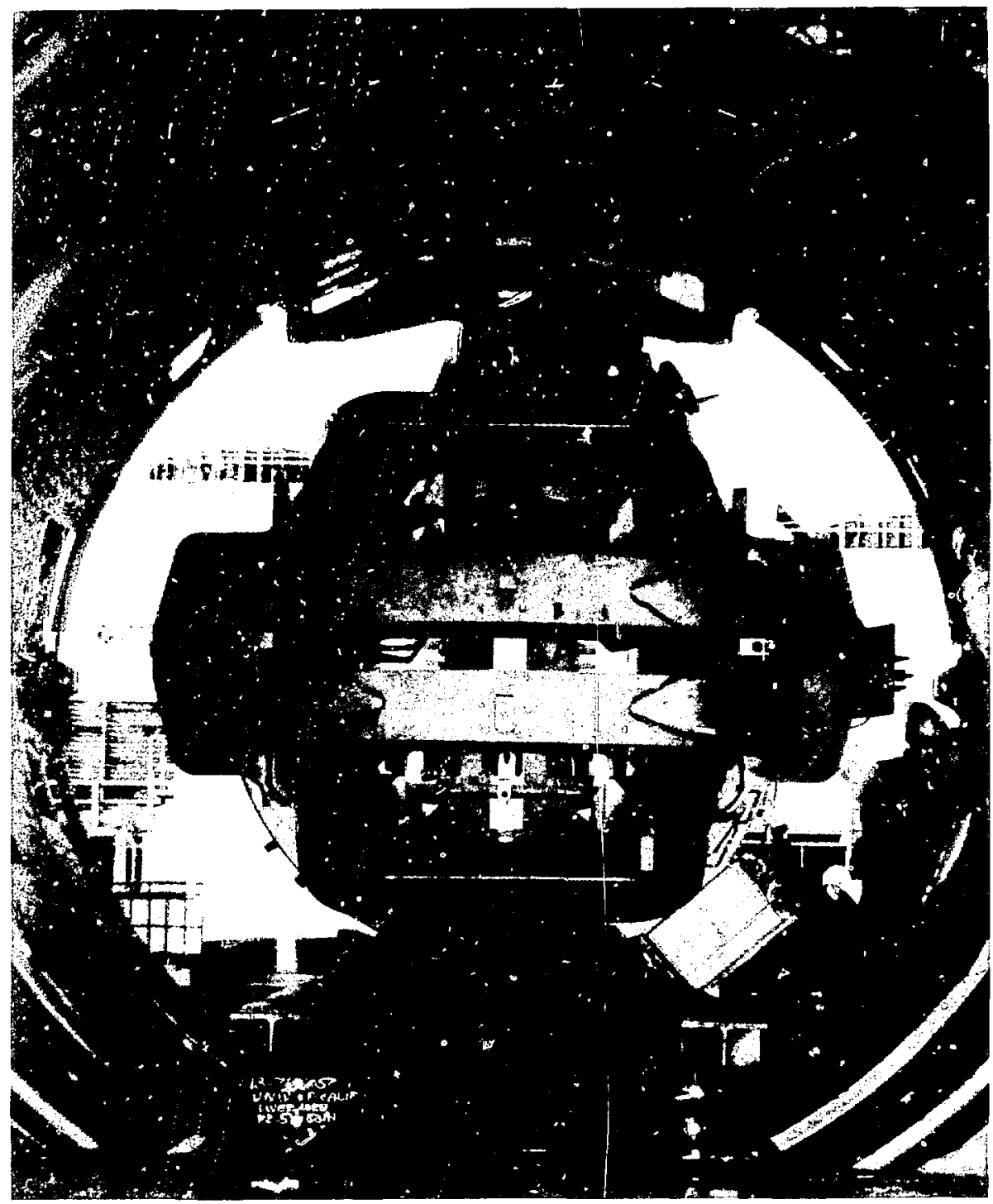

Figure 18. Insertion of the west-end coils within the the vacuum chamber of TMX Upgrade. Temporary rails provide support for the assembly process. Once the coils are suspended from the framework at the top of the chamber, the rails are removed, and the remaining section is moved to the machine area for the addition of another component. 


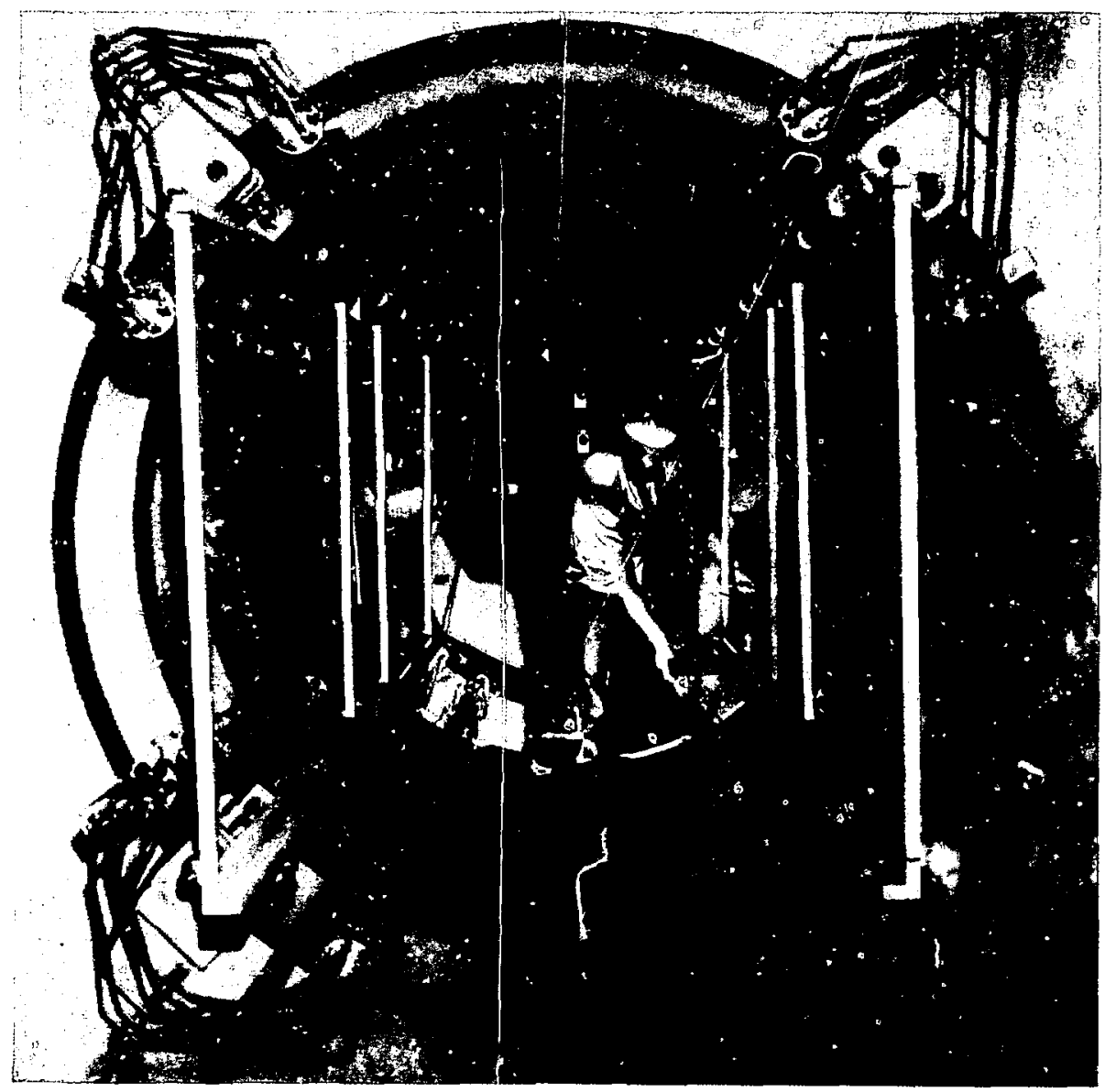

Figure 19. Final assembly of the central cell of TMX Upgrade with the magnets and titanium getters in place. In the foreground is the rectangular framework, which supports the stainless-steel panels that will form the wall nearest the plasma. In the background are the quadropole nagnets of the transition and end-plug sections. 


\section{Confinement Systems}

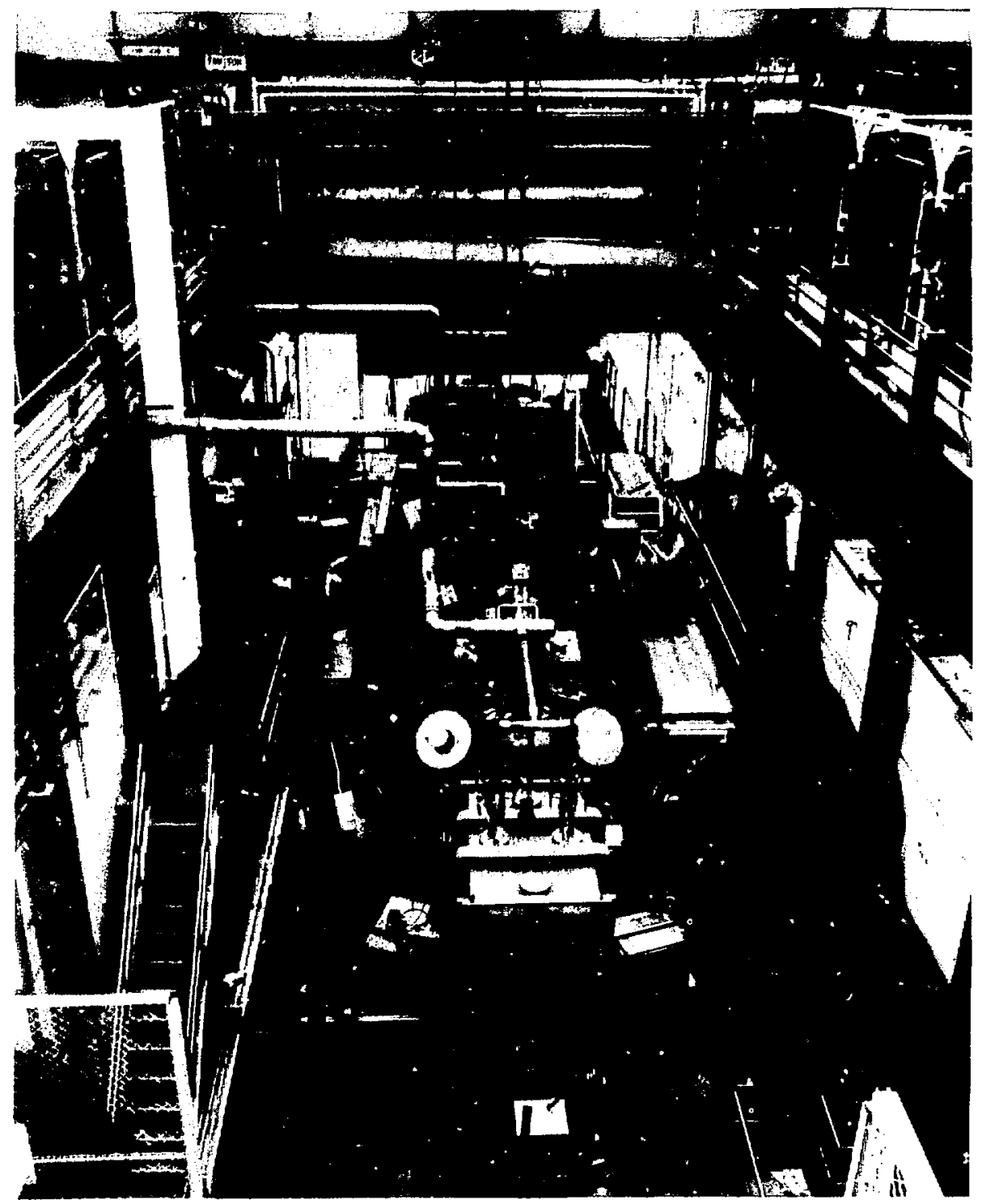

Figure 20. Final checkout of the completed TMX Upgrade. After successful testing of the vacuum, magnet, neutral-beam, and diagnostics subsystems, initial plasma experiments will begin next quarter. 


\section{Development and Technology}

The Development and Technology Program seeks to develop the technology required for carrying out the magnetic fusion reactor program. This program is divided into three areas' component development, materials and radiation effects, and reactor systems and applications.

\section{Component Development}

- Superconducting Magnets: The mirror program is the only fusion program in the United States that has used superconducting magnets for major confinement experiments; the largest confinement experiment presently under construction in this country actually using these magnets is the tanden Mirror Fusion Test Facility (MFTF-B) at Lawrence Livermore National Laboratory (LLNL). The LLNL magnet prograin developed and tested the conductor for MFTF-B. Now under development, with indusiry's cooperation, are practical high-field materials, e.g., multifilament niobium-tin $\left(\mathrm{Nb}_{3} \mathrm{Sn}\right)$ th. ${ }^{+}$will be needed fur future experiments. A key feature of this program is the High Field Test Facilitv (HFTF) - under construction-in which the first large multifilament $\mathrm{Nb}_{3} \mathrm{Sn}$ coils will be evaluated.

- Neutral Atom Beams: A major program for producing neutral beams for plasma heating and fueling is being conducted at Lawrence Berkeley Laboratory (LBL), which also operates several high-power test facilities. Neutral beams based on negative-ion sources, which maintain good efficiency at very high energy, are critical to future mirror facilities. The coordination of the negative-ion program is an LLNL responsibility.

- End-Plasma Technology: Technology pertaining to the end regions of tandem mirrors is an important and unique aspect of tandem mirror reactors (TMRs). A coordinated program underway in this area involves direct conversion of plasma exhaust energy to electricity, vacuum pumping, heat removal, and a study of the end region.

\section{Materials and Radiation Effects}

The Rotating Target Neutron Source (RTNS-II) is a unique source of 14-MeV neutrons developed and operated by LLNL as a national facility for the irradiation of fusion materials. Experiments at RTNS-Il are aimed at characterizing the damage produced by fusion neutrons and correlating this damage with that produced by other irradiation environments.

\section{Reactor Systems and Applications}

- Advanced Mirror Systems: Design studies of mirror reactors form a basis for evaluating mirror concepts and for guiding our long-range program. Emphasis is on comparing magnetic-field geometries for an eventual TMR and a facility to follow MFTF-B called Tandem Mirror Next Step (TMNS).

- Fusion-Fission Hybrids: A study with major involvement by industry and other laboratories is underway to evaluate a fusion-reactor/blanket combination optimized to produce fissile fuel for light-water reactors (LWRs).

- Chemical Fuels: The practicality of fusion reactors, particularly TMRs, as a heat source for producing chemical fuels is the subject of a study. Activity is concentrated on the use of thermochemical processes for producing hydrogen.

- Tritium Control: Several key problems on tritium control and handling that must be solved for any large deuterium-tritium (D-T) fusion device are being investigated in the LLNL tritium laboratory; emphasis is on cleanup at low tritium concentrations in reactor-containment buildings, vacuum-pump ex'raust, and related facilities. 


\title{
Development and Technology
}

\author{
Magnetic Systems
}

\author{
Superconducting Magnet \\ i)evelopment \\ (i) ㄷunish, R. W. Hoard, R. M. Scamlan, and J. P. \\ $(n, i \cdot m k)$
}

We must advance the technology of superconciuctors and superconducting magnets to nispare for the construction and operation of ?perimental mirror machines and, ultimately, actors. Already we have designed, developed, and tested a Nb-Ti conductor for the MFTF yin-yang coils, and we have completed construction of a new Superconducting Magnet Laboratory where we will continue this development work on a larger scale. Now we are developing $\mathrm{Nb}_{3} \mathrm{Sn}$ conductors for future mirror devices; our main emphasis has been to build a High Field Test Facility (HFTF) to demonstrate their feasibility and to test prototype tokamak conductors. This quarter we have investigated coil operation and performance in response to the reduced critical current expected in a number of the conductor lengths. The $\mathrm{Nb}_{3} \mathrm{Sn}$ coil used for the HFTF will now consist of 14 double pancakes instead of 20 , and although the critical current in some will be as low as $4000 \mathrm{~A}$, we will expect the coil to operate at $5000 \mathrm{~A}$ and to produce more than 11 T. Equipment installation continues in the new laboratory.

\section{IIigh-Field Test Facility}

Niobium-Tin $\left(\mathrm{Nb}_{3} \mathrm{Sn}\right)$ Coil System. It hecame dear last quarter that the production lengths of HITF conductor would not meet the critical current specification. Consequently, we have evaluated the loses that will arise during coil operation at the $5000-A$ design current with the high-field portion of the coil operating in a slightly resistive mode. Our analysis indicated that material with a critical current as low as $4000 \mathrm{~A}$ (using a $0.5 \mathrm{~V} / \mathrm{cm}$ criterion) could be operated at $5000 \mathrm{~A}$ with an acceptable liquid-helium boil-off rate. Critical current measurements showed that 14 out of the 24 production lengths of HFTF material are expected c.. meet the criterion of 4000 -A critical current.
We also calculated the effects on coil performance of using 14 lengths, instead of 20. (The original HFTF design :ncludes another four spare production lengths.) When no test coils are inserted, the facility will produce a maximum field of $11.24 \mathrm{~T}$ in the $40-\mathrm{cm}$ bore. Using the insert coil being built by General Atomic (GA), we can achieve a maximum field of $12 \mathrm{~T}$ at the insert coil; with the smaller test coil of one double pancake instead of three now being proposed by the Massachusetts Institute of Technology (MJT), we are able to attain a maximum field of $10.1 \mathrm{~T}$. At a meeting at Department of Energy (DOE) Headquarters, representatives of DOE, Lawrence Livermore National Laboratory (LLNL), and Airco agried that the $\mathrm{Nb}_{3} \mathrm{~S}_{1}$ coils should be built with 14 double pancakes, instead of the 20 originally proposed.

$\mathrm{Nb}_{3} \mathrm{Sn}$ Conductor. Critical current values have been determined for the 24 HFTF production lengths. As discussed above, 14 of these lengths have a minimum critical current value of $4000 \mathrm{~A}$ and will be used in the HFTF coil.

To understand the variability of critical current achieved when production lengths are processed under supposedly identical conditions, we attempted several correlations. The $\mathrm{Nb}_{3} \mathrm{Sn}$ material had been processed into strands in three batches. We found that lengths from Batches 1 and 3 yielded critical currents greater than $4000 \mathrm{~A}$, while lengths from Batch 2 yielded critical currents of about $2000 \mathrm{~A}$ (Fig. 21).

We concluded that some production step was incorrecty followed for Batch 2. The step most likely responsible is one of the intermediate anneals given to the material during reduction to strand size. We speculate that the furnace temperature exceeded the specified annealing temperature so that significant quantities of $\mathrm{Nb}_{3} \mathrm{Sn}$ were formed. This $\mathrm{Nb}_{3} \mathrm{Sn}$ layer would he broken up into particles during subsequent cold work. Two precautions have been taken to prevent repetition of this problem: the annealing temperature has been lowered from $520^{\circ}$ to $480^{\circ} \mathrm{C}$, and more redundancy has been added to the furnace monitoring and control systems. 


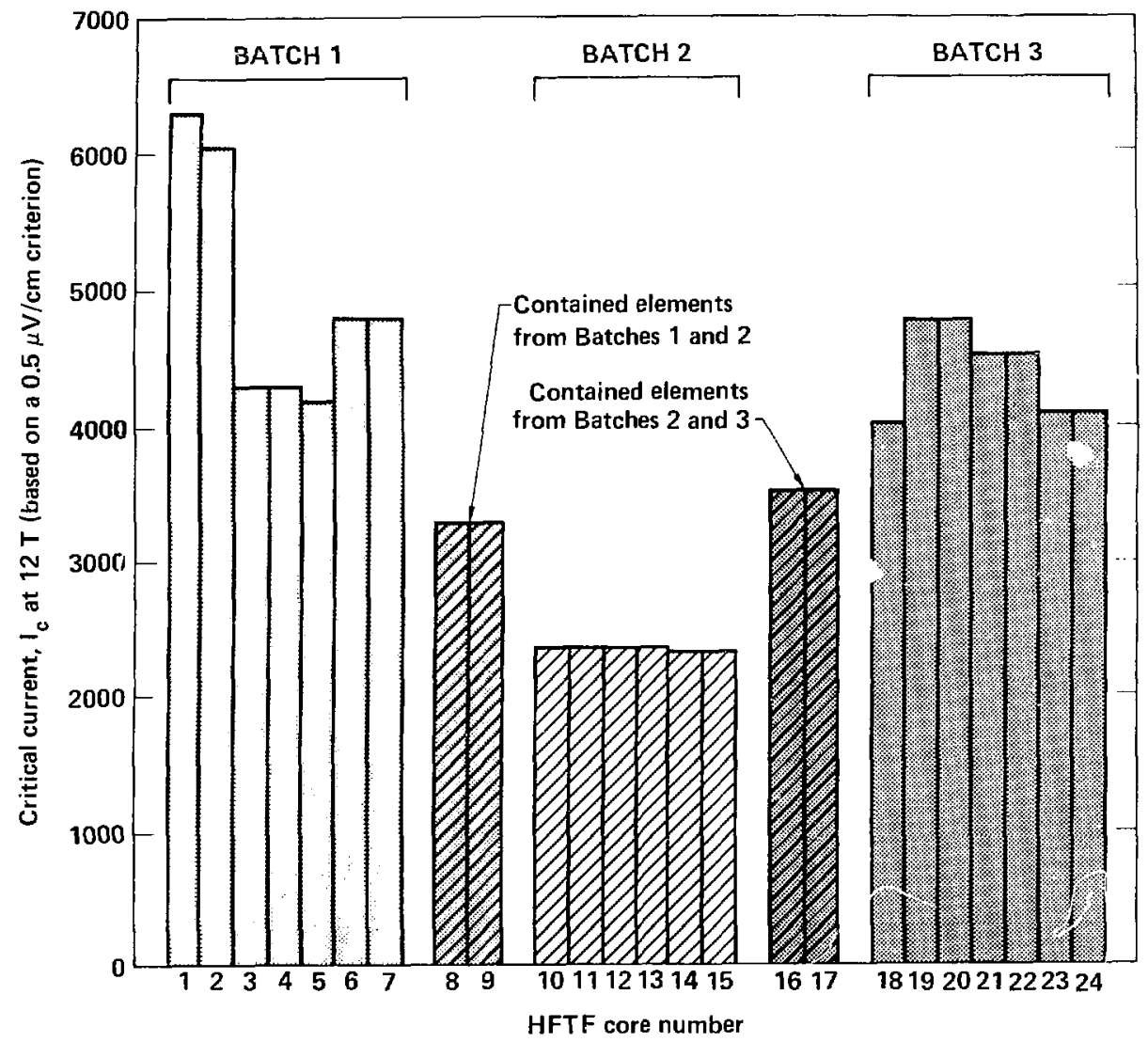

Figure 21. Critical current at $12 \mathrm{~T}$, measured on samples taken from production lengths of $\mathrm{Nb}_{3} \mathrm{Sn}$ conductor for the High Field Test Facility (HFTF).

Several items of equipment have been designed, fabricated, assembled, and sent to Airco for use in the stabilizer cladding line. They include an ultrasonic inspection station for checking the solder bonding, two conductor cleaning stations, and a pay-off conductor reel station. A technician from LLNL is in residence at Airco to assist in achieving a satisfactory standard for the solder plating and conductor cladding lines.
An additional HFTF length will be made during FY 82 to assess whether all of the production problems have been identified and corrected.

Two lengths of $\mathrm{Nb}_{3} \mathrm{Sn}$ conductor, without stabilizer, have also been ordered from Wah Chang to the original HFTF specifications. The second of these lengths will be made with a small addition of titanium in the niobium, which should increase the critical current density at $12 \mathrm{~T}$. 


\section{Development and Technology}

Four-Meter-Diameter Cryostat. Pittsburg-Des Moinu Corporation continues the fabrication of the main vessels of the 4-m-diam cryostat. Qualification of the various types of welds is being carrited out at L.LNL.

\section{New Superconducting Magnet Laboratory}

Installation of equipment moved from the old iryegenics laboratory is continuing. The main outricul supply distribution system has been complesed, together with wiring to the $h$ : th irrent, dc power supply used for magnet - hind and shorl-sample testing; the main power ... alus been wired to the control room and the walle iesler. Work has now been started on in- stallation of equipment and wiring in the main control room.

Railings around the main pit, together with a stairway and intermediate platforms, are now in position, and the 2-in cryostat has been lowered into the pit.

Liquid-nitrogen, vacuum-insulated transfer tubes have been designed and fabricated and are now being installed.

\section{Twelve-Tesla Insert Test Coils}

It now looks as if it will be possible to test both the GA and the MIT insert coils in the HFTF in the 2-m cryostat. Final design interface details are now being worked out.

\section{Fusion Reactor Materials}

\section{Summary of RTNS-II Operation: 1981}

(1) N. Hakkmill mal (. M. logan)

Knowledge gained through RTNS-II exferiments has been applied throughout the magnetic mirror and laser fusion programs at I I.NI. Projects at other laboratories have also benefited from irradiations conducted at RTNS-11.

During 1981, we operated the Rotating Target Ninutron Source-II (RTNS-II) facility on a 10 shiffinere hasis (excluding holidays and weekends). Irradialions vere performed on samples for 15 different experimenters representing six labora- tories during the past year. These are outlined in Table 3.

Average availability of the facility was $78 \%$. excluding scheduled outages. There were three reasons for major scheduled outages:

- Experiment installation and removal.

- Decay of induced radioactivity.

- Installation and testing of the $50-\mathrm{cm}$ target assembly.

In addition, appreciable unscheduled outage occurred when the vacuum seal in the rotating target failed.

Total neutron production was $6.2 \times 10^{14}$ using $4 \times 10^{5} \mathrm{C}$ of deuteron bean (corresponding to $2.5 \times 10^{2 t}$ deuterons). The average neutron source strength was $1 \times 10^{13} \mathrm{n} / \mathrm{s}$. 
Table 3. Users of RTNS-II during 1981.

\begin{tabular}{|c|c|c|}
\hline Affiliation & Principal contact & Irradiation sample/experiment \\
\hline $\mathrm{HEDL}^{\lrcorner}$ & E. Bradley & Niobium. vanadium, titanium \\
\hline Northrop's & J. Srour & Integrated circuits \\
\hline $\operatorname{LLNL}^{\mathrm{c}}$ & D. Nethway & ${ }^{2019}$ Bismuth, lutetium, rhodium, thulium \\
\hline Los Alamos & I. Bender & Strontium \\
\hline HEDL & N. Panay otou & Microtensile and TLM disks of numerous materials \\
\hline HEDL & H. Brager & Copper, copper-aluminum, copper-manganese \\
\hline Los Alamos & G. Huiley & Insulators \\
\hline Los Alamos & R. Jalbert & Tritium detector development \\
\hline BNL"ILLNL & C. Snead/M. Guinan & Supereonducting wires \\
\hline 1. LNL & C. Logan/D. Heikkinen & Thermocouple wires \\
\hline LLNI. & W. Barmore & Ir situ creep of ninbium and nickel \\
\hline LLNL & L. Coleman/M. Singh & Laser glasses \\
\hline U/Wisconsin' & S. Zinkie & Copper \\
\hline Las Alamos & J. Fowler & Mica \\
\hline LLNL & R. Mallon & Cit shale \\
\hline
\end{tabular}

¿Hanford Engineering Development Laboratory.

"Northrop Corporation.

- Lawrence Livermore National Laboratory.

'Los Alamos National Laboratory.

"Brookhaven National Laboratory.

'University of Wisconsin.

\section{Fusion Systems Engineering/Advanced Mirror Systems}

\section{Comparative Study of End Plugs for Tandem Mirror Reactors}

(G. A. Carlson, W. L. Barr, B. M. Boghosian, R. S. Direto, 1. N. Duggett, G. W. Hamiltan, B. M. Johnston, W. N. Kumai, I. D. Lec, B. G. Logan, R. W. Moir. W. S. Nect, and R. B. Camphell

For one year we have evaluated four different thermal-barrier end-plug designs for a tandem mirror reactor. The modified-cusp and axicell configurations show the most promise in terms of enhanced performance and lower

"TRMi. Ini. cost (as low as $\$ 1150 / k W e$ direct cost in the examples considered).

\section{Introduction}

During the quarter we have completed a comparative study of four thermal-harrier enctplug designs for a commercial tandem mirror reactor (TMR). ${ }^{\text {th }}$ Our results are also relevant to future work on the Tandem Mirror Next Step (TMNS).

The end-plug configurations that we considered are

- A-cell.

- Modified cusp.

- Axicell.

- Axicell with electron-ring stabilization. 


\section{Development and Technology}

The A-cell configuration (Fig. 22) is the hasis for the tandem Mirror Fusion Test Farility (Ail.TH-B) design. The second configuration, the modified cusp (Fig. 23), uses all circular coils, with the magnetic fields in one of them opposing the antral-coll field. The third configuration, the a) (ل) (Jig. 2t), has a simple mirror cell produced in iwo circular coils (surrounding a smaller buck1.7 ; coil). followed by a transition coil and a vin yang pair. Fur the axicell with electron-ring stabilisation. we eliminate the Iransition coil and bir ing pais.
Among the reactor configurations studied, the cusp and the axicell were superior with respect to plasma energy gain (Q) and cost. Both result in a 1000-MWe TMR at a direct capital cost of about $\$ 2000 / \mathrm{kWe}$ at present one-of-a-kind costs for magnets and electron-cyclotron resonant heating (ECRH) ( $\$ 5 / W$ injected); hoth offer opportunities for improved performance and lower cost in the future as low as $\$ 1150 / \mathrm{k}$ We direct cost in the examples considered). Of these two configura. tions, we have chosen the axicell for further study in 1r82 hecause it retains the conservative

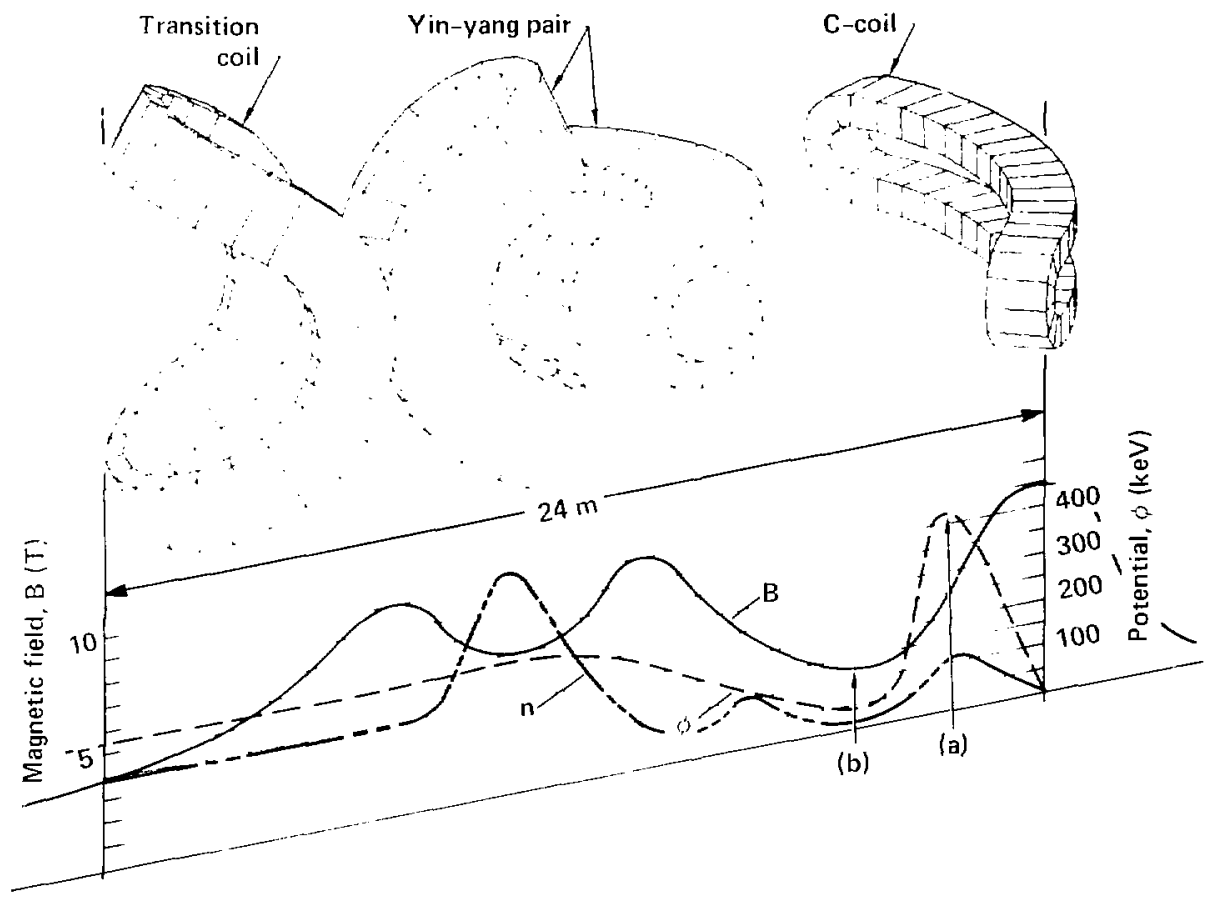

Figure 22. The A-cell end-plug configuration with four coils including a yin-yang magnet. Points (a) and (b) refer to the locations of the potential peak (which confines the central-cell ions) and the thermal barrier. I his figure and the two that follow illustrate the three of the four configurations studied by LLNL scientists for use in future tandem mirror reactors. 


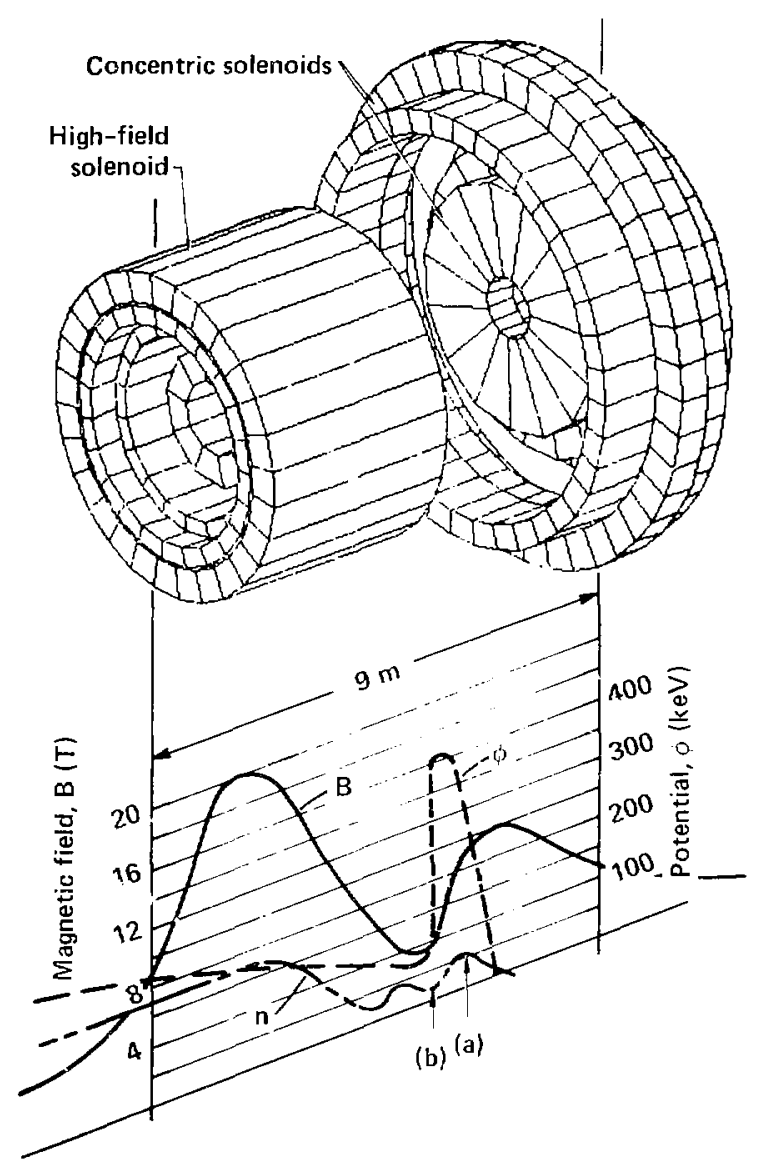

Figure 23. The modified-cusp end-plug configuration, which is the shortest in length.

vin yang approach to magnetohydrodynamic (MHD) stability emploved in MFTF-B and many other past and present mirror experiments. Furthermore, an experimental facility called TARA that incorporates the axicell configuration is planned at the Massachusetts Institute of Technolog: $(\mathrm{MIT})^{4^{-}}$
As illustrated in Fig. 24, the axicell consists of a circular thermal-barrier end plug preceding a yin-yang MHD "anchor." The major advantage of this configuration is that the circular end-plug roils can be engineered to produce very high magnetic fields, much higher than is probable in the yin-yang or A-cell magnet. A higher field in the 


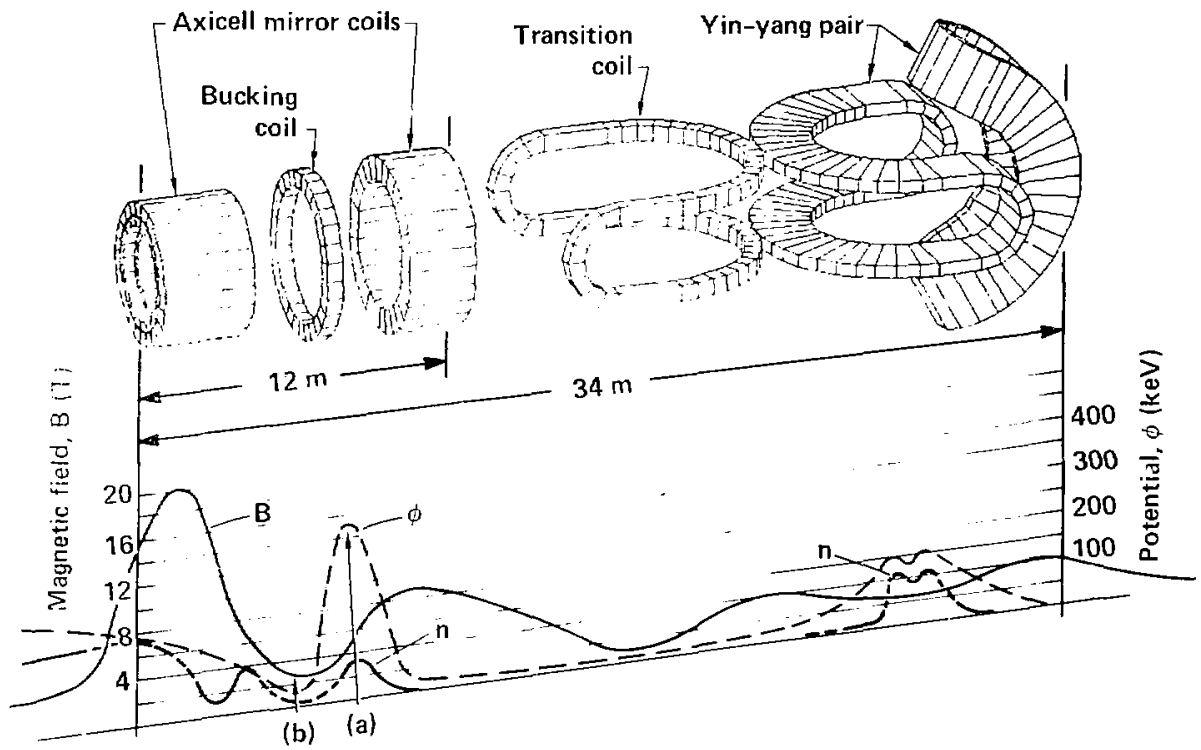

Figure 24. The axice!] end-plug configuration, which incorporates six coils including a yin-yang anchor.

whd plug coil nearest the center cell greatly rein a es tive plama density required in the thermalbarrier plug and hence, the power required to Ane the plugs. On the other hand, it is both perinasilnte and desirable to design the yin-vang anchur at a relatively low field. Because MHD stabilit derive trom high beta in good curvature, it is preferahle to make high hota at low plasma pressure and low field as in axicell's yir y'ang anchor. In addition to lower yin-yang field and cost, the aicell arrangement will probably offer reduced radial transpert due to axisymmetry in the central coll although quantitative estimates of such trans. port are still uncertain.

While choosing the axicell configuration now for further study, we also recognize the possibility of trlimination of the yin-yang anchor altogether chould other means of achieving MHD stability for the axicell become available. For example, - inuld beta limits for Elmo Bumpy Torus
(EBT)-type, hot-electron rings prove better experimentally than theory now predicts, one could design a low-field, hot-electron cusp as an improved axisymnetric anchor, or possibly even design an ERT-ring-stabilized axicell alone without an anchor.

\section{The End-Plug Configurations}

Figure 22 show's the end-plug magnets (conductor bundles only, excluding coil cases and external structure) for the A-cell configuration. The central cell is to the left of the end-plug coils. The coil arrangement consists of a transition coil, a yin-yang pair, and a $C$-shaped coil oriented in the same plane as the outer coil of the yin-yang pair. This configuration creates two mirror cells-one in the yin-yang and one between the yin-yang and the $\mathrm{C}$-coil. Both the thermal barrier and the final potential peak are created in the auxiliary mirror cell (the A-celi), whereas mirror-confined 
ions in the yin-yang cell serve mainly to provide MHD stability. This configuration is the one used for the MFTF-B.

Figure 23 depicts the end-pirg magnets for the modified-cusp configuration. (This present configuration is modified from the originally proposed cusp configuration, "which was found to be unacceptable due to poor alpha particle confinement." of a high-field solenoid followed by a concentric pair of solenoids. The current of the inner concentric coil opposes the current of all the other coils and produces a field null on the axis of the machine. A hollow plasma forms because of nonadiabatic losses near the axis. The magnetic flux bundle from the central cell passes as an annulus between the concentric solenoids. This configuration produces only one mirror cell-between the high-field solenoid and the concentric pair of solenoids. Both the thermal barrier and the final potential peak are created in this mirror cell. MHD stability is obtained by a combination of favorable magnetic curvature and (for the inner radial regi(in) hot-electron stabilization or plasma rotation due to the radial electric field.

Figure 24 shows the axicell end-plug magnets. The plug's coil arrangement consists of an arially spaced pair of solenoids (the first stronger than the second) followed by a transition coil and a yin-yang pair. (In the present design as shown in Fig. 24, we have included a third solenoid, miving between the main two, with its current opposite the other coils' currents. This bucking solenoid serves to shorten the axicell, which advantageously reduces the plasma volume there.) This configuration creates two mirror cells, one between the solenoids and one in the yin-vang. The thermal barrier and the final poteniial peak are created in the axisymmetric cell while the outboard yin-yang (called the anchor) provides a region of favorable curvature for MHD stability. (As a fourth case, we considered a variant of this configuration that elıminates the transition coil and yin-yang pair and provides MHD stability by means of an EBT-type electron ring in the axicell.)

\section{Methodology of Comparative Study}

To compare several end-plug magnet configurations, we have concentrated our design efforts in FY81 on those aspects of tandem-reactor design that are strongly influenced by the plug' magnet geometry, such as MHD beta limits, mag net cost, barrier ECRH and pumping porer. Wis have given less attention to the central cell and balance of plant (BOP) in this study-even though they are essential elements in a complete reactor design-because we believe those items to be common to all tandem-mirror designs and nol decisive in the ultimate choice of an end-plug con figuration. fRecause we selected the axicell for fur ther study, our Fig2 reacter design effort, the Mir ror Adianced Reactor Study (MARS), will concentrate on the engineering of the axicell plug configuration and devote increased attention to central-cell design, balance of plant, and generic fusion problems such as activation, waste disposal, and safety.]

To evaluate the A-cell, modified cusp, and axicoll plug contigutations on an equal basis, we designed the end-plug magnets and coupled each end plug with a 150 -m-long central cell that pro duces 3500 silw of fusion power at a first-wall neutron loading of about $2.3 \mathrm{MW} / \mathrm{m}^{2}$. We used the same zero-dimensional fluid model to determine the plasma parameters and neutral-beam and ECRH power requirements for the end plug. Our cost estimates were based on the same unit costs for the neutral beans, ECRH, plug magnets, end-leakage direct converter, vacuum vessel. and reactor huilding for each plug coniguration The absolute capital costs are omly approximate, hul because our goal was to compare piug configura tions to choose the best marnet geometry for fu ture study, relative cost comparsone were the most useful.

\section{Summary of Performance and Cost Comparisons}

Tabkes 4 to 7 summarize the plasma parameters, power flows, major component costs, and direct capita! cost per net kilowat electric $(\$ / \mathrm{kWe})$, respectively, for each of the four plug configurations we studied. Using the plasina analysis, we can determine the trapped plug powers indicated in Table 5. The power-flow analysis and assumptions of injection and generation efficiencies led to the other power flows and net electric powers outlined in Table 5 . Table 6 lists the direct capital costs for the major reactor subsystems derived from the cost-estimating methodology and unit cost assumptions, together with plug magnet 


\section{Development and Technology}

Table 4 . Plasma parameters for four end-plug configurations.

\begin{tabular}{|c|c|c|c|c|}
\hline Parameter & A-Cell & $\begin{array}{l}\text { Modified } \\
\text { cusp }\end{array}$ & Axicell & $\begin{array}{l}\text { Axicell with } \\
\text { EBT stabilization }\end{array}$ \\
\hline laston prosere, l' lasol (MW) & 3500 & 3500 & 3500 & 3500 \\
\hline i'lam mergy gain, $Q$ & 10.3 & 19.7 & 22.3 & 12.2 \\
\hline I it-1-wall neutron loading, $\Gamma_{4}$ ( $\left(M W / m^{2}\right)$ & 2.3 & 2.3 & 2.3 & 2.2 \\
\hline \multicolumn{5}{|l|}{ (antral coll: } \\
\hline Plumma ractius, $r,(m)$ & 1.0 & $\mathbf{i} . \mathbf{0}$ & 1.0 & 1.0 \\
\hline 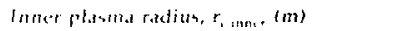 & - & 0.5 & - & - \\
\hline 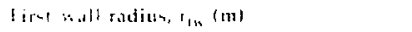 & 1.3 & 1.3 & 1.3 & 1.3 \\
\hline $1 \cdots+\mathrm{h}_{\mathrm{l}} \mathrm{l} \mathrm{\textrm {m }}$ & 150 & 150 & 150 & 150 \\
\hline$\therefore 1.11,1$ lect.1. & 0.56 & 0.7 & 0.7 & 0.7 \\
\hline : te: 1, an dinglts. n, $100^{1:} \mathrm{cm}$, & 1.6 & 2.2 & 1.6 & 1.6 \\
\hline lun temperature. I therl & 40 & 40 & 40 & 40 \\
\hline Heterin lemperature I, thevel & 36 & 33 & .32 & 33 \\
\hline 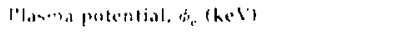 & 270 & 260 & 240 & 240 \\
\hline \multicolumn{5}{|l|}{ Horrer plus. } \\
\hline$l_{\text {Lnglh, }} l_{41} \mid \mathrm{ml}$ & 8 & 7 & 8.6 & 8.6 \\
\hline Plasma betso, $x_{n}$ & 0.63 & 0.61 & 0.71 & 0.36 \\
\hline 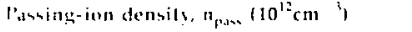 & 5.0 & 5.5 & 3.4 & 4.4 \\
\hline Injection energy; $I_{\text {In }}$ thets & 350 & 300 & 250 & 250 \\
\hline 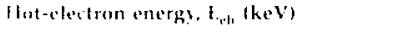 & 520 & 390 & 750 & 240 \\
\hline Marm-elecloun temperature, $T_{\text {e.w }}$ (kev) & 43 & 110 & 82 & 150 \\
\hline Barrier potential dip. do (kevel & 230 & 190 & 210 & 170 \\
\hline lun confining ponlenlial o thel's & 150 & 150 & $1+0$ & 140 \\
\hline \multicolumn{5}{|l|}{ Anthor: } \\
\hline Elanmal radius, $r, \mid \mathrm{ml}$ & 0.84 & & 1.2 & \\
\hline Planmia betal, as & 0.7 & & 0.3 & \\
\hline 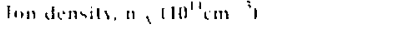 & $1 . i$ & & 0.15 & \\
\hline 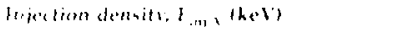 & 200 & & 150 & \\
\hline werige lon energes, I, (hel) & 310 & & 150 & \\
\hline 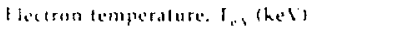 & - & & 32 & \\
\hline lolumal polential, sh, thell & - & & 160 & \\
\hline
\end{tabular}

data (such as superconduct'sr and structural steel rolumes in each roil). Dividing those costs by the net electric power (Table 5) results in the $\$ / \mathrm{kWe}$ presented in Table 7.

Table 7 is the best single composite figure of merit to compare the different end-plug magnet configurations. Our calculated $\$ / \mathrm{k}$ We reflects not only the cost of the magnets themselves, but also the cost of the plug input powers. which depend on the differing magnet geometries, peak achievable mirror fields, and physics requirements for ion adiabaticity and MHD stability. The differences in bottom-line costs result almost exclusively from differences in the plugs because not only are the central cells chosen to have the same length and fusion power, but it also turns out that the contral-cell density and radius for each case results in nearly the sane central-cell wall loading and thus, wall radius. Therefore, while we have made no attempt to optinize the design of the central cell, the focus of this study on plug differences is justified in its goal: selection of the most promising plug configuration. In the future it will be important to pursue design optimization since the central cell and BOF now represent approximately $50 \%$ of the total cost.

The hottom-line $\$ / \mathrm{kWe}$ in Table 7 shows the modified-cusp and axicell configurations to be nearly equivalent at 2130 and $2029 \$ / \mathrm{kWe}$, respectively: compared to the higher A-cell cost at 
Table 5. Results of power-balance analysis fer four end-plug configurations (all powers in MW).

\begin{tabular}{|c|c|c|c|c|}
\hline & A-cell & $\begin{array}{l}\text { Mlodified } \\
\text { cusp }\end{array}$ & Aritell & $\begin{array}{l}\text { A icell with } \\
\text { \& } 1 \text { I tobilisation }\end{array}$ \\
\hline \multicolumn{5}{|l|}{ Trapped powers: } \\
\hline ECRII & 4:- & bo & $+\pi$ & 174 \\
\hline Pump heams & 148 & 98 & 43 & $4:$ \\
\hline Slosting beams & 66 & 20 & 12 & 35 \\
\hline Anchor bestms & 24 & - & 5 & \\
\hline romal & .340 & 178 & $15 \%$ & $2 \mathrm{HG}$ \\
\hline \multicolumn{5}{|l|}{ Injucted powers: } \\
\hline ICRII & $10 \mathrm{H}$ & hi & 52 & $1: 1$ \\
\hline P'ump beams & 177 & 118 & 115 & 1115 \\
\hline Sloshing beams & 122 & 4.3 & 52 & 154 \\
\hline Anchor beams & 31) & - & 15 & - \\
\hline 10141 & 137 & $2 \mathrm{hH}$ & 234 & 135 \\
\hline \multicolumn{5}{|l|}{ Recirculated powere: } \\
\hline ICRHI & 216 & 1.34 & 104 & 3.42 \\
\hline Pump be.umb & 35.4 & $23 \mathrm{~h}$ & 23.31 & 2111 \\
\hline Slamhing beams & $24+1$ & 1 tht & 104 & $31 \mathrm{H}$ \\
\hline Anchor beams & (.01) & - & 30 & - \\
\hline Copper coils & - & 72 & 72 & 72 \\
\hline TOTAi & 874 & 608 & $5+10$ & $\omega_{42}$ \\
\hline Thermal-converter output & 1176 & $117 \mathrm{~h}$ & $117 \mathrm{~h}$ & $11 \% \mathrm{~h}$ \\
\hline Direct-converter outfut & 520 & 4.39 & 124 & 49.3 \\
\hline IOTAL (Gross electrical) & $164 \mathrm{G}$ & $1 \mathrm{th} 15$ & 1605 & 1669 \\
\hline $\begin{array}{l}\text { Recirculated power } \\
\text { Cirass electrical }\end{array}$ & 0.52 & $0.3 \mathrm{H}$ & 0.34 & $0.5 \mathrm{~h}$ \\
\hline Net electrical power & 822 & 1147 & 1065 & 727 \\
\hline
\end{tabular}

$3733 \$ / k$ we. The lower cost of the axicell and modified-cusp plug magnet configurations contributes substantially to this difference, but the biggest differences in $\$ / \mathrm{k}$ We are due to the differences in ECRH and neutral-beam power-power to pump the thermal barriers, to generate the electrostatic potentials, and to provide MHD stability

Table 6 show: that the combined costs of ECRH and neutral-beam power (conservatively assuming "today's" unit costs of beams and ECRH) exceed the costs of the plug magnets alone' by a factor of at least two in all cases. Since fusion power is constant at $3500 \mathrm{MW}$ in all cases, more plug power consumption results in less net electric power produced. Therefore, the differences in plug power costs are amplified in the net $\$ / \mathrm{k}$ We of Table 7 .

\section{Axicell Improvements To Consider}

Bexides the possibility of EBT stabilization of the axiceil (which must await progress in EBT theory and related experiments before it can be considered), we have ilentified a number of other potential improvements for the axicell with a yin-yang anchor. We have not yet fully investigated these improvements or incorporated them in our comparative study; homever, w'e believe many will prove feasible after further research.

7 wo inprosements that may not have much impact on capital cost or recirculating power but which can lead to simpler plug and anchor designs are negative plugs" and hot-electron anchors." The negative plugs would eliminate the reed for sloshing ions and ECRH at the potential 


\section{Development and Technology}

Table 6. Cost in millions of dollars for the four end-plug configurations.

\begin{tabular}{|c|c|c|c|c|}
\hline & A-cell & $\begin{array}{l}\text { Modified } \\
\text { cusp }\end{array}$ & Axicell & $\begin{array}{l}\text { Axicell with } \\
\text { EBT stabilization }\end{array}$ \\
\hline Wenm (1) $\$ 2 / W$ injected & 658 & 402 & 364 & 528 \\
\hline " kll (A 55/W injected & $5+0$ & 335 & 260 & 855 \\
\hline Mitü magrets & 628 & 251 & 302 & 175 \\
\hline linect cormeerter & 158 & 83 & 152 & 127 \\
\hline entral cell & 450 & 450 & 450 & 450 \\
\hline lieratur burlding & 165 & 154 & 162 & 149 \\
\hline 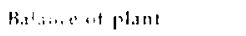 & 270 & 470 & 470 & 470 \\
\hline .111 & 3069 & 2145 & 2160 & 2754 \\
\hline
\end{tabular}

lable 7 . Cost per $k$ We for the four end-plug configurations.

\begin{tabular}{|c|c|c|c|c|}
\hline & A-cell & $\begin{array}{l}\text { Modific } 3 \\
\text { cusp }\end{array}$ & Axicell & $\begin{array}{c}\text { Axicell with } \\
\text { EBT stabilization }\end{array}$ \\
\hline Picamb (it 52, 16 injected & 800 & 399 & 342 & 639 \\
\hline IC Rll (A S5ils injected & 657 & 3.33 & 244 & 1176 \\
\hline Plag magnets & 764 & 249 & 284 & 212 \\
\hline Mirest encererter & [92 & 82 & 143 & 152 \\
\hline (entral cell & 5.47 & 447 & 423 & 545 \\
\hline Redstor building & $20 \mathrm{I}$ & 15.3 & 152 & 180 \\
\hline B.olance uf plant & 572 & 467 & 441 & 569 \\
\hline 1010 & 373.3 & 2130 & 2029 & 3473 \\
\hline
\end{tabular}

?uh. point (a). Neggalive plugs may require more trapped cold-ion density, hot-electron density, and ECRH power at the thermal barrier, point (b), but aiso shou'd require less pump power. Hat-slectron anchors would elimilate the need for uloshing ions (for microstability) in the anchors a: we]l as the need tor access for angledbean injection. Thus smaller, lower-mirror-ratio vin-yangs might be possible with hot-electron anchors.

Besides those improvements th it simplify the design, we have considered a number of possible improvements that would reduce the cost of power from the reactor. Table 8 summarizes these improvements, first singly and then in various rombinations. Also shown in the table are the performance and cost data for the axicell case discussed in the previous sections.

Overall, our research, and the potential for improvement, have convinced us that the axicell is an economically attractive reactor candidate. 
Table 8. Cost and performance of potential improvements in the axicell TMR.

\begin{tabular}{|c|c|c|c|c|}
\hline Improvement & $\begin{array}{c}\text { Direct } \\
\text { capital cost } \\
(\$ B)^{2}\end{array}$ & $\begin{array}{c}\text { Net } \\
\text { power } \\
\text { (MWe) }\end{array}$ & $\begin{array}{l}\text { Cost of } \\
\text { power } \\
\text { (S/kWel }\end{array}$ & $\begin{array}{c}t \\
\text { recirculated power } \\
\text { grose electrical power }\end{array}$ \\
\hline Reference case: & 2.16 & 1070 & 2030 & 0.34 \\
\hline \#1, more-efficient neutral beams & 2.16 & 1190 & 1820 & $0.2 \mathrm{~h}$ \\
\hline \#2, less-expensive ECRH & 2.00 & 1070 & 1880 & 0.34 \\
\hline \&3, less-expensive superconductor & 2.07 & 1070 & 1450 & 0.34 \\
\hline \#4, low-cost, low-power barrier pumping & 1.9 .7 & 1250 & 1550 & 0.20 \\
\hline \#5, higher-field-strength barrier coil & $1.8 \mathrm{~B}$ & 1190 & 1580 & 0.25 \\
\hline Combination of $\# 1,2,3,4$ & 1.64 & 1290 & 13011 & $0.1=$ \\
\hline Combination of $\sharp 1,2,3,5$ & 1.7 .5 & 1240 & 1350 & 0.14 \\
\hline Combination of $\# 1,2,3,4,5$ & 1.53 & 1.350 & 1150 & 0.14 \\
\hline
\end{tabular}

" \$B billions of dollars. 
Ihe Mirror Fusion Test Facility (MFTF), now being constructed, will bridge the gap between frenel-day small mirror experiments and future fusion-reactor activity based on magnetic mirrors, e.g. an ipurimental lusion reactor planned for operation by 1990. In MFTF, we shall investigate advanced 'nginuring problems such as those associated with superconducting magnets (MFTF uses a -Hpurumduting magnet of yin-yang design that will be capable of continuous operation), neutral-beam inievtors, plasma-wall interactions, the disposal of neutral particles and ions escaping from the plasma chamber, and high-sped vacuum-pumping techniques.

In Oetoler 1980 . the scope of MFTF was revised, comverting the facility to a large tandem-mirror anfiguratom. This in now the main-line approach to mirr--fusion reactors. Our plan is to proceed dwe!! w thin tandem configuration, called MPTF-B, without first operating MFTF in the single-cell mode. R: are the equipment now under construction for MFTri, we can complete construction of the MFTF-B $\therefore$ a damuary 1985.

I the germetri of MFTF-B is show'n schematically in lïg. 25. Several operating modes are envisioned. in. pronary mote-the thermal-barrer mode-utilizes the yin-yang cell solely to anchor the plasma .

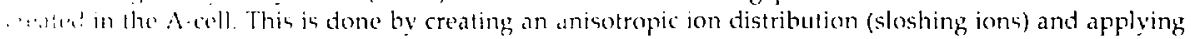

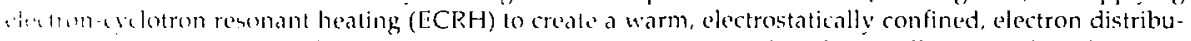
um. In astdition, a potential minimun, or thermal barrier is created in the A-cell. This is done by using FC'RI to form a hot, magnetically confined, electron distribution. Addition Il, simple-tandem operating mater wimilar to the Tandem Mirror Expreriment, are also possible. In the modes, there is no thermal farree, and the ion-confining potentials are created in the yin-yang cells.

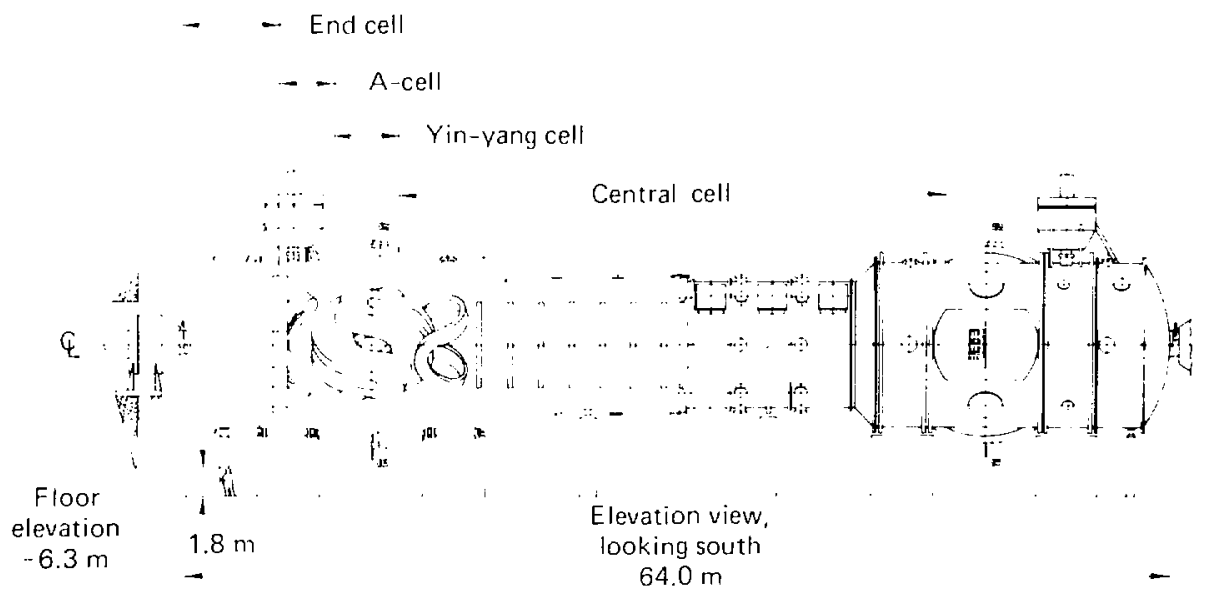

Figure 25. Machine regions in MFTF-B. 


\section{Technical Support}

The objectives of the MFTF Technical Support Group follow:

- To monitor the MFTF design for consistency with the physics requirements.

- To provide research leading to improved performance of MFTF auxiliary components such as startup neutral-beam sources, streamingplasma sources, and vacuum accessories.

- To keep the MFTF system requirements consistent with the current understanding of mirror-fusion physics.

\section{Introduction}

(G. D. Porter)

During this reporting period we have examined three issues of importance to the design of the MFTF-B. We include a brief review of each problem here with more details following in the subsequent sections.

- In our continued study of the operating modes of an axisymmetric upgrade to MFTF-B, we have modified the magnetic geometry to permit higher central-cell plasma pressures. This permits operation with the central-cell confinement parameter of $10^{14} \mathrm{~cm}^{3} \cdot \mathrm{s}$.

- We have calculated the magnetic-field perturbations due to a proposed steel support structure for the central cell. We find a 1 to $2 \mathrm{G}$ perturbation at the plasma-a perturbation of $10 "$, which is within tolerable limits.

- We have calculated the net-pumping rate for the hi, ${ }_{2}^{2 h}$-energy pumf beam, including the effect of the one-half and one-third energy compoments $\mathrm{cf}$ the beam. Our results indicate that the fractional energy' components of the heam remove particles from the well even if they do not pump at the bottom of the well, but trap particles instead. This occurs because the majority of the pumping occurs near the ends of the well where the density and potential are high.

\section{The Redesigned Axisymmetric-Barrier Upgrade of MFTF-B}

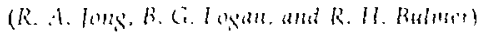

We have continued our study of the axisymmetric-barrier upgrade of MFTH-B and have designed a new configuration that inproves plasma parameters to require less neutral-beam and ECRH power than earlier designs.

Because the design for the axisymetric barrier upgrade of MFTF-B summarized in Ref. 52 could only be sustained using significantly more neutral boams and microwase prover than was available for MFTF-B. the main thrust of cur recent study has been wo lower the perwer requirements while improving, if possible, the operating plasma paraneters. We redesigned the magnets to include a high-field insert, thus creating a 14-T field at the inner mirror of the barried coll. Magnetic-field optimization produced the magnetohydrodynamic (MHD) stability limits $5.3 \mathrm{~mm}$ a rized in Fig. 26. A central-cell beta limit of 11.4 wis maintained, although with a slight decrease in the barrier beta from 0.2 to 0.11 (when compared to the original designs"-).

We decreased the plasma radius of the new configuration from a central-cell value of 50 to $30 \mathrm{~cm}-\mathrm{a} 64 \%$ decrease in the plasma cross section. While the neutral-beam utilization is less with the smaller radius plasma, the neutral-beam and microwave power necessary to sustain the plasma are also much smaller as a result of the decreased plasma volume.

In the next section. we present the results of our latest operating point calculation and highlight the major consequences of the design changes.

Our present calculations follow the same formulation used in the previous design,"? and detailed in Ref. 53. Table 9 sumnarizes the plasma parameters for the revised axisymmetric design. For comparison, the corresponding values for the 


\section{Mirror Fusion Test Facility}

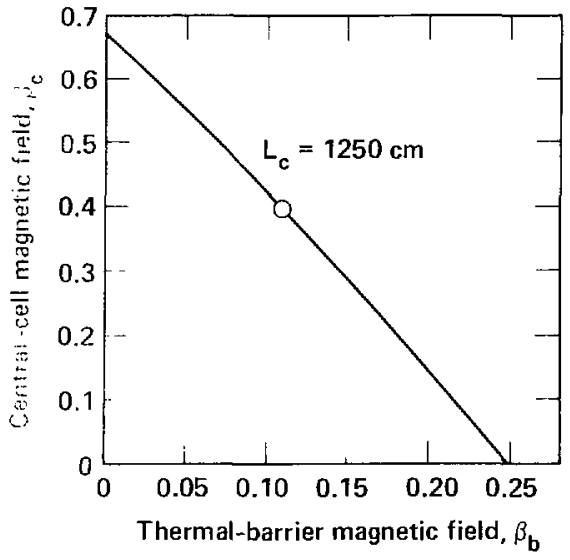

Figure 26. Magnetohydrodynamir (MHD)stability limits for the axisymmetric-barrier upgrade of MFTF-B. The effective plasma length is $L_{i}$. The $\beta_{\text {anchor }}$ is 0.55 ; the $\beta_{\text {Iransition }}$ is 0 .

- tanctard case ( $\phi_{1} \leq 40 \mathrm{kV}$ ) from Ref. 52 are included. White the central-cell beta of has been keft sumbant. we have increased the central-cell inn lemperature fand hence lowered the writral (a)l density) for the revised calculations. Wi have also rasised the confinement parameter ni, and conseguently; the central-coll equivalent (). (detined an the ratio of fusion power to power lont from the contral cell) is higher.

The decrease in required electron-cyclotron resomant heating (ECRH) at both the barrier midplane (b) and the potential peak (a) results from the smaller plasma volumes and lower plasma densities in these regions, as shown in Table 9 . The plasma volume is lower because of the smaller plasma radius. The lower plasma densities result from the higher magnetic field $B_{m k}$ at the inboard mirror of the barrier, from the larger value of harrier potential $\phi_{k}$, and from the smaller cold-electron fraction $F_{12}$.

With smaller barrier densities, the scattering losses of the hot and warm electrone are much lowser for the revised operating point. In addition, the warm-electron confining potential $\delta \phi$, is eleind and contributes to the lower warm-electron loss rate. This also leads to a lower microwave power or ECR.j requirement at (a).

Furthermore, the smaller barrier densities and volumes produce smaller values of the $\phi$ - and $\mu$-trapped currenis in the barrier and require smaller values for the absorbed pump-beam currents. In our present calculation we have also included the low-energy, pump-beam current $I_{L}$. omitted from the original table. ${ }^{52}$ This calculation of the $\mu$-trapped ions follows the revised nethed of Devoto ${ }^{7+}$ that corrects an error in the original formulation by Logan as reported by Baldwin pot al.

Besides the smaller plasma volumes, the largor confinement parameter $n t$ produces a smaller Pasthukov loss current $l_{\text {lous }}$ from the central cell. This results in much smaller neutralram and gas input to the central cell for the re $v$ ised design. We have also calculated the sloshing-ion beam requirements for the barrier using a new model suggested by Logan ${ }^{\text {if }}$ (see Table 10).

Our study of the sloshing-ion beam current requirements in the barrier takes into account the molecular mix of the incident beam and assumes that the one-third energy component of the beam is not confined by the magnetic field, but is in fact lost because the beam is injected at a position of high potential. We assumed the full-and half-energy beam components are both confined. If the half-energy component is not confined, then no stexdy'-state, sloshing-ion distribution is possible with the present available beams. Moreover, our calculations indicate that even if the full-and half-energy heam components are confined, a stediy-state, sloshing-ion distribution can be achieved with a reasonable value of sloshing-ion current only if the one-third fraction of beam energy is kept below about $5 \%$.

This low value is necessary because the unconfined sloshing-beam components act as a charge-exchange punp on the high-energy sloshing ions as well as on both the low-energy trapped and passing barrier ions. Our results indicate that the dominant loss mechanism for the sloshing ions is charge exchange off the high-energy pump heam (53\%), followed by a charge exchange off the one-third energy beam component $(36 \%)$, and scattering losses out the ends of the barrier (11\%). Charge-exchange losses of the sloshing beam off the low-energy pump 
Table 9. Comparison of plasma parameters for the axisymmetric-barrier upgrade of MFTF-B for the standard case $^{52}$ and the revised case.

\begin{tabular}{|c|c|c|}
\hline & Original & Revised \\
\hline \multicolumn{3}{|l|}{ Central-cell parameters: } \\
\hline Ion temperature, $T_{n}$ (ke $V$ ) & 15 & 20 \\
\hline Electron tempetature, $T_{w}$ (keV) & 12 & 12 \\
\hline Plasma density, $\left.n_{16} 110^{14} \mathrm{~cm}^{2}\right)$ & 3.7 & 3.1 \\
\hline Confinement paranseter, nז $\left(10^{17} \mathrm{~cm}^{3}\right.$. st & 7.2 & 10.4 \\
\hline Central-cell energy gain, $Q_{1}$ & $0 . h$ & 1.3 \\
\hline lon confining potential, $\alpha_{1}(k V)$ & 35.6 & +3.2 \\
\hline Electron confining potential, $\phi_{,}(\mathrm{k} v)$ & 77.2 & 74.2 \\
\hline liffective plasmu length, $l .,|c| n \mid$ & 1500 & 12.50 \\
\hline Plasma radius, $\mathrm{r}_{\mathrm{i}}(\mathrm{cm})$ & 50 & 30 \\
\hline Magnetic field, B, , : & 1 & 1 \\
\hline Beta, $\beta$, & 0.4 & 0.4 \\
\hline \multicolumn{3}{|l|}{ Barrier parameters: } \\
\hline Hot-electron energy, E $E_{\text {ih }}$ (kev) & 105 & 140 \\
\hline Warm-electron temperature, $T_{\text {ase }}$ (keV) & 96.2 & 97.6 \\
\hline Sloshing-ion temperalure, $T_{n}$ (keV) & 50 & 50 \\
\hline Betu. $\beta_{\mathrm{b}}$ & 0.2 & 0.11 \\
\hline Cold-electron fraction, $r$ & 0.18 & 0.05 \\
\hline Total ion density at $(h)^{\prime \prime} n_{1}\left(10^{12} \mathrm{~cm}\right.$ ) & 7.23 & 2.59 \\
\hline Passing ion density at (b), $n_{p}\left(10^{12} \mathrm{~cm}\right.$ ') & 1.81 & 0.648 \\
\hline Hot-clectron density at $(b), n_{r, h}(b) 110^{12} \mathrm{~cm}$ ') & 5.93 & $2 .+6$ \\
\hline Cold-electron density at $(b), n_{4}(b)\left(10^{12} \mathrm{~cm}\right.$ ') & 1.30 & 0.130 \\
\hline Ion density at (d), $\mathrm{n}(\mathrm{s})\left(10^{\prime \prime} \mathrm{cm}\right.$ ' & 1.09 & 0.389 \\
\hline Warm-electron density a $(a), \pi_{6 \cdot u}(a)\left(10^{12} \mathrm{~cm}\right)$ & R.05 & 2.79 \\
\hline Hot-electron density at (a). $n_{c h}(a)\left(10^{12} \mathrm{~cm}\right.$ & 2.22 & 1.04 \\
\hline Cold-electron density at (a), $n_{1,}(a)\left(10^{11} \mathrm{~cm}{ }^{3}\right)$ & 5.72 & 0.487 \\
\hline Barrier potential, $\phi_{1},(k v)$ & 39.6 & 61 \\
\hline Warm-electron confining potential, $\delta \phi_{4}(k v)$ & 75.2 & 104.2 \\
\hline Warm-electrun length, $L,(\mathrm{~cm})$ & 70 & 106 \\
\hline Hot-electron tength, $L_{t},(\mathrm{~cm})$ & 42 & 1,36 \\
\hline Magretic field at $(a), B_{a}(T)$ & 2 & 2 \\
\hline Mugnelic field at $(b), B_{1}(T)$ & 1 & 1 \\
\hline Peak barrier magnetic ficid, $B_{m h}(T)$ & h & 14 \\
\hline \multicolumn{3}{|l|}{ I:CRH power: } \\
\hline Power at $\left.(a), P_{3} \mid k W\right)$ & 770 & +.82 \\
\hline Power at $(b), P_{h}(k w)$ & 760 & 12.4 \\
\hline Trapped current, $I_{\text {trap }}$ (A) & 2.51 & 0.484 \\
\hline Pastukhov loss current, $I_{\text {lam }}$ (A) & 12 & 1.78 \\
\hline Central-cell incident beam current, $I_{r}(A)$ & 38.8 & 10.2 \\
\hline Central-cell gas current, $I_{\text {Rds }}$ (A) & 0.96 & 0.583 \\
\hline Iigh-energy pump-beam current, $I_{\mathrm{H}}(\mathrm{A})$ & 13.6 & 0.605 \\
\hline Low-energy pump-beam current, $I_{1}$ (A) & - & 1.16 \\
\hline
\end{tabular}

${ }^{a}$ (b) : barrier midplane.

ta) - potential peak. 
Table 10. Sloshing-ion beam currents for the MFTF- $B$ axisymmetric-barrier upgrade.

\begin{tabular}{|c|c|}
\hline Hin rien licam currents: & (A) \\
\hline [nident s losling-ion current & 10.6 \\
\hline Itorobed sloshing-ion current & 0.740 \\
\hline lasused slouhing-ion rurrent & 0.377 \\
\hline
\end{tabular}

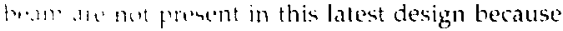
1. inme at injection of the low-energy pump

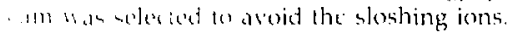

through ont salualatione we have obtained i: Vlll) wable "perating poinl for an ans mmetric-harrite rersion of MFTF-B that can le - whaned sith the neutral-heam and ECRH powe avalable for MAPT-B. Maintenance of the bishing ion barrier and anchor depends crucially (n) the mosicular mix of the neutral beams. The amesutines pertions of the beam must not exced . Inest 5 ".

\section{Perturbation of Solenoid Magnetic Field by Steel Support Beams}

\section{(1. S. Shiner and B. M. Johnstun)}

We calculated a 1 to $2 \mathrm{G}$ upper-limit perturbation in the central-cell plasma region due to a proposed support-beam structure built of structural magnetic steel. This result, plus similar earlier work, implies that magnetic steels can be substituted for the more expensive nonmagnetic stainless steels in many parts of the MFTF- $B$ as well as in future magnetic-fusion designs.

One of the recent proposed designs for the mechanical support of the vacuum system in the central cell of the tandem Mirror Fusion Test Fasility (MIFTF-B) contained two large, longitudinal bleel beams close to the racuum vessel see Fig. 27). If these beams were made of structural (or ordinary magnetic steel, they would be less expensive than nonmagnetic stainless steel. On the (a)

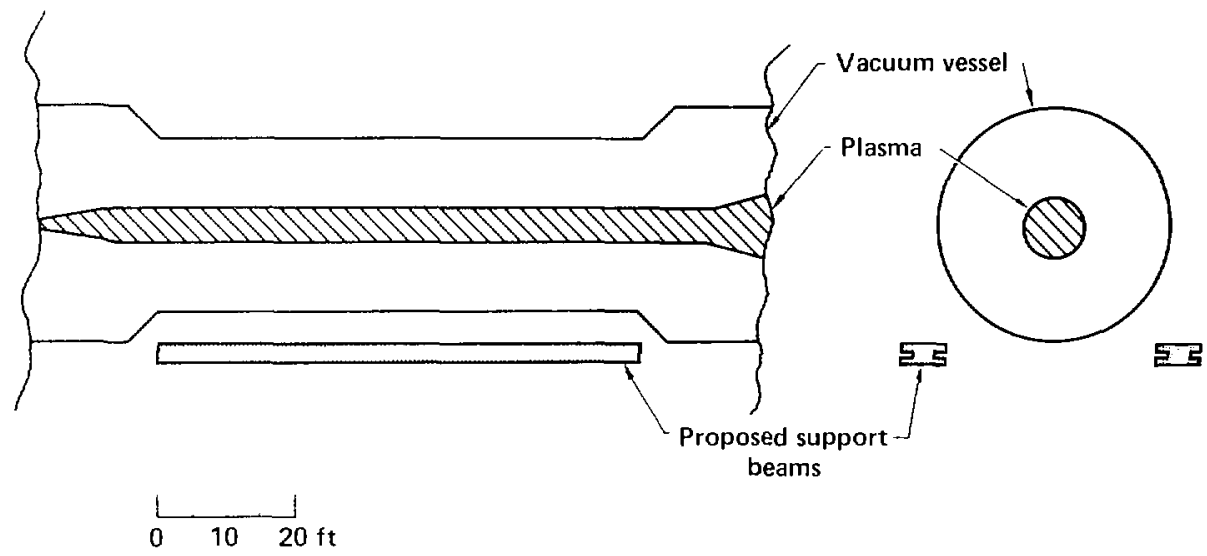

(Approx. scale)

Figure 27. Two proposed ordinary-steel support beams for MFTF-B, each approximately 73-ft-long in 25 -in. ${ }^{2}-$ wide, shown approximately $22 \mathrm{ft}$ from the plasma axis. The locations of the maximum field perturbations in the plasma were close to those in the transition sections, near the ends of the support beams. Note that (a) indicates the side view and (b) illustrates ihe cross section. 
other hand, such magnetic materials could affect the uniformity of the central-iell magnetic field at the plasma.

Analyzing this perturtation problem is beremat the present limited capabilities of the GIUN magnetic materials conde." Conserouently: we used an approsimate upper-limit method to estintate the effect of the jron (in magnetic steel) at the phoms. One can take advantage of the fact that the magnetic field inside the irom is saturated at approximately $20 \mathrm{hC}$ when it is located in the $10(0)$.

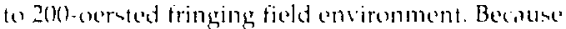
the beam is porallel to the axis of the solenowdal roil. we knewe that the flus is given by the preduct of this field with the cross sectional ared of the beam. Once this flut is knewn. one can use the magnetic colde Eltitis to delermine the effect of the iron dempite the fuct that EFFl doen mon hande magnetic materials. This is done in the colde by subutituting a hong solenoridal coil at the beam por. Gition. which corrien the same flux as the heam.

()ur actual E:HFl code computations contained (n)l thene "substitute solenotids" that moskest up the two suppert beams: the outpul fields at variour plasma pusitions were found to he in the nange of 1 to 2 G. Me judged this negligityly small compured to the 5 . to $10-k G$ specification for the contral-cedl magnetic field at the plasma. Furthermore, it in an upper limit fer two redsums. First, the significant perturbations for the plasma are actualle feld ditferences across the diameter, rather than the geometry calculated here. Second, in the atedal facilits the nuxes in the beame are simply dieplaced flunes from regions near the beams. Iherefore, the real perturbation would be lass than our calculation. Which evaluates the beam flur effect alone without subtracting the effects of the undisplaced tlus.

This low result for the magnetic perturbation of these large steel beams is particularly striking hecause it exems to contradict common physical intuition about magnets. We believe that the main reason for the apparent paradox has beon that there is very liftle experience in large volume 100 to 20 on-oersted environments. In such fields, the magnetic permeability of jom is only 100 to 200 dece to saturation. Me found similar surprises earlier when we andyzed the small quantities of mannetic iron in the "pop risets" of the cryo. punuping pancls." Their effect on the magnetic field at the plama was negligible, and their local magnotic forces were easily supportable.
We comclude that ordinars ated is a definite condidate for present and future magnetse funden

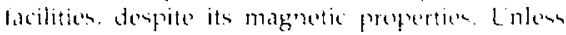

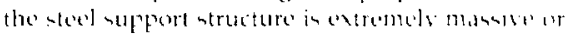
extremely clome (6) the planma, at will reet undaly perturb the magnetic field. Finally. It keterentims

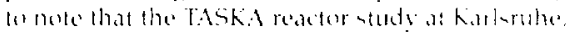

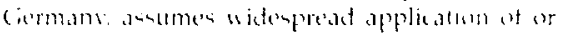
dimary uleel."

\section{Calculation of Net Trapping ard Pumping Rates in the A-Ce!i Thermal Barrier}

(1. 11 lopinatin)

We have recently calculated the net trapping and pumping rates in the thermal barrier of the A-cell of MITF-B. Our results show that even for a relatively large confining potential ( $48 \mathrm{kV})$, both the one-third and halfenergy components of the high-energy pump beam (HLPB) are more effective as pumps of trapped ions 27 ; for 26.7 keV, $29 \%$ for 40 keV) than the full-eicery component $116^{\prime \prime}$ at 80 keVi.

(lor ands rempended to the frequents ex preseded comesn that it the eners at the ane that

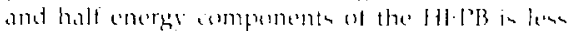
than the bane contingeng pootentiat, then the net effect of the pump heam is to ade to the trapped

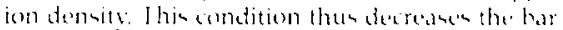

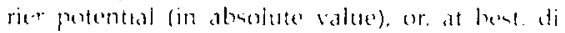

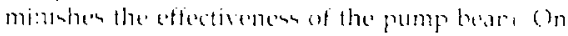
the other hand. exen if the bottiom af the barriter

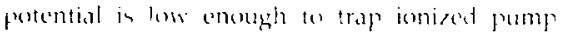
beam particters much of the density in the batrer in at locesl potentialo that are not contining to the

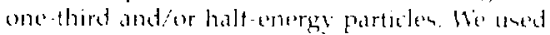
Cohenn."

- The ion dentribution function utiggented by

- The astimer relationshipe among electro tatic potential magnetic field and demsite of both the pareing and trapped ions as weell as coldt electroms.

- The EFFin calculations of the magneticfield profile to pertorm a calculation that integrates the local contribution (- or -..) to the trapped ion dennity an the pump beam progereseres alomg the 1 -axs. We accounted for the attenuation of the beam by ionisation and charge-exchange. 


\section{Mirror Fasion Test Facility}

A locally writen code, POTNE2, ${ }^{\text {h2 }}$ uses the Cihe' $n^{\prime \prime}$ ion energ: distribution to obtain $B, n_{t}, n_{f \prime}$, and $n, h$ as functions of electrostatic potential $\phi$. iis combined our code results with the output of IIf in to generate values of axial position $z$ at the ..hues of $B$, corremponding to the given values of

\section{Our actual $\because$ ulation is}

$$
\begin{aligned}
& (4+1+1 \\
& \text {. } 17, \ldots+1
\end{aligned}
$$

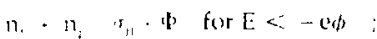

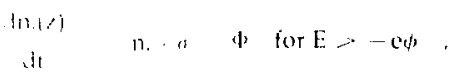

where

$$
\begin{aligned}
& \text { 11. trapperi un density. } \\
& n_{1} \text { passing ion density. } \\
& n_{1} \quad \text { cold chetron density }=n_{t}+n_{p}-n_{d-1} \\
& \text { 11. croms } 4 \text {. ion for ionization of deuterium }
\end{aligned}
$$

(I) by electrons

$$
\begin{aligned}
& \text { r. Crose a ion for ionization of D by } D \text {. } \\
& \pi_{1} \text {. crass - tion for charge exchange. } \\
& \text { d neutral eam fux. } \\
& \text { (anil cha }:
\end{aligned}
$$

Ihus, we in e able to generate Table II, whth given w. B. . n... and $n_{\text {, h }}$ as functions of $z$; the hathe also in uden the three cross sextions linted aboue spe ficilly, we obtained the cross uretion for ionisa in belectrons by dividing the reaction rate for a a electrons by the velocity of a deuteren at 80 tol. and $26.7 \mathrm{keV}$ respectivels: The $r$ axis profile of o, $B, n_{1}, n_{1}, n_{1}$, anci $n_{1}$, are shown in firg. 28 i to 0 ).

Table 11. Ionization and charge-exshange cross sections for MFTF-B.

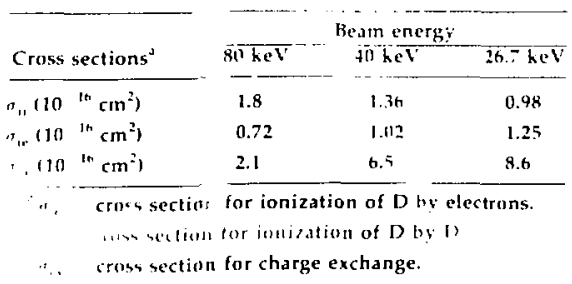

The loss-cone angle for the harrier on the yin-yang side is

$$
\tan { }^{\prime}-\frac{1}{\frac{4}{0.68}-1}=24.5^{\circ}
$$

Berause the HEPB is aligned along the axis $\left( \pm 2^{\circ}\right)$. the ionized beam particles are always within the loss cone. Therefore, mirror-trapping does not have to be considered.

Starting at the zone closest to the end wall, this calculation is performed for each energy component of the pump beams $(80,40$, and $26.7 \mathrm{keV})$. W'e set $\Phi$ (for each component) at $1 \mathrm{~cm}=s$ '. As the calculation progresses, the attenuation is subtracted from $\Phi$ for each zone-and $n_{\text {, }}$ is added to or subtracted from-as the value of $E+$ ed diclates.

The values for the operating parameters are the current nominal values for MFTF-B:

Contral-cell density $=2 \times 10^{13} \mathrm{~cm} ;$ Outer mirror density $=0.93 \times 10^{13} \mathrm{~cm}$ : $B_{\text {minn }}=4 \mathrm{~T}$.

$B_{1, \ldots}=0.68 \mathrm{~T}$ (minimum), $3 \mathrm{~T}$ (maximum).

Barrier confining potential from yin-yang (i) - max to barrier $(-\min )=-48 \mathrm{kV}$.

Central-cell ion temperature $\left(T_{11}\right)=15 \mathrm{keV}$.

Contral-cell electron temperature $\left(T_{\because}\right)$ $=6 \mathrm{keV}$.

Table 12 shows the results of our calculation for the three energies: full $(80 \mathrm{keV})$, one-half $\left(40 \mathrm{ke}^{2} \mathrm{~V}\right)$, and one-third $(26.7 \mathrm{keV})$ : we compare the rates for gross pumping, gross trapping, and net pumping. The numbers given in the tables are, in effoct efficiencies, i.e, the number of ims Irapped per incident neutral atom. Thus, we have concluded that both the one-third and half-energy components of the HEPB are more effective as wapper ions than the full-energy component.

Basically: our results demonstrate that the length over which $\mathrm{E}<-$ eo is small enough (and the density there is low enough) so that the number of beam particies trapped there is considerably less than the number of trapped particles punped in either side of the trapping region. where $E>-$ eot.

Our calculations have been normalized to an input beam inten-ity of 1 particle' $\mathrm{m}^{2} / \mathrm{s}$. For in. tense beams, the actual rates would be high 

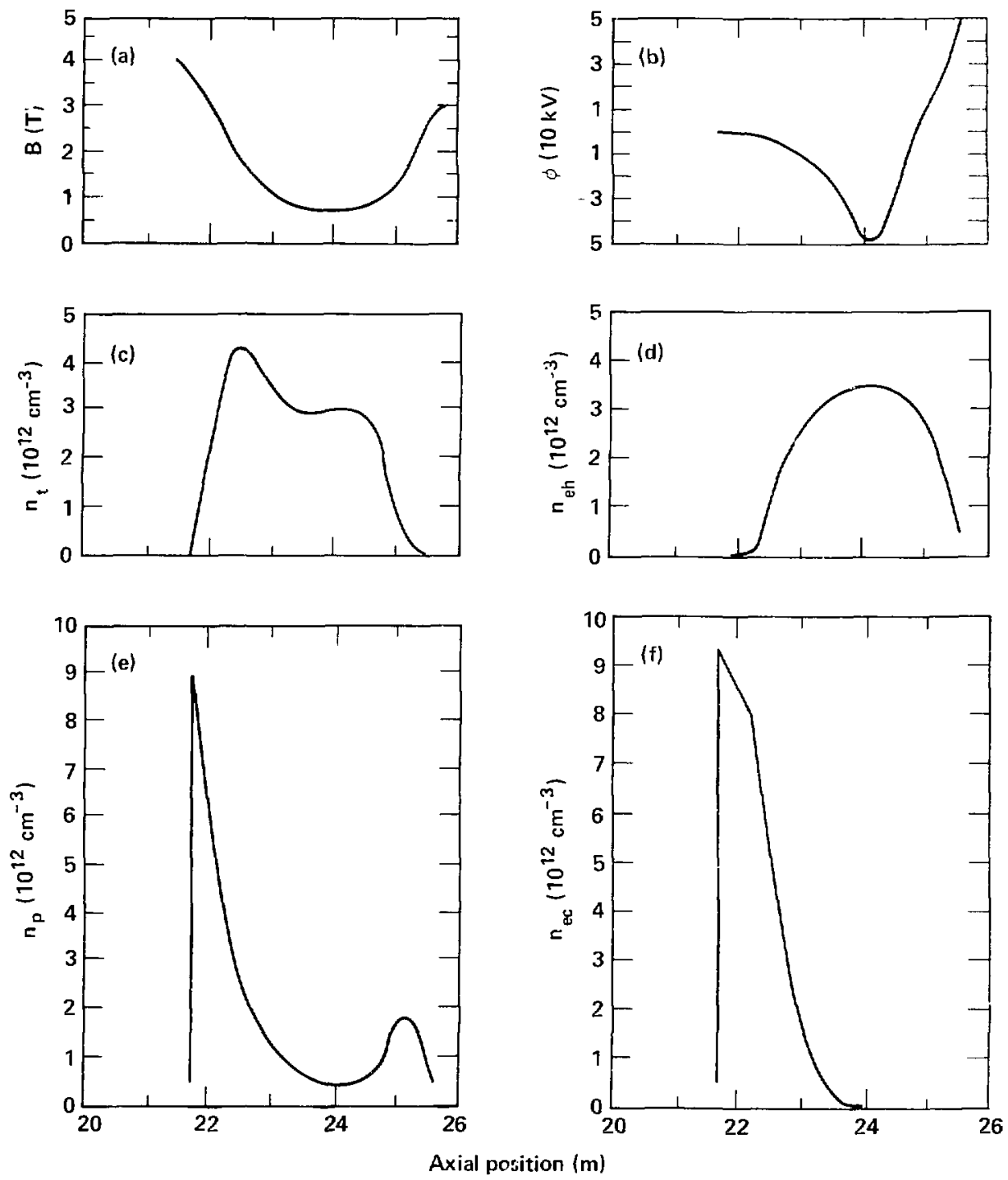

Figure 28. Functions of axial position for MFTF-B: (a) magnetic field B; (b) electrostatic potential $\phi$; (c) trapped-ion density $n_{i}$; (d) hot-electron density $n_{e h}$; (e) passing-ion density $n_{p}$, and (f) cold-electron density $n_{\mathrm{ec}}$. 
Table 12. Pumping and trapping rates in the A-cell barrier for MFTF-B.

\begin{tabular}{|c|c|c|c|}
\hline \multirow[b]{2}{*}{ Rate } & \multicolumn{3}{|c|}{ Beam energy } \\
\hline & $80 \mathrm{keV}$ & $40 \mathrm{keV}$ & $26.7 \mathrm{keV}$ \\
\hline Grous trapping & 0 & 0.017 & 0.021 \\
\hline Gross pumping & -0.158 & 0.310 & 0.294 \\
\hline $\begin{array}{l}\text { Net (negative values } \\
\text { when net pumping) }\end{array}$ & 0.158 & 0.293 & -0.273 \\
\hline Iransmianion of the IfLPB & 0.460 & 0.201 & 0.133 \\
\hline
\end{tabular}

enough to affect the trapped and passing density distributions because particles are being subtracted from one part of $V^{2} / V^{2}$ phase space and added to another. There must be some readjustment in a barrier-transit tıme because the particles are not localized. However, to calculate the particle distribution and potential profile functions consistent with pumping is beyond the level of the approach taken hire.

\section{Design and Construction}

\section{General Progress}

\section{(1. M. Mam and l'. N. Karpenko)}

Work continued on the Technology Demonstration (Tech Demo) and on the design, fabrication, and construction of additional systems for the tandem Mirror Fusion Test Facility (MFTF-B). Specifically, five major systems were verified through integrated lests during Tech Deno: magnet, vessel, external vacuum, cryogenic, and control. This is the fifth quarter of the MFTF-B construction project.

\section{Introduction}

Highlighting this period was the Mirror Fusion Test liacility Dedication on October 23. Deputy Secretary, Department of Energy (DOE), 11. Kunneth Davis; Director of the Office of Fnergy Research, DOE, Alvin Trivelpiece, and Director of Open Confinement Systems, DOE, William Ellis, were among the platform peakers. Other DOE representatives and senior management representatives of major contractors joined L.Ist personmel and local officials for the ceremony on the lawn of the new Magnetic Fusion Energy office huilding. The cover photograph of this Quartirly depicts the press conference held prior to the dedication.

\section{Magnet System}

Ye leak-checked and sealed the magnets, guard yacuum, liquid nitrogen (LN) liners, and cryopiping system. Then, as necessary, we repaired welded juints to reduce fluid losses and re- placed guard-vacuum flanges to eliminate outside air infusions. In December two high-speed cryopumps wre added to aid in this pumpdown process; the third cycle of vacuum pumpdown began on December 30.

After installation of the magnet power supply system, we tested both of the two C-coil power units. They achieved design current in resistive load tests. All magnet instrumentation was checked out in preparation for the magnetcold-power tests.

\section{Vacuum Vessel System}

The cryopanels and vessel were readied for vacuum pumping, following the magnet tests. The $t$ it program for these systems will be completed in early 1982; this is the planned date for completion of the vessel section of the Fusion Chamber System subcontract, a part of the original MFTF Project.

\section{Cryogenic System}

In preparation for the magnet-cold-power testing, the hehium refrigerator/liquefier produced 13,000 liters (1) of liquid helium (LHe); at more than $600 \mathrm{l} / \mathrm{h}$ this significantly exceeded the LHe liquefaction rate specifications. The helium refrigerator also surpassed its specified heat removal rate of $3075 \mathrm{~W}$.

\section{External Vacuum System}

We used computer codes to display residual gas analyzer (RGA) scans on the central console of the Supervisory Control and Diagnostic System 
(SCDS). Acture' testing of the gas analyzers and external vacuum system through SCDS continued during Tech Demo.

Using the external vacuum system cryopumps, we pumped dow'n the vessel to $6 \times 10^{\text {i }}$ Tor. After the LN liners and guard-vacuum subsistems of the magnet system were leak-checked and sealed, pumpdown restarted. We employed the rough-vacuum system and cryopump pods (five high-vacuum punps) to verify the actual pumping capabilities of the external vacuum systens.

\section{0-kV Power Supplies}

Work continued on integration of the shunt switch assembly into the first unit of the $80-\mathrm{kV}$ Sustaining Neutral Beam Power Supply System (SNBPSS), although we encountered some difficulties with the controls. To overcome delays in the integration and test of the 24 SNBPSS sets, we restructured the schedule and scope of work with the supplier. Both the integration of the individual units and testing have been undertaken by law. rence Livermore National Laboratory (LLNL).

The SNBPSS arc-power-supply subsystem was successfully tested in two modes: $150 \mathrm{~V} /$ $1500 \mathrm{~A}$ and $130 \mathrm{~V} / 1000 \mathrm{~A}$. We made this test to confirm performance compatibility of SNBPSS with the uperation of $30 / \mathrm{s}$ prototype neutral-beam-source modules developed by Lawrence Berkeley Laboratory and Oak Ridge $\mathrm{Na}$ tional Laboratory. Using the SCEPTRE computer program, we designed a two-capacitor, arc-current-notcher circuit, which has an exponential decay at the end of the current-notch pulse. This new design will reduce the arc current overshoot and permit accel voltage to more closely follow the arc curre $t$ during source module operation.

Many components of the $2480-\mathrm{kV}$ sets were installed in Building 431. Integration of the components into working sets is actively underway.

\section{Control System}

We continued to exercise : רe Local Control and Instrumentation Systems (LCIS) with the Supervisory Control and Diagnostic System (SCDS) for the major elements of Tech Demo:

- The distributed LCIS control and data elements, through connecting light pipes, worked well up to $200 \mathrm{~m}$ from the local computers.
- The SCDS functioned through the LCIS microcumputers, using the central control consoles.

Monitoring and control functions were successfuily verified for the vessel, external vacuum, and cryogenic systems as well as the magnet power supplies. Full integrated control vill be $\mathrm{cm}$ ployed during the magnet-cold-power test stheduled for the next quarter.

\section{Design and Procurement of MFTF-B Systems}

After installation of the ground-plane insulation on the first coil form, winding of the second yin-yang magnel began in December. Mort than 60) lengthe of superconductor are now at LI.NI.. It will take 58 lengthe of the copper-wrapped superconductor core (ass $\cdot$ minled conductor) to complete the first of the two C-coils for the yin-yang magne't.

Documentation for the Final Design Review (FDR) was completed for the A-cell, transition, and solenoid magnets. In addition, a number of significant technical tasks were finished in this design and development area. Specifically, we de. cided to assemble the transition coil with the coil wound directly on the outer case. This is possible due to the reduced magnel loads and case thickness in the transition coils, compared to the $A$-cell and yin-yang coils. Magnetic field analyses completed during the quarter showed a peak field of $8.3 \mathrm{~T}$ for the A-cell coils rather than the $8.1 \mathrm{~T}$ previously identified. There is still sufficient margin in the design of the A-cell case. Structural analy'ses showed no problems with forces or stress and strain levels for currents up to 1.05 times the normal operating current.

In addition, the FDR for the vacuum ressel was held. Suggested foundation changes were evaluated, and additional analyses of vessel, foundation, and vault interactions under thermal and seismic loads are underway. Stainless-steel plates for the vessel are now being polished for assembly.

For the electron-cyclotron-resonant heating (ECRH) design, we completed:

- Proposal evaluations for the powersupply' construction.

- Preliminary waveguide and antennae layouts.

Procurement this quarter of increased computer capacity and higher-speed processors will 


\section{Mirror Fusion Test Facility}

permit the SCDS to incorporate added on-line components without suffering data-base lockup.

Bidding for extension of the west wall of Building 431 was finalized in December.

\section{Summary}

Funding limitations in FY 1983 were mandated by DOE for the MFTF-B Construction
Project and related program elements. The altered funding picture will necessitate a major restructuring of contract and in-house efforts to complete the work. We are currently studying these cost and schedule impacts. However, work during this quarter proceeded on schedule and within the overall cost of $\$ 226.1$ million. 
1. A. Friedman, A. B. Langdon, and B. I. Cohen, "A Direct Method for Implicit Particle-In-Cell Simulation," Comments Plasma Phys. Controlled Fusion 6(6), 225 (1981).

2. B. 1. Cohen, A. B. Langdon, and A. Friedman, Implicit Time Integration for Plasma Simulation, Lawrence Livermore National Laboratory, Livermore, CA, UCRL-86350 (1981); to appear (in revised form) in 1. Comput. Phys.

3. J. Denavit, "Time-Filtering Particle Simulations with $\omega_{1 \mathrm{ru}} \mathrm{dt}>1$, " I. Comput. Phys. 42, 337 (1981).

4. R. I. Mason, "Implicit Moment Particle Simulation of Plasmas," /. Compul. Phys. 41, 233 (1981).

5. A. B. Langdon, A. Friedman, and B. I. Cohen, Implicit Large-Time'step Particle Simulatimn of Plasints, Lawrence Livermore National Laboratory, Livermore, CA, UCRL-87135 (1982); submitted to /. Comput. Phys.

6. C. F. Curtiss and J. O. Hirschfelder, "Integration of Stiff Equations," in Pric. Nal. Acad, Sctuces, U.S., Washington, DC, 1951 (Mack Printing Company, Easton, ГA, 1952), Vol. 38, p. 235.

7. B. I. Cohen and R. P. Freis, Stability and Application of an Orbit-Azcraged Magneto-Inductize Particls Codi, Lawrence Livermore National Laboratory, Livermore, CA, UCRL-86429, Rev. 1, Part H (1981); to be published by I. Comput. Phys.

8. B. I. Cohen, R. P. Freis, and V. Thumas, Orbit-Averaged Implicit Particle Codes, Lawrence Livermore National Laboratory, Livermore, CA, UCRL-86429, Rev. 1, Part I (1981); to be published by J. Comput. Plits.

9. W. C. Turner, G. C. Goldenbaum, E. H. A. Granneman, D. S. Prono, C. W. Hartman, and J. Taska, "Beta II Compact Torus Experiment Plasma Equilibrium and Power Balance," in 4th 5 ymp. on the Phys. and Tich of Compact Toruids, Lawrence Livermore National Laboratory, Livermore, CA, 1981 (to be published); now available through LLNI, UCRL-87358 (1981).

10. H. W. Hoida, I. Henins, T. R. Jarboe, J. Lipson, J. Marshall, D. A. Platts, and A. R. Sherwood, "Impurity Observations in Coaxial-Source-Generated Spheromaks," in 4th Symp. an th' Physs. amh Te'th. of Compat Toroids, Lawrence Livermore National Laboratory, Livermore, CA, 1981 (to be published),

11. G. K. Morikawa, "Double-Toroidal Hydromagnetic-Equilibrium Configurations within a Serfectly Conducting Sphere," Phys. Fluids 12(8), 1648 (1969).

12. M. N. Rosenbluth and M. N. Bussac, "MHD Stability of Spheromak," Nucl. Fuston 19(4), 489 (1979).

13. A. Bondeson, G. Marklin, Z. G. An, H. H. Chen, Y. C. Lee, and C. S. Liu, "Tilting Instability of a Cylindrical Spheromak," Phys. Fluids 24(9), 1682 (1981).

14. D. E. Post, R. V. Jensen, C. B. Tarter, W. H. Grasberger, and W. A. Locke, Steady State Re'ative Cooling Rates for Low-Dersity, High-Temperature Plasmas, Princeton Plasma Physics Laboratory, Princeton, NI, PPPL-1352 (1977).

15. D. E. Shumaker, J. K. Boyd, B. McNamara, and W. C. Turner, Numerical Simulation of the Betn II Experime'nt, Lawrence Livermore National Laboratory, Livermore, CA, UCRL-85579 (1981).

16. E. J. Caramana and F. W. Perkins, Effects of Impurty Radintion on Retersed-Ficld Pinch Eivilution, Princeton Plasma Physics Laboratory, Princeton, NJ, PPPL-1626 (1980).

17. G. E. Guest and D. J. Sigmar, "Stability of Microwave-Heated Plasmas," Nucl. Fusion 11, 151 (1971).

18. Y. Matsuda, W. M. Nevins, and R. H. Cohen, "Electron-Cyclotron Resonant Heated Electron Distribution Functions," in Proc. Workshop EBT Stability Theory, Oak Ridge, TN, 1981 (N. A. Uckan, Ed., Oak Ridge National Laboratory, Oak Ridge, TN, 1981), p. 211.

19. B. W. Stallard, Y. Matsuda, and W. M. Nevins, "Fokker-Planck Calculations of Electron Cyclotron Resonant Heating (ECRH) in Mirror Geometry," in Proc. 2nd Worksitop on Hot Elcctron Ring Physics, San Diego, 1981 (to be published by Oak Ridge National Laboratory, Oak Ridge, TN); now available through Lawrence Livermore National Laboratory, Livermore, CA, UCRL-86826 (1981).

20. J. D. Callen and G. E. Guest, "Electromagnetic Effects on Electrostatic Modes in a Magnetized Plasma," Nucl. Fusion 13, 87 (1973).

21. N. T. Gladd, N. A. Krall, S. Hamasaki, and J. L. Sperling, "Microstability of the EBT Boundary," in Proc. Workshop EBT Stability Theory, Oak Ridge, TN, 1981 (N. A. Uckan, Ed., Oak Ridge National Laboratory, Oak Ridge, TN, 1981), p. 181. 
22. B. H. Quon, R. A. Dandl, N. H. Lazar, and R. F. Wuerker, "Heating of Energetic Electrons by Multi-Frequency Microwave Sources in Symmetric Mirror," Bull. Am. Phys. Soc. 26(7), 893 (1981).

23. I E. Howard, A. I. Lichtenberg, and M. A. Lieberman, "Multifrequency ECRH," Bull. Am. Phys. Soc. 26(T), $1036(1981)$.

24. T. D. Rognlien and Y' Matsuda. "Tandem Mirror Confinement in the Presence of lon Cyclotron Fluctuations," Vucl. Fusion 21(3), 345 (1981).

25 G. R. Smith, i. A. Byers, and L. I.. LoDestro. "Superadiabatic and Stochastic Jon Motion in the Presence of a Wave in a Mirror-Macnine Plasma," Phys. Fluids 23(2), 278 (1980).

26. E. T. Whittaker, A Treatise on the Analytical Dynmics of Partiches and Rigid Bodies (Cambridge Lriver-1t: Press, I.ondon, 1937), paragraph 152.

2. I ford, S. D. Stoddard, and J. 5. Turner, "On the Integrability of the Toda Lattice," Prog. Theo. Thus. $50(7), 1747(1973)$.

- S rtinen and C. Heiles, "The Applicability of the Third Integral of Motion' Some Numerical Experimonts," Antmen. 1. 69(1), 73(1964).

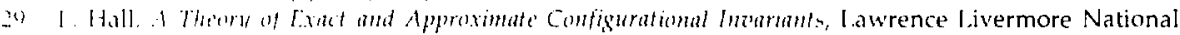
i aburatery, livermore, CA, UCRI.-87094 (in preparation).

ill. R. I Pout and M. N. Rosenbluth, "Electrostatic Instabilıtes in Finite Mirror-Confined Plasmas," Phus. llaring $9(4), 730(1966)$.

3!. H. I.. Berk. T. K. Fowler, I.. D. Pearlstein, R. F. Post, J. D. Callen, C. W. Horton, and M. N. Rosenbluth, "Criteria for Stabilization of Electrostatic Modes in Mirror-Confined Plasmas," in Plasma Phus. and (im!. Nul. Fusm Re's. Novosibirsk, 1968 (International Atomic Energy Agency, Vienna, 1969). W. II. P. 151 .

32. I). F. Baldwin and R. A. Jong, "Potential-Confined Cold Plasma Stabilization of Loss-Cone Modes in Mirror Machines," Pitys. Fluts 22(1), 119 (1979).

33. H. Coensgen, W. F Cummins, B. G. logan, A. W. Molvik, W. E. Nexsen, T. C. Simonen, B. W. Stallard, and $\mathrm{W}$. C. Turner, "Stabilization of a Neutral-Beam-Sustained, Murror-Confined Plasma," Phis. Rin litt. 35(22), 150] (1975).

3. R. I. Drake. T. A. Cásper, J. I: Clauser, F. H. Coensgen, D. L. Correll, W. F. Cummins, J. C. Davis. I H. Forte, A. H. Futch, R. K. Goodman, D. F. Grubb, R. S. Hoinady, W. E. Nexsen, T. C. Simonen, and B. W. Stallard, "The Effect of End-Cell Stability on the Confinement of the Central-Cell Plasma in TMY," Nut. lintm 21(3), 359 (1981).

35. M. 4. Ioffe. B. I. Kunaev, V. P. ['astukhov, and E. E. Yushmanov, "Stabilization of Cone Instability of

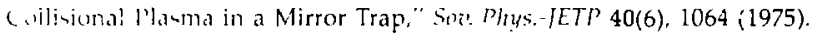

36. I Kinner Inverse Ambipolar Potential in a Magnetic Mirror Configuration," Plasma Phus. 15, 577 $(1,-3)$.

37. R 4. Desoto. I awrence livermore National Laboratory, Livermore, CA, private communication september 1981).

38. T. A. Cutler, 1.. D. Pearlstein, and M. E. Rensink, Computation of the Bounce-Aicrage Codc, Lawrence Livermore National Laboratory, Livermore, CA, UCRL-52233 (1977).

39. J. M. Wadtehra and J. N. Bardsley, "Vibrational- and Rotational-State Dependence of Dissociative Attachment in $\mathrm{c}^{\prime} \mathrm{H}_{2}$ Collisions," Prys. Ret Letf. 41(26), 1795 (1978).

40. J. N. Bardsley and J. M. Wadehra, "Dissociative Attachment and Vibrational Excitation in Low-Energy Collisions of Electrons with $\mathrm{H}_{2}$ and $\mathrm{D}_{2}$," Plys. R'z. A20(4), 1398 (1979).

41. J. R. Hiskes, "Cross Sections for the Vibrational Excitation of the $\mathrm{H}_{2}\left(x^{1} \mathrm{~s}_{\mathrm{g}}\right)$ State Via Electron Collisional Excitation of the Higher Singlet States." 1. Appl. Pluss. $51(9), 4592$ (1980).

42. A. M. Karo, Molecular Pitintials and Relaxntion Dymamis, Lawrence Livermore National Laboratory, Livermore, CA, UCRL-85577. Rev. 1 (1981).

43. M. Pealat, J. .. E. Toran, J. Taillet, M. Bacal, and M. Bruneteau, I. Appl. Phys. 52(4), 2687 (1981).

44. M. Bacal, A. M. Bruneteau, W. G. Graham, G. W. Hamilton, and M. Nachman, "Pressure and Electron Temperature Dependence of $H$ Density in a Hydrogen Plasma," I. Appl. Phys. 52(3), 1: +; (1981). 


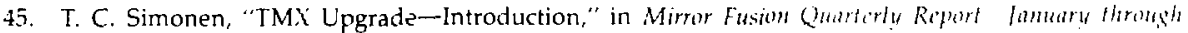
March 1981, M. A. Harrison and C. K. McGregor, Eds., Lawrence livermore National I.ahoratory. Livermore, CA, UCRL-50051-81-1 (1981), p. 10.

46. G. A. Carlson, W. L. Barr, B. M. Boghosian, R. S. Devoto, J. N. Doggett. G. W. Hamilun, B. M. Johnston, W. N. Kumai, J. D. Lee, B. G. Logan, R. W. Moir, W. S. Neef, and R. B. Campbell. Cimmura tive End-Plug Study for Tande'm Mirror Re'actors, Lawrence Livermore National laboratorv, Livermore, CA. UCID-19271 (1981).

47. J. Kesner, B. D. McVey, R. S. Post, and D. K. Snith, A Tandem Morar anth Axmmmetrit (intral cill Ion Confinement, Massachusetts Institute of Technology, Cambridge, MA, PIC/ $A$ SI-11 (1981): w be published in virl. Fusion.

48. B. G. Logan, An Axisymmetric, Hagh Bela Tandem Morror Reater, Lawrence livermore Nalional lathoratory, Livermore, CA, UCRL-83555 (1979).

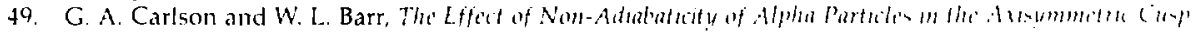
TILR, I anrence Livermore National Laboratory, I ivermore, CA UCID-19150 (1981).

50. P. Po ulsen, S, L. Allen, T, A. Casper, D. P. Grubt, R. A. Jong, W. E. Nexsen, C. D. Purter, and T. C.

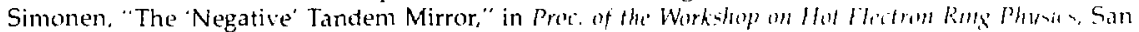
Diego, 1981 (to be published by Oak Ridge National Laboratory, Oak Ridge. TN): now as'ailable" through Lawrence livermore National Laboratory, Livermore, CA, L'CRI.-86845 (1981).

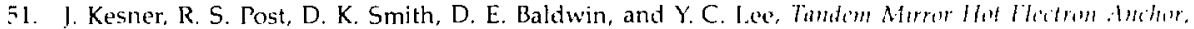
Massachusetts Institute of Technology. Cambridge, MA, PFC/JA-81-17 (1981).

52. R. A. long and R. H. Bulmer, "Study of MFTF-B Upgrade Using Axisymmetric Barriers,", in "Mom" Fusm Quarterlu Repert-April through /ume 1981, M.A. Harrison and C. Gerich. Eds., I.awrence I.jer more National Laboratory, Livernore, CA, LCRI-50051-81-2 (1981).

53. R. A. Jong, report in progress.

54. R. S. Devoto, Lawrence Livermore National Laboratory, Livermore, $\mathrm{CA}$, private communication (December 1981).

55. D. E. Baldwin, B. G. Logan, and T. C. Simonen, Physes Basis for MTIT K, I.awrence livermore National Lahoratory Livermore, CA, UCID-18496, Part 1 (1980).

56. B. G. Logan, Lawrence Livermore National Idboratory, Livermore, CA, privale communication (December 1981)

57. J. W. Shearer, T. A. Cutler, L. W. Dilgard, J. Fabyan, F. M. Holl, G. D. Porter, and J. S. Colonias Magnetic Shiclding of Neut"al Beam Sonres in Mirror Fusion Test Fathitu. Lawrence Livermore National Laboratory, Livermoit, CA, UCRl-52824 (1979).

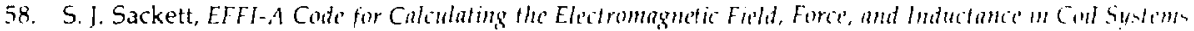
If A rbirary Geometry, Lawrence Livermore National Laboratory, Livermore, CA, UCRL -52412 (1978).

59. J. W. Shearer, Lawrence Livermore National Laboratory, Livermore, CA, private communication (June 18, 1981).

60. John Osher, Lawrence Livermore National Laboratory, Livermore, CA, private communication (December 1981).

61. R. H. Cohen, Axial Potential Profiles in Thermal-Barrier Cells, Lawrence Livernore National Labora. tory; Livermore, CA, UCRL-84535 (1980).

62. G. D. Porter, Lawrence Livermore National Laboratory, Livermore, CA, private communication (September 1981). 


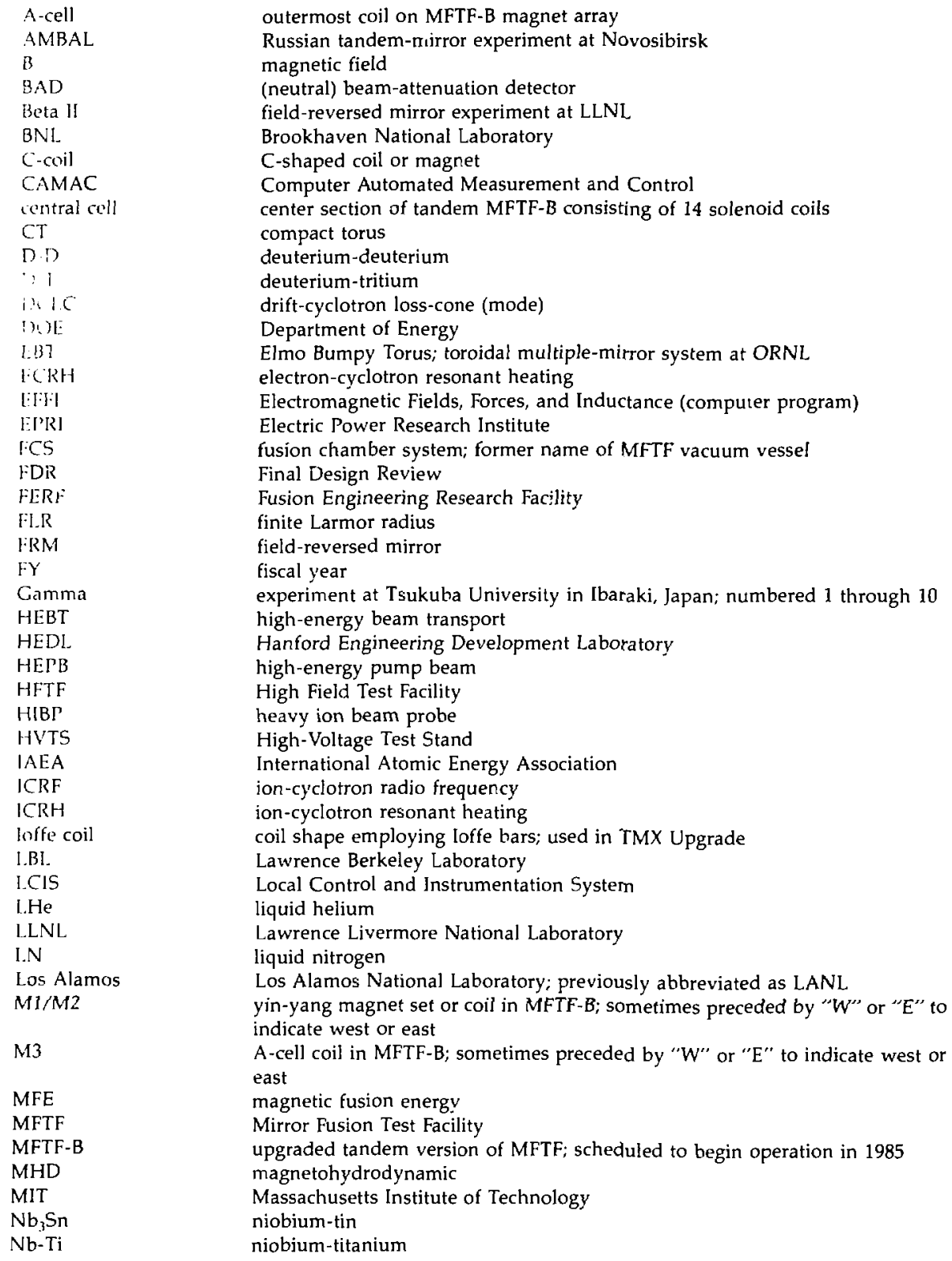




\section{NMFECC \\ ORNL \\ PHAEDRUS \\ plasma \\ PPM \\ PPPL \\ $Q$ \\ If \\ RGA}

RNTS-II

s

$\mathrm{S} 1$ to $\mathrm{S7}$

SCDS

SCR

SED

SM

SNBISSS

solenoid

$\mathrm{T}$

T1

$T_{t}$

$T_{1}$

TARA

TDF

TMNS

TMR

TMX

TMX Upgrade

tokamak

transition coil

UHLC

yin-yang magnet

2XIIB

$\beta$

nT
National Magnetic Fusion Energy Computer Center

Oak Ridge National Laboratory

small tandem-mirror device at the University of Wisconsin

ionized particles that fuel fusion machines

pulse power module

Princeton Plasma Physics Laboratory

plasma energy gain (i.e., ratio of fusion power output to the power input to the plasma)

radio frequency

residual gas analyzer

Rotating Neutron Target Source II; facility at l.LNI. used to investigate effects of fusion neutrons

second

solenoid coils in the MFTF- $B$ central cell; sometimes preceded by " $W$ " or " $E$ " to indicate west or east

Supervisory Control and Diagnostics System

silicon-controlled rectifier

secondary-emission detector

symmetric nirror

Sustaining Neutral-Beam Power Supply System

circular magnet used in both the MFTF-B and TMX Upgrade

tritium; tesla

transition coil in MFTF-B; sometimes preceded by " $W$ " or " $E$ " to indicate went or eăst

electron temperature

ion temperature

tandem-mirror facility at MIT

Technology Development Facility

Tandem Mirror Next Step

tandem mirror reactor

Tandem Mirror Experiment

Tandem Mirror Experiment Upgrade

toroidal fusion machine

C-shaped coil inboard the yin-yang manget in MFTF-B

upper-hybrid, loss-rone (mode)

original magnet configuration in MFTF; to be duplicated for tandem version and complemented by 20 other magnets

early single-cell mirror machine at LLNL

ratio of the plasma particle pressure to the pressure of the confining magnetic field

containment parameter; particle density times particle confinement time 